RELATIVE EFFECTS OF CHLORINE AND

AMMONIA FROM WASTEWATER TREATMENT

FACILITIES ON STREAM BIOTA 
Digitized by the Internet Archive in 2013

http://archive.org/details/relativeeffectso8324heid 
The person charging this material is responsible for its return to the library from which it was withdrawn on or before the Latest Date stamped below.

Theft, mutilation, and underlining of books are reasons for disciplinary action and may result in dismissal from the University.

To renew call Telephone Center, 333-8400

UNIVERSITY OF ILLINOIS LIBRARY AT URBANA-CHAMPAIGN

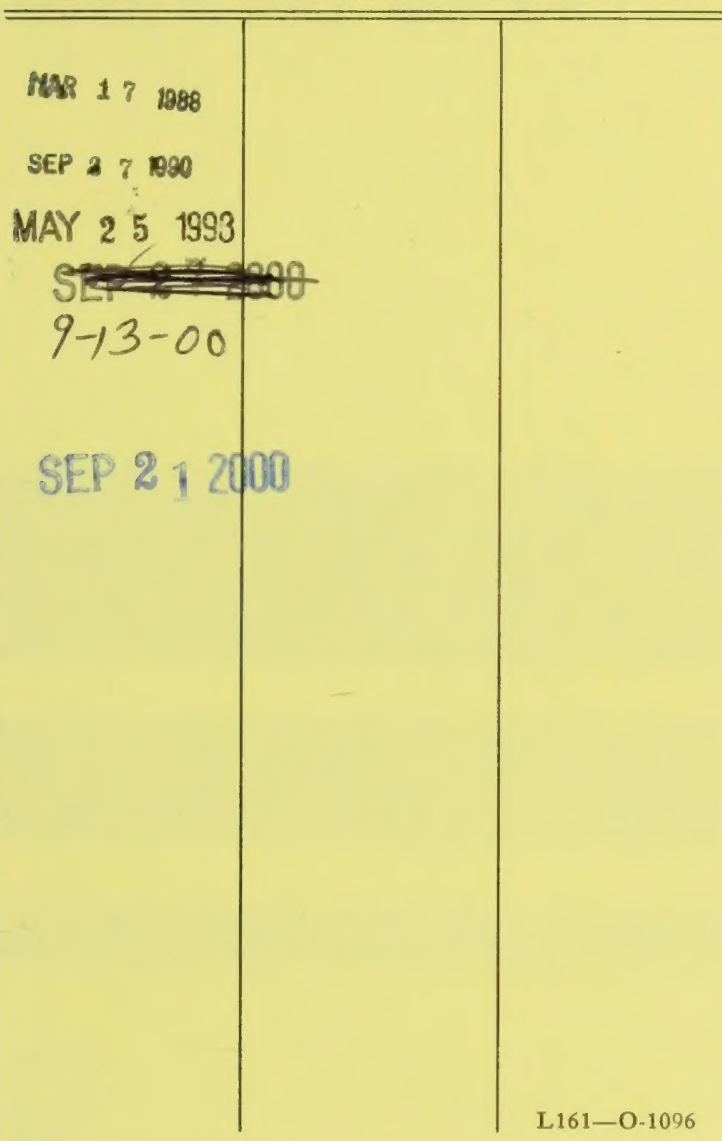





\section{RELATIVE EFFECTS OF CHLORINE AND AMMONIA FROM WASTEWATER TREATMENT FACILITIES ON STREAM BIOTA}

\section{Document No. 83/24}

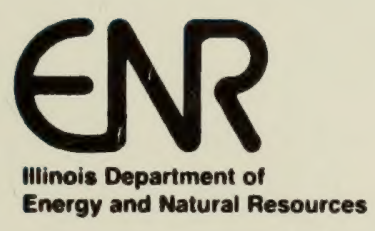

James R. Thompson, Governor

Michael B. Witte, Director 
UNIVERSITY OF

ILLINOIS LIBRARY

AT URBANA.CHAMPAIGN

$C P \& L A$ 


\section{RELATIVE EFFECTS OF CHLORINE AND AMMONIA FROM WASTEWATER TREATMENT FACILITIES ON STREAM BIOTA}

Drs. Roy C. Heidinger and William M. Lewis ${ }^{1)}$ Principal Investigators

Michael H. Paller, Jimmy H. Waddell and Larry J. Wawronowicz Researchers

PROJECT NO. $83 / 2002$

James R. Thompson, Governor State of Illinois
Michael B. Witte, Director Department of Energy and Naturat Resources

1) Prepared under contract with the I17inois Department of Energy and Natural Resources as project number $33 / 2002$; to the Fisheries Research Laboratory, Southern Illinois University, Carbondale, Illinois 62901 . 
This report has been reviewed by the Department of Energy and Natural Resources and approved for publication. Views expressed are those of the contractor and do not necessarily reflect the position of DENR.

Printed by the Authority of the State of Illinois

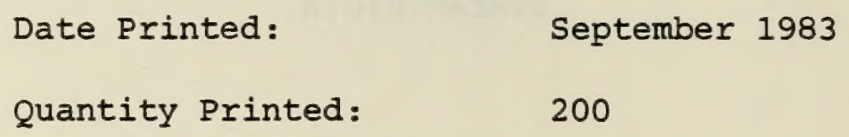

One of a series of research publications published since 1975. This series includes the following categories and are color coded as follows:

\begin{tabular}{|c|c|c|}
\hline & $\begin{array}{l}\text { Prior to } \\
\text { July, } 1982 \\
\end{array}$ & $\begin{array}{c}\text { After } \\
\text { July, } 1982 \\
\end{array}$ \\
\hline Air Quality & -Green & Green \\
\hline Water & - Blue & Blue \\
\hline Environmental Health & -White & Grey \\
\hline Solid and Hazardous Waste & -White & Olive \\
\hline Economic Impact study & - Buff & Brown \\
\hline Noise Management & - Buff & Orange \\
\hline Energy & -Cherry & Red \\
\hline Information Services & -Canary & Yellow \\
\hline
\end{tabular}

Illinois Department of Energy and Natural Resources Energy and Environmental Affairs Division 325 West Adams Street Springfield, Illinois 62706

(217) 785-2800 


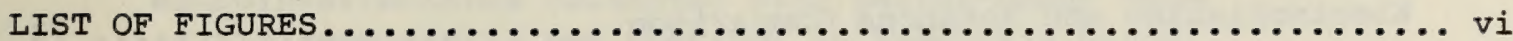

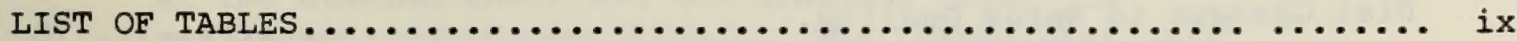

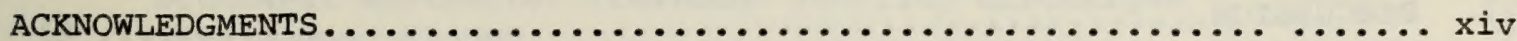

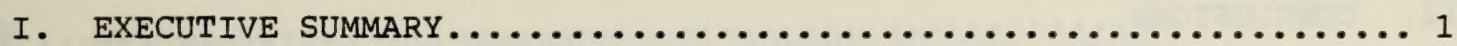

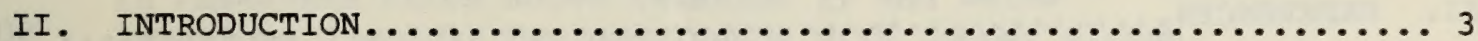

III. METHODS AND MATERIALS $\ldots \ldots \ldots \ldots \ldots \ldots \ldots \ldots \ldots \ldots \ldots \ldots \ldots \ldots \ldots$

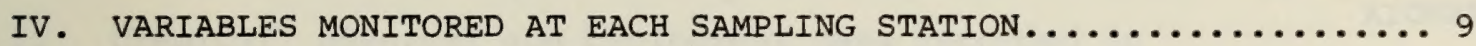

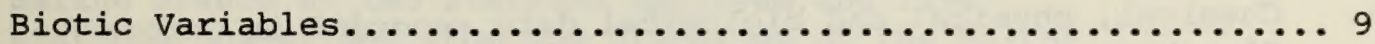

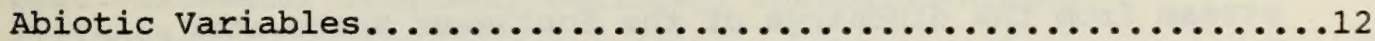

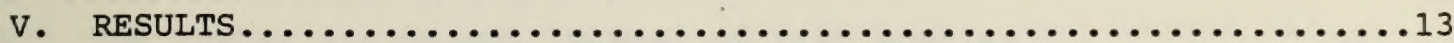

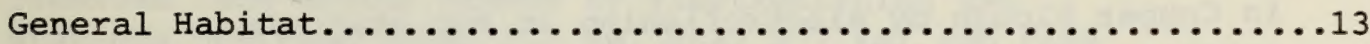

Chemical Parameters in Copper Slough..................

Copper Slough Fish Community.........................

Copper Slough Macroinvertebrate Samples..................

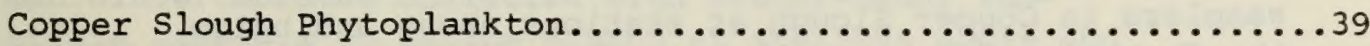

Chemical Parameters in Kaskaskia Ditch......................

Kaskaskia Ditch Fish Community....................

Kaskaskia Ditch Macroinvertebrate Samples................. 47

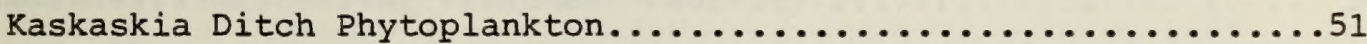

Saline Branch Chemical Parameters........................ 51

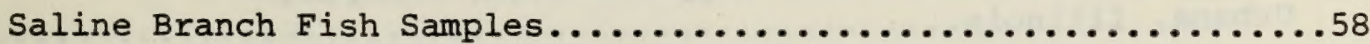

Saline Branch Macroinvertebrate Samples...................65

Saline Branch Phytoplankton.......................... 
TABLE OF CONTENTS (Cont.)

V. RESULTS (Cont.)

Electrofishing and Rotenone Comparison................ 73

Diel Changes in water Quality..................... 78

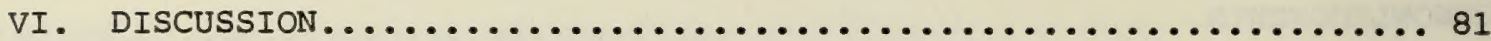

VII. CONCLUSIONS................................. 88

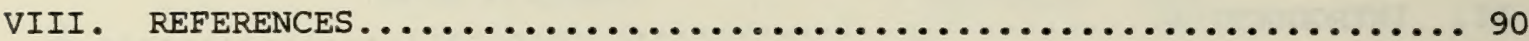

(The appendices are printed separately from this report)

APPENDIX

A. Chemical, physical and biological data recorded in Copper slough at two stations upstream and three stations downstream from the discharge of the Southwest Wastewater Treatment Facility, Champaign-Urbana, Illinois..............

B. The number and weight ( $g$ ) of fish species recorded in Copper Slough by electrofishing at two stations upstream (Stal $1.25 \mathrm{~km}$, Sta2 $0.75 \mathrm{~km}$ ) and three stations downstream (Sta $30.25 \mathrm{~km}$, Sta $4,0.62 \mathrm{~km}$, Sta5 $1.6 \mathrm{~km}$ ) from the discharge of the Southwest Wastewater Treatment

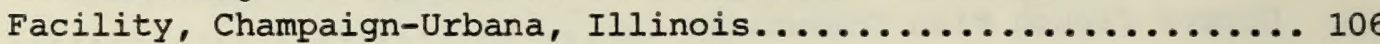

C. Number and total wet weight per $\mathrm{m}^{2}$ of benthic macroinvertebrates collected with Hester-Dendy substrate samplers in Copper Slough at stations above and below the Champaign-Urbana Southwest Wastewater Treatment

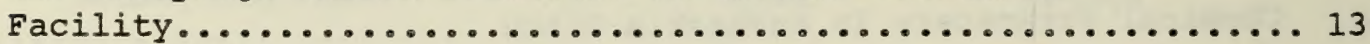

D. Chlorophyll-a and pheophytin-a concentrations $\left(\mathrm{mg} / \mathrm{m}^{3}\right)$ in Copper Slough above (stations 1 and 2) and below (stations 3, 4 and 5) the Champaign-Urbana Southwest Wastewater Treatment Facility...................... 164

E. Chemical, physical and biological data recorded from Kaskaskia Ditch at one station above and two stations below its confluence with Copper Slough, ChampaignUrbana, Illinois.

F. The number and weight (grams) of fish species recorded by electrofishing in Kaskaskia Ditch at one station above (Stal $0.25 \mathrm{~km}$ ) and two stations below (Sta2 $1.1 \mathrm{~km}$, Sta $32.7 \mathrm{~km}$ ) its confluence with Copper Slough, Champaign-Urbana, Illinois. 
G. Number and total wet weight per $\mathrm{m}^{2}$ of benthic macroinvertebrates collected with Hester-Dendy substrate samplers ( 3 per station) in Kaskaskia Ditch at the station above and the stations below its confluence with Copper Slough. The Champaign-Urbana Southwest Wastewater Treatment Facility discharges

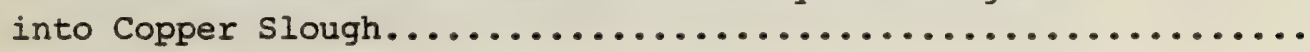

H. Chlorophyll-a and pheophytin-a concentrations $\left(\mathrm{mg} / \mathrm{m}^{3}\right)$ in Kaskaskia Ditch above (station 1) and below (stations 2 and 3 ) its confluence with Copper Slough. Copper slough receives sewage effluent from the Champaign-Urbana Southwest Wastewater Treatment Facility.......

I. Chemical, physical and biological data recorded in Saline Branch at two stations upstream and five stations downstream from the discharge of the Northeast Wastewater Treatment Facility, Champaign-Urbana,

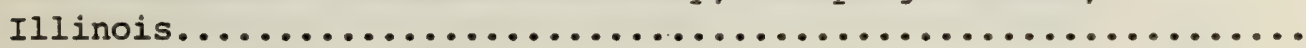

J. The number and weight (grams) of fish species recorded from Saline Branch by electrofishing two stations upstream (Stal $6.3 \mathrm{~km}$, Sta2 $5.7 \mathrm{~km}$ ) and five stations downstream (Sta $30.3 \mathrm{~km}, 5 t a 4,1.9 \mathrm{~km}$, Sta5 $3.8 \mathrm{~km}$, sta6 $10 \mathrm{~km}$, Sta $712.6 \mathrm{~km}$ ) from the discharge of the Northeast Wastewater Treatment Facility, Champaign-Urbana,

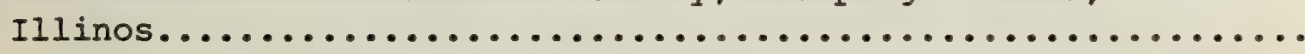

K. Number and total wet weight per $\mathrm{m}^{2}$ of benthic macroinvertebrates collected with Hester-Dendy substrate samplers in Saline Branch at stations above and below the discharge of the Champaign-Urbana Northeast

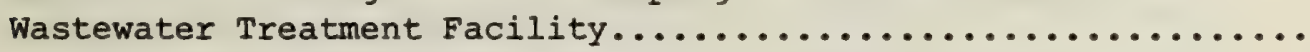

I. Chlorophyll-a and pheophytin-a concentrations $\left(\mathrm{mg} / \mathrm{m}^{3}\right.$ ) in Saline Branch above (stations 1 and 2) and below (stations 3-7) the discharge of the Champaign-Urbana Northeast Wastewater Treatment Facility. 


\section{LIST OF FIGURES}

Number

Page

1 Location of the five sample stations on Copper

Slough and the three sample stations on Kaskaskia

Ditch in Relation to the Champaign-Urbana South-

west Wastewater Treatment Facility. Distance $(\mathrm{km})$

from the outfall is measured along the stream bed..........

2 Location of the seven sample stations on Saline

Branch in relation to the Champaign-Urbana Northeast

wastewater Treatment Facility. Distance (km)

from the outfall is measured along the stream bed..........

3 Mean number of invertebrate taxa in Copper Slough at sample stations above and below the outfall of the Champaign-Urbana Southwest Wastewater Treatment Facility. Invertebrates were usually collected monthly with Hester-Dendy substrate samplers (usually 3 samplers per station). Phase I lasted from $11 / 79$ to $9 / 80$, Phase II lasted from $10 / 80$ to $6 / 81$, and Phase

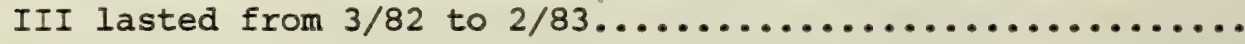

4 Mean wet weight (expressed as $\mathrm{g} / \mathrm{m}^{2}$ of sampler substrate) of invertebrate samples taken from Copper Slough at sample stations above and below the outfall of the Champaign-Urbana Southwest Wastewater Treatment Facility. Invertebrates were usually collected monthly with Hester-Dendy substrate samplers (usually 3 samplers per station). Phase I lasted from $11 / 79$ to $9 / 80$, Phase II lasted from $10 / 80$ to $6 / 81$, and Phase III

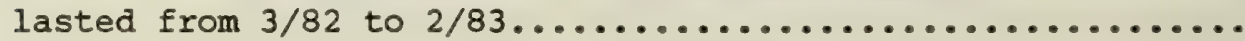

5 Percentage of macroinvertebrates (by number) in Annelida and/or Diptera recorded in samples taken from Copper Slough above and below the outfall of the ChampaignUrbana Southwest Wastewater Treatment Facility. Each data point is an average derived from 2 (above outfall) or 3 (below outfall) sample stations. Invertebrates were secured with Hester-Dendy substrate samplers ( 3 per

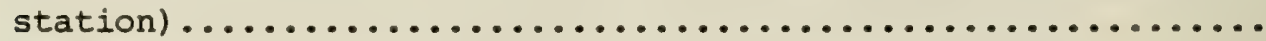

6 Mean number of invertebrate taxa in Kaskaskia Ditch at sample stations above and below its confluence with Copper Slough. Copper Slough received sewage effluent from the Champaign-Urbana Southwest Wastewater Treatment Facility. Invertebrates were usually collected monthly with Hester-Dendy substrate samplers (usually 3

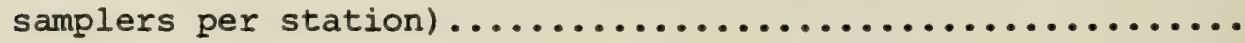


Mean wet weight (expressed as $\mathrm{g} / \mathrm{m}^{2}$ of sampler substrate) of invertebrate samples taken from Kaskaskia Ditch at sample stations above and below its confluence with Copper Slough. Copper Slough received sewage effluent from the Champaign-Urbana Southwest Wastewater Treatment Facility. Invertebrates were usually collected monthly with HesterDendy substrate samplers (usually 3 samplers per station)

8 Number of fish species and unionized ammonia-nitrogen concentrations in Saline Branch below the outfall of the Champaign-Urbana Northeast Wastewater Treatment Facility. Each data point is an average based

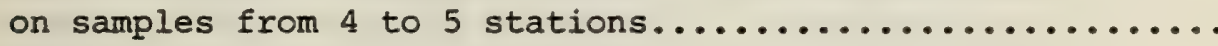

9 Number of fish collected in Saline Branch at sample stations $3.8 \mathrm{~km}$ (station 5) and $12.6 \mathrm{~km}$ (station 7) below the outfall of the Champaign-Urbana Northeast

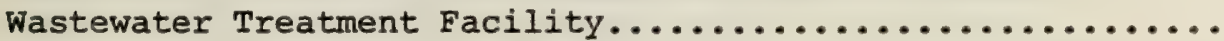

10 Mean number of invertebrate taxa in Saline Branch at sample stations above and below the outfall of the Champaign-Urbana Northeast Wastewater Treatment Facility. Invertebrates were usually collected monthly with Hester-Dendy substrate samplers (usually 3 samplers per station). Phase I lasted from $11 / 79$ to $9 / 12 / 80$, Phase II-division 1 lasted from $9 / 23 / 80$ to $4 / 81$, Phase IIdivision 2 included the period $5-6 / 81$ and $3-9 / 82$, and Phase III lasted from $10 / 82$ to $2 / 83 \ldots \ldots \ldots \ldots \ldots \ldots \ldots \ldots$

11 Mean wet weight (expressed as $\mathrm{g} / \mathrm{m}^{2}$ of sampler substrate) of invertebrate samples taken from Saline Branch at sample stations above and below the outfall of the Champaign-Urbana Northeast Wastewater Treatment Facility. Invertebrates were usually collected monthly with Hester-Dendy substrate samplers (usually 3 samplers per station). Phase I lasted from $11 / 79$ to $9 / 12 / 80$, Phase II-division 1 lasted from $9 / 23 / 80$ to $4 / 81$, Phase II-divison 2 included the period $5-6 / 81$ and $3-9 / 82$, and Phase III lasted from $10 / 82$ to $2 / 83 \ldots \ldots \ldots \ldots \ldots \ldots \ldots . . \ldots$

12 Percentage of macroinvertebrates (by number) in Annelida and/or Diptera recorded in samples taken from Saline Branch above and below the outfall of the ChampaignUrbana Northeast Wastewater Treatment Facility. Each data point is an average derived from 2 (above outfall) or 5 (below outfall) sample stations. Invertebrates were secured with Hester-Dendy substrate samplers (3 per station) 
13 Diel changes in dissolved oxygen concentration and $\mathrm{pH}$ at station 1 , Saline Branch, on $9 / 8 / 82$. Station 1 is $6.3 \mathrm{~km}$ above the Champaign-Urbana Northeast Wastewater Treatment Facility..

14 Diel changes in dissolved oxygen concentration and $\mathrm{pH}$ at station 5, Saline Branch, on $9 / 8 / 82$. Station 5 is $3.8 \mathrm{~km}$ below the Champaign-Urbana Northeast Wastewater Treatment Facility. 
Average (and highest) total ammonia-nitrogen, unionized ammonia-nitrogen and total residual chlorine concentrations measured at monthly intervals in Copper slough while three consecutive modes of sewage treatment were practiced at the Champaign-Urbana Southwest Wastewater Treatment Facility. Phase I (11/79-9/80) consisted of secondary treatment and chlorination, Phase II $(10 / 80-6 / 81)$ consisted of secondary treatment without chlorination, and Phase III (3/82-2/83) consisted of tertiary treatment without chlorination......... 16

2 Average dissolved oxygen, turbidity, phosphorous, nitrate-nitrogen, and $\mathrm{pH}$ concentrations in Copper slough while three modes of sewage treatment were practiced at the Champaign-Urbana Southwest Wastewater Treatment Facility. Phase I (11/79-9/80) consisted of secondary treatment and chlorination, Phase II (10/80-6/81) consisted of secondary treatment without chlorination, and Phase III (3/82-2/83) consisted of tertiary treatment without chlorination......... 18

3 Average metals, fluoride, cyanide, phenol and hardness concentrations ( $\mathrm{mg} / \mathrm{l}$ ) in Copper slough, based on monthly samples from station $3,0.25 \mathrm{~km}$ below the outfall of the Champaign-Urbana Southwest

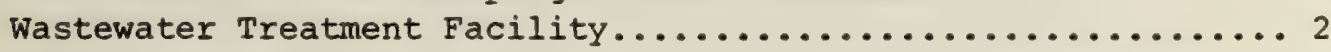

Mean volumes of flow and flow rates in three sewage receiving streams, based on monthly measurements at stations above and below the

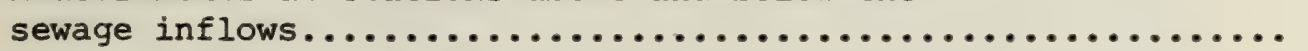

Analysis of monthly electrofishing samples taken from Copper Slough above and below the outfall of the Champaign-Urbana Southwest Wastewater Treatment Facility. Three modes of sewage treatment were practiced: secondary treatment and chlorination (Phase I, 11/79-9/80), secondary treatment without chlorination (Phase II, 10/80-6/81) and tertiary treatment without chlorination (Phase III, $3 / 82-2 / 83$ ) 
Unionized ammonia-nitrogen concentrations and species number taken by electrofishing at station 3 on Copper slough while secondary treatment without chlorination was practiced at the Champaign-Urbana Southwest

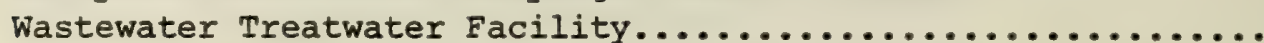

Coefficients of variation (percent) of several electrofishing sample parameters.....................

Statistical analysis (Kruskal-Wallis Test)

(16) of species number taken by electrofishing

at sample stations on Copper Slough. Stations 1

and 2 were above the outfall of the Champaign-Urbana

Southwest Wastewater Treatment Facility; 3, 4, and 5 were below it. Secondary treatment with chlorination was practiced during Phase I (11/79-9/80), secondary treatment without chlorination during Phase II (10/80-6/81), and tertiary treatment without chlorination during Phase III $(3 / 82-2 / 83) \ldots \ldots \ldots \ldots \ldots 30$

Taxonomic composition of monthly invertebrate samples taken from Copper Slough above and below the Champaign-Urbana Southwest Wastewater Treatment Facility. Three modes of sewage treatment were practiced: secondary treatment and chlorination (Phase I), secondary treatment without chlorination (Phase II), and tertiary treatment without

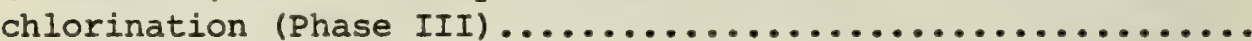

Average chlorophyl1-a and pheophytin-a concentrations in Copper Slough above and below the discharge of the Champaign-Urbana Southwest Wastewater Treatment Facility. Three modes of sewage treatment were practiced: secondary treatment and chlorination (Phase I), secondary treatment without chlorination (Phase II), and tertiary treat-

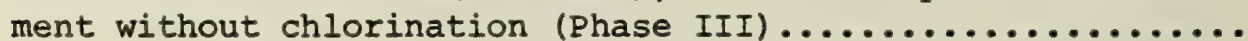

11 Average (and highest) total ammonia-nitrogen, unionized ammonia-nitrogen and total residual chlorine concentrations measured at monthly intervals in Kaskaskia Ditch above and below its confluence with Copper Slough. Three modes of sewage treatment were practiced at the Champaign-Urbana Southwest Wastewater Treatment Facility, which discharges into Copper Slough. Phase I (11/79-9/80) consisted of secondary treatment and chlorination, Phase II (10/80-6/81) consisted of secondary treatment without chlorination and Phase III $(3 / 82-2 / 83)$ consisted of tertiary treatment without chlorination...................... 
Average dissolved oxygen, turbidity, phosphorous, nitrate-nitrogen, and $\mathrm{pH}$ concentrations in Kaskaskia Ditch at stations above and below its confluence with Copper Slough. Three modes of sewage treatment were practiced at the Champaign-Urbana Southwest Wastewater Treatment Facility, which discharges into Copper Slough: secondary treatment with chlorination (Phase I), secondary treatment without chlorination (Phase II), and tertiary treatment without chlorination (Phase III)........

13 Analysis of monthly electrofishing samples taken from Kaskaskia Ditch above and below its confluence with Copper slough. Three modes of sewage treatment were practiced at the Champaign-Urbana Southwest Wastewater Treatment Facility, which discharges into Copper Slough. Phase I (11/79-9/80) consisted of secondary treatment and chlorination, Phase II $(10 / 80-6 / 81)$ consisted of secondary treatment without chlorination, and Phase III $(3 / 82-2 / 83)$ consisted of tertiary treatment without

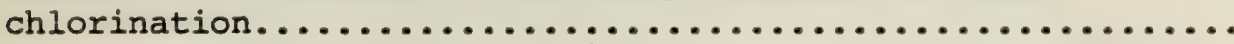

14 Statistical analysis (Kruskal-Wallis Test) (16) of species number taken by electrofishing at sample stations on Kaskaskia Ditch. Kaskaskia Ditch receives sewage effluent from Copper Slough, its tributary stream. Station 1 was above the Kaskaskia Ditch-Copper Slough confluence; stations 2 and 3 were below it. Secondary treatment with chlorination was practiced during Phase I $(11 / 79-9 / 80)$, secondary treatment without chlorination during Phase II (10/80-6/81), and tertiary treatment without chlorination during Phase III $(3 / 82-2 / 83) \ldots \ldots \ldots \ldots \ldots \ldots \ldots \ldots \ldots \ldots$

15 Taxonomic composition of monthly invertebrate samples taken from Kaskaskia Ditch above and below its confluence with Copper slough. Three modes of sewage treatment were practiced at the Champaign-Urbana Southwest Wastewater Treatment Facility, which discharges into Copper Slough: secondary treatment and chlorination (Phase I), secondary treatment without chlorination (Phase II), and tertiary treatment without chlorination (Phase III)................

16 Average chlorophyll-a and pheophytin-a concentrations in Kaskaskia Ditch above and below its confluence with Copper slough. Three modes of sewage treatment were practiced at the Champaign-Urbana Southwest wastewater Treatment Facility, which discharges into Copper Slough: secondary treatment and chlorination (Phase I), secondary treatment without chlorination (Phase II), and tertiary treatment without

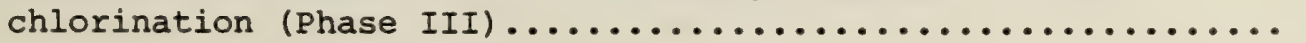


17 Average (and highest) total ammonia-nitrogen, unionized ammonia-nitrogen and total residual chlorine concentrations measured at monthly intervals in Saline Branch while four consecutive modes of sewage treatment were practiced at the Champaign-Urbana Northeast Wastewater Treatment Plant. Phase I $(11 / 79-9 / 12 / 80)$ consisted of secondary treatment and chlorination, Phase II-division 1 (9/23/80-4/81) consisted of incomplete (due to plant renovation) secondary treatment without chlorination, Phase II-division 2 (5-6/81 and 3-9/82) consisted of secondary treatment without chlorination, and Phase III (10/82-2/83) consisted of tertiary treatment

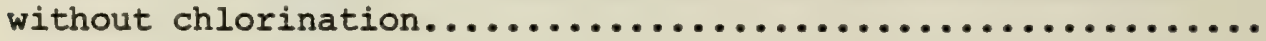

18 Average dissolved oxygen, turbidity, phosphorous, nitratenitrogen and $\mathrm{pH}$ in Saline Branch while three modes of sewage treatment were practiced at the Champaign-Urbana Northeast Wastewater Treatment Facility. Phase I $(11 / 79-9 / 12 / 80)$ consisted of secondary treatment and chlorination, Phase II consisted of secondary treatment without chlorination, and Phase III (10/82-2/83)

consisted of tertiary treatment without chlorination. Phase II has been split into two divisions: division 1 (9/23/80-4/81) characterized by poor effluent quality during plant renovation, and division 2 (5-6/81 and $3-9 / 82$ ) characterized by normal effluent quality after

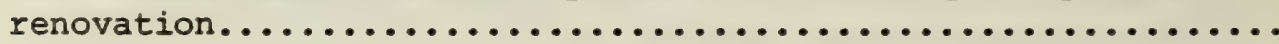

19 Average metals, fluoride, cyanide, phenol and hardness concentrations $(\mathrm{mg} / \mathrm{l})$ in Saline Branch based on monthly samples from station $3,0.3 \mathrm{~km}$ below the outfall of the Champaign-Urbana Northeast Wastewater Treatment

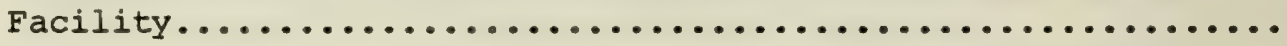

20 Analysis of monthly electrofishing samples taken from Saline Branch above and below the outfall of the Champaign-Urbana Northeast Wastewater Treatment Facility. Four modes of sewage treatment were practiced: secondary treatment and chlorination (Phase I, 11/79$9 / 12 / 80$ ), incomplete (due to plant renovation) secondary treatment without chlorination (Phase II-division 1 , 9/23/80-4/81), secondary treatment without chlorination (Phase II-division 2, 5-6/81 and 3-9/82) and tertiary treatment without chlorination (Phase III, 10/82-2/83)....... 
21 Ammonia-nitrogen concentrations and species number taken by electrofishing at stations 5 and 7 on Saline Branch while secondary treatment without chlorination (Phase II-division 2) was practiced at the ChampaignUrbana Northeast Wastewater Treatment Facility............

Statistical analysis (Kruskal-Wallis Test) (16) of species number taken by electrofishing at sample stations on Saline Branch. Stations 1 and 2 were located above the outfall of the Champaign-Urbana Northeast Wastewater Treatment Facility; stations $3,4,5,6$ and 7 were below it. Secondary treatment with chlorination was practiced during Phase I (11/79-9/12/80), poor secondary treatment (due to plant renovation) without chlorination during Phase II-division 1

(9/23/80-4/81), secondary treatment without chlorination during Phase II-division $2(5-6 / 81)$ and 3-9/82), and tertiary treatment without chlorination during

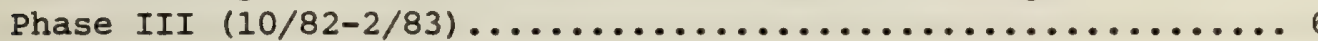

23 Taxonomic composition of monthly invertebrate samples taken from Saline Branch above and below the outfall of the Champaign-Urbana Northeast Wastewater Treatment Facility. Four modes of sewage treatment were practiced: secondary treatment and chlorination (Phase I), incomplete secondary treatment without chlorination (Phase II-division 1), secondary treatment without chlorination (Phase II-division 2), and tertiary treatment without chlorination (Phase III) ..............68

24 Average chlorophyll-a and pheophytin-a concentrations in Saline Branch above and below the discharge of the Champaign-Urbana Northeast Wastewater Treatment

Facility. Four modes of sewage treatment were practiced: secondary treatment and chlorination (Phase I), incomplete secondary treatment without chlorination (Phase II-division 1), secondary treatment without chlorination (Phase IIdivision 2), and tertiary treatment without chlorination

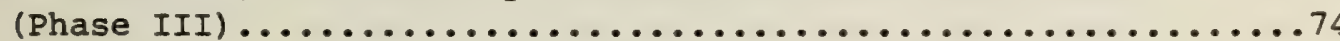

25 Comparison of an electrofishing sample $(9 / 17 / 82)$ and $a$ rotenone sample $(9 / 28 / 82)$ taken at station 2 , Saline Branch. Station 2 is $5.7 \mathrm{~km}$ above the ChampaignUrbana Northeast Wastewater Treatment Facility............ 76 


\section{ACKNOWLEDGMENTS}

During the course of this study, many individuals contributed toward the completion of the work. Tim Bachman, director of waste operations for the Champaign-Urbana Sanitary District, provided plant operating data and kept us continuously informed about plant operational status. J. Park, J. Anderson and R. Frazier coordinated the sample analyses performed by the Illinois Environmental Protection Agency. We are especially grateful to Wendy Coleman of the IEPA for exchanging data with us and reviewing this manuscript. The authors also express their appreciation to Carl Garrison, executive director of the Champaign-Urbana Sanitary District, and to Walt Zyznieuski of the research section, Energy and Environmental Affairs Division, Illinois Department of Energy and Natural Resources, without whose help this project could not have been completed. 


\section{EXECUTIVE SUMMARY}

In recent years, regulatory agencies have promulgated increasingly restrictive discharge criteria concerning ammonia concentrations in sewage. Meeting such standards would compel many communities to build expensive tertiary sewage treatment facilities. However, prior studies suggest that the chlorine added to sewage effluents for disinfection purposes is actually causing much of the environmental impact mistakenly attributed to ammonia toxicity. The objective of this study is to more clearly define the relative impacts of the two pollutants.

The intent of this study was to intensively monitor significant biological, chemical and physical variables in several Champaign-Urbana (Illinois) area sewage receiving streams: Copper Slough, Kaskaskia Ditch and Saline Branch. Monitoring, which lasted from November 1979 to February 1983, was divided into three consecutive phases. Phase I consisted of monitoring the streams while they received chlorinated secondary effluent. Phase II consisted of discontinuing chlorination and then monitoring while the streams received unchlorinated secondary effluent. Phase III consisted of monitoring the streams as newly constructed tertiary treatment facilities came on line at the Champaign-Urbana sewage plants. The effluents remained unchlorinated during Phase III.

During the chlorination period the fish community in Copper slough was extremely poor quantitatively and qualitatively. Within seven days after the cessation of chlorination, the Copper slough fish community recovered to levels characteristic of ambient areas above the outfall. The Kaskaskia Ditch fish community responded similarly to the cessation of chlorination. Recovery occurred in these streams despite ammonia-nitrogen concentrations typical of good quality secondary sewage effluent. The reduction of ammonia 
concentrations to very low levels by tertiary treatment did not result in further improvements in the fish community of either stream.

The fish community in Saline Branch did not recover immediately after the cessation of chlorination. The cessation of chlorination at the Northeast Treatment Plant coincided with a worsening of other effluent quality parameters due to operational problems caused by plant renovation. As a result, very high ammonia levels, very low oxygen levels and the deposition of sludge materials were observed in Saline Branch throughout the first half of the secondary treatment/no chlorination period. The fish community was very poor during this period just as it was during the secondary treatment/chlorination period. However, during the second half of the secondary treatment/no chlorination period effluent quality improved to good quality secondary treatment levels. In response, the Saline Branch fish community recovered to levels characteristic of ambient areas. The reduction of ammonia concentrations to very low levels by tertiary treatment did not result in further improvements in the Saline Branch fish community.

The invertebrate community in Copper Slough demonstrated marked quantitative improvements following the cessation of chlorination. However, qualitative recovery was not evident, i.e., pollution tolerant taxa still predominated. Full recovery from both a qualitative and quantitative standpoint occurred only after the onset of tertiary treatment.

The invertebrate community in Saline Branch was very poor during both the secondary treatment/chlorination period and the first half of the secondary treatment/no chlorination period. The improvement of effluent quality to normal secondary treatment levels during the second half of the secondary treatment/no chlorination period resulted in significant quantitative recovery of the macroinvertebrate community, but did not result 
in qualitative recovery. Nor was qualitative recovery clearly apparent during the subsequent tertiary treatment period, possibly because the tertiary treatment period was too short for complete recovery to develop.

The Kaskaskia Ditch macroinvertebrate comunity showed little unequivocal evidence of degradation during any phase of sewage treatment because of the weakness of the effluent entering Kaskaskia Ditch.

The cessation of chlorination did not result in excessive algal growth, significant decreases in dissolved oxygen, or adverse aesthetic effects in any of the streams under study.

The most important conclusions of this study are: 1) The elimination of residual chlorine from good quality secondary sewage effluents will result in quantitative and qualitative restoration of the fish communities in average Illinois streams receiving such effluents. 2) The reduction of ammonia concentrations from typical secondary treatment levels to extremely low levels by tertiary treatment will not necessarily effect obvious improvements in the fish communities of average Illinois streams. 3) The cessation of chlorination will result in marked quantitative improvements in the macroinvertebrate communities of streams receiving good quality secondary effluent, but tertiary treatment may be needed for both quantitative and qualitative recovery. 4) The elimination of residual chlorine from poor quality secondary sewage effluents or secondary sewage effluents derived largely from toxic industrial wastes will not necessarily effect biological improvements in streams receiving such effluents.

\section{INTRODUCTION}

Ammonia is a natural by-product of the decomposition of nitrogen-containing organic matter and thus occurs naturally in nearly all surface waters. However, waters polluted by organic materials, such as 
sewage, contain far more ammonia than pristine waters. High concentrations of ammonia, as sometimes occur in waters receiving sewage, may be detrimental to aquatic life (6).

In recent years, regulatory agencies have promulgated increasingly restrictive discharge criteria concerning ammonia. To meet such requirements, many communities will be forced to build expensive tertiary treatment facilities (17). The rationale behind stringent ammonia standards is the protection of streams and, in particular, the preservation of aquatic life.

Ammonia toxicity is not dependent solely on ammonia concentration, but also on $\mathrm{pH}$ and temperature. Ammonia exists in a $\mathrm{pH}$ and temperature governed dynamic equilibrium state in an ionized and an unionized form. For all practical purposes, the unionized form alone is toxic to fish (11). High pH and temperature push the equilibrium toward the toxic unionized form with $\mathrm{pH}$ particularly important in this respect (7). The term "total ammonia" refers to the sum of both the ionized and unionized components.

There may also be a second mechanism, independent of the ionized-unionized ammonia equilibrium, by which temperature influences ammonia toxicity. Some laboratory studies indicate that any given concentration of unionized ammonia is more toxic to fish at low temperatures than at high temperatures $(5,20,28)$. This effect is presumably caused by temperature-modulated changes in fish physiology and is not nearly as important as the actual concentration of unionized ammonia in determining toxicity.

Ammonia can be indirectly detrimental to aquatic life. Ammonia is converted to nitrite and then nitrate by oxygen-consuming bacteria. Thus, high concentrations of ammonia can exert an appreciable oxygen demand 
resulting in oxygen depletions in polluted waters. Furthermore, nitrate is an important plant nutrient which, under some conditions, can stimulate algal blooms or the proliferation of other undesirable vegetation.

There are other potentially detrimental materials besides ammonia in secondary sewage. Residual chlorine, a product of effluent disinfection, can produce toxic effects on fish at concentrations as low as $45 \mathrm{ppb}$ (24). Residual chlorine can take several forms. It combines with the ammonia generally found in secondary effluents to produce chloramines, principally monochloramines (25). In contrast, chlorine can exist as an uncombined or free residual in effluents containing no or little ammonia, such as those subjected to tertiary nitrification. The term "total residual chlorine" refers to the sum of both free and combined residuals. The toxicities of free and combined residual chlorine are of about the same order with that of the free residual being slightly greater. The combined residuals, however, are more stable, hence potentially more detrimental to aquatic life.

Recognition of the potential impacts of ammonia and chlorine have prompted concern among agencies interested in protecting the aquatic environment. Standards have been promulgated, but in the case of ammonia the strong evidence needed to satisfactorily balance regulation and protection has been largely unavailable.

Most of the information concerning ammonia toxicity is based on laboratory bioassay studies which generally describe the short-term responses of fish to high ammonia concentration. A review of the literature indicates that for time periods of 1 to 4 days the acute toxicity level of unionized ammonia-nitrogen ranges from 0.2 to $3.1 \mathrm{mg} / \mathrm{l}$ depending upon physical and chemical parameters of the water, and the species of fish (27). Bioassay 
studies, although important, do not necessarily reflect field conditions with accuracy.

Unfortunately, there have been relatively few field studies concerning ammonia toxicity. Ellis (6) found that "desirable" fish communities were seldom associated with total ammonia levels exceeding $2 \mathrm{mg} / \mathrm{l}$. In contrast Tsai (23) concluded that residual chlorine and sludge rather than ammonia were responsible for the impact of secondary sewage upon fish communities. In a recent Illinois study, Lewis et al. (14) similarly suggested that residual chlorine was causing much of the environmental impact mistakenly attributed to the ammonia in secondary sewage. They (14) further hypothesized that the installation of expensive tertiary treatment facilities for ammonia removal would generally fail to alleviate existing environmental damage if current chlorination practices were continued, and that the cessation of effluent disinfection with chlorine would usually result in greater environmental benefits than would tertiary ammonia removal.

The principal deficiency of the preceding field studies is that they were unable to unequivocally isolate and measure the relative impact of the various materials contained in secondary sewage. However, such information is needed to substantiate sewage discharge policies. This report describes the results of a field study specifically designed to isolate and evaluate the ecological effects of ammonia and residual chlorine in sewage effluents. A description of earlier phases of this study is given in the Illinois Department of Energy and Natural Resources document 81/35: Relative Effects on Stream Biota of Chlorine and Ammonia Occurring in Secondary sewage (15). The present report includes all data and salient analyses contained in the above document, in addition to new data and analyses generated since its appearance. 
III. METHODS AND MATERIALS

The study was designed to intensively monitor significant biotic and abiotic variables in three sewage receiving streams while three modes of sewage treatment were consecutively practiced over a 40-month period. Phase I consisted of monitoring each stream while it received chlorinated effluent from a secondary treatment plant. Phase II consisted of obtaining a variance to discontinue chlorination and then monitoring while each stream received unchlorinated secondary effluent. In Phase III the effluents remained unchlorinated but the streams were monitored after ammonia concentrations were reduced to very low levels by newly constructed tertiary nitrification facilities. Therefore, the overall study design permitted comparisons between aquatic communities found in the presence of both residual chlorine and relatively high ammonia levels (Phase I), aquatic communities found in the presence of relatively high ammonia levels only (Phase II), aquatic communities found in the presence of neither high ammonia levels nor chlorine (Phase III), and aquatic communities found in ambient areas upstream from the sewage outfalls.

Three Illinois streams of moderate size (mean volume of flow ranged from 1.5 to $2.91 \times 10^{8}$ liters/day) were selected for this study: Copper slough, which receives effluent of wholly domestic origin from the Champaign-Urbana Southwest Wastewater Treatment Facility; Kaskaskia Ditch, which receives effluent from Copper Slough, its tributary stream (the confluence is approximately $1.8 \mathrm{~km}$ from the treatment plant); and Saline Branch, which receives effluent from the Champaign-Urbana Northeast Wastewater Treatment Facility. Sewage treated at the Northeast Plant is 80 percent domestic and 20 percent industrial (primarily food processing) waste. 
In the original project design, each monitoring phase was to last 12 months, thus assessing conditions across an entire annual cycle. However, delays in the completion of the tertiary treatment facilities and other factors precluded the realization of this goal. Instead, in Copper Slough and Kaskaskia Ditch, Phase I lasted from November 1979 through September 1980 (11 months), Phase II from October 1980 through June 1981 (9 months), and Phase III from March 1982 through February 1983 (12 months).

The situation in Saline Branch was more complex. Phase I lasted from November 1979 to mid-September 1980 (10.5 months). Phase II lasted from mid-September 1980 through June 1981 and, after an eight-month hiatus, from March 1982 through September 1982 (16.5 months). It was also necessary to separate Phase II into two divisions. Division 1 of Phase II included a period of extensive construction activity at the Northeast Plant lasting from mid-September 1980 through April 1981 ( 7.5 months). These activities interfered with plant performance, resulting in anomalously poor effluent quality during this period. Division 2 of Phase II extended from May through June 1981 and then from March through September 1982 (9 months). Plant performance was normal during this period and the effluent typical of secondary treatment (although unchlorinated). Phase III began after the onset of tertiary nitrification and lasted from October 1982 through February 1983 (5 months).

Samples were usually collected once a month except during the aforementioned eight-month interregnum extending from July 1981 through February 1982. Only three samples were taken during the interregnum, one in Saline Branch on November 13-14, 1981, and two in Copper Slough on August 23 and October 7-8, 1981. These three samples, designated as "follow-up" samples, were taken to verify trends that developed earlier in the study. 
There were also two months during which two samples, rather than one, were taken. Saline Branch was sampled twice during September 1980, and Copper Slough was sampled twice during October 1980. Sampling was doubled during these months in order to closely monitor the cessation of chlorination on September 13, 1980, at the Northeast Plant and on September 30, 1980, at the Southwest Facility.

There were five sample stations on Copper Slough, three on Kaskaskia Ditch and seven on Saline Branch. In each stream, one (Kaskaskia Ditch) or two (Saline Branch and Copper Slough) stations were located above the sewage outfall and subsequent mixing zone, while the remaining stations were located below it (Figures 1 and 2). The same stations were used during all phases of the study with the exception of station 4 on Saline Branch, which became inaccessible at the beginning of Phase II-division 2. However, to facilitate comparisons between phases, the station designations used in Saline Branch during Phase II-division 2 and Phase III are the same as those used during the earlier phases.

\section{VARIABLES MONITORED AT EACH SAMPLING STATION}

\section{Biotic Variables}

The fish community was sampled by electrofishing a 150-m reach for 15-20 minutes with a 3-phase, 230-volt, 3000-watt generator mounted in a canoe; the three electrodes were arranged to approximate an equilateral triangle. Fish were collected from Copper Slough while moving downstream through the sample area. Fish were collected from Saline Branch and Kaskaskia Ditch, which were somewhat larger, by traversing the sample area along one bank and then reversing direction and traversing the sampling area along the other bank. Fishes were separated by species (21), enumerated and weighed. Fish sampling 


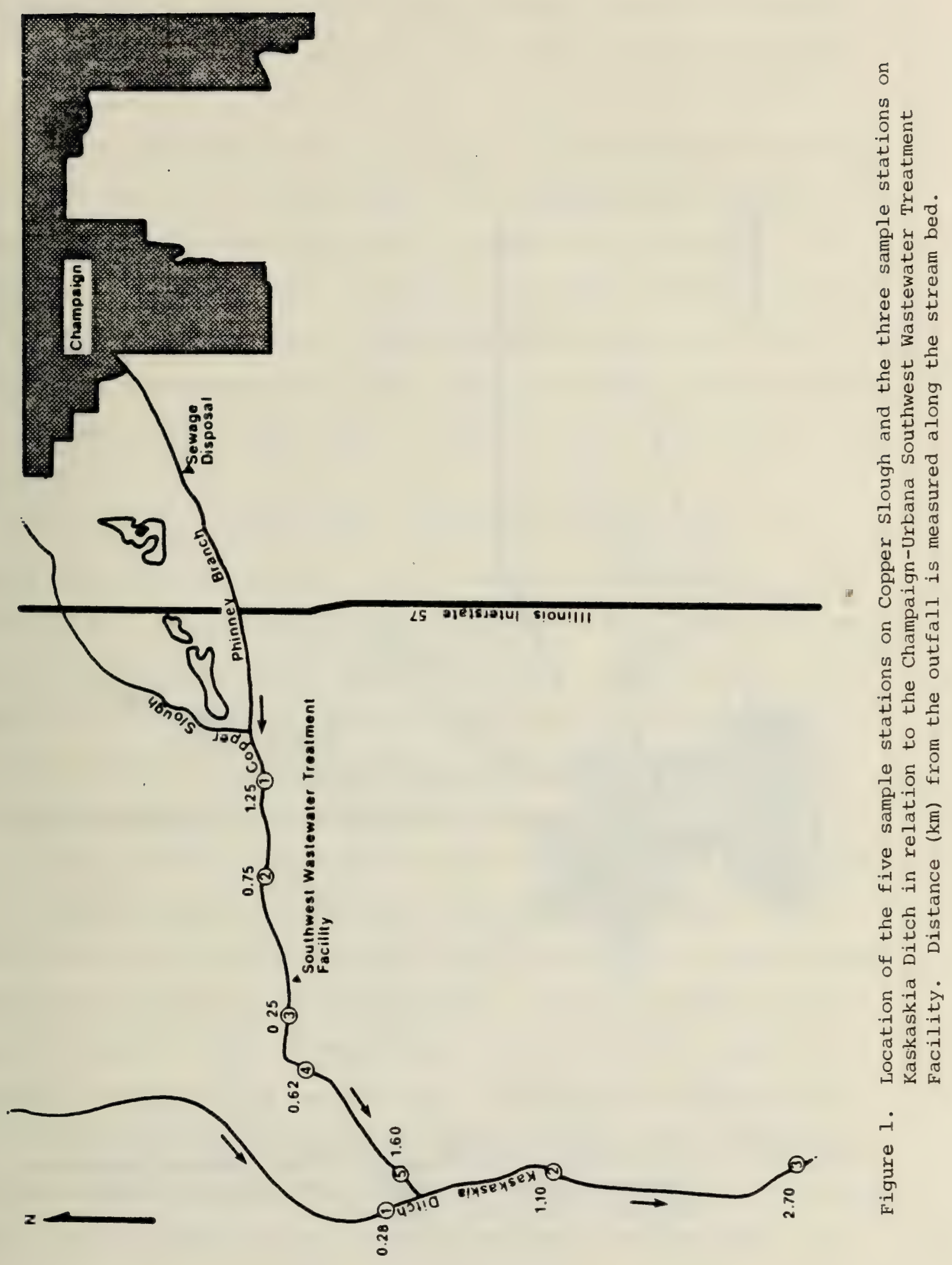




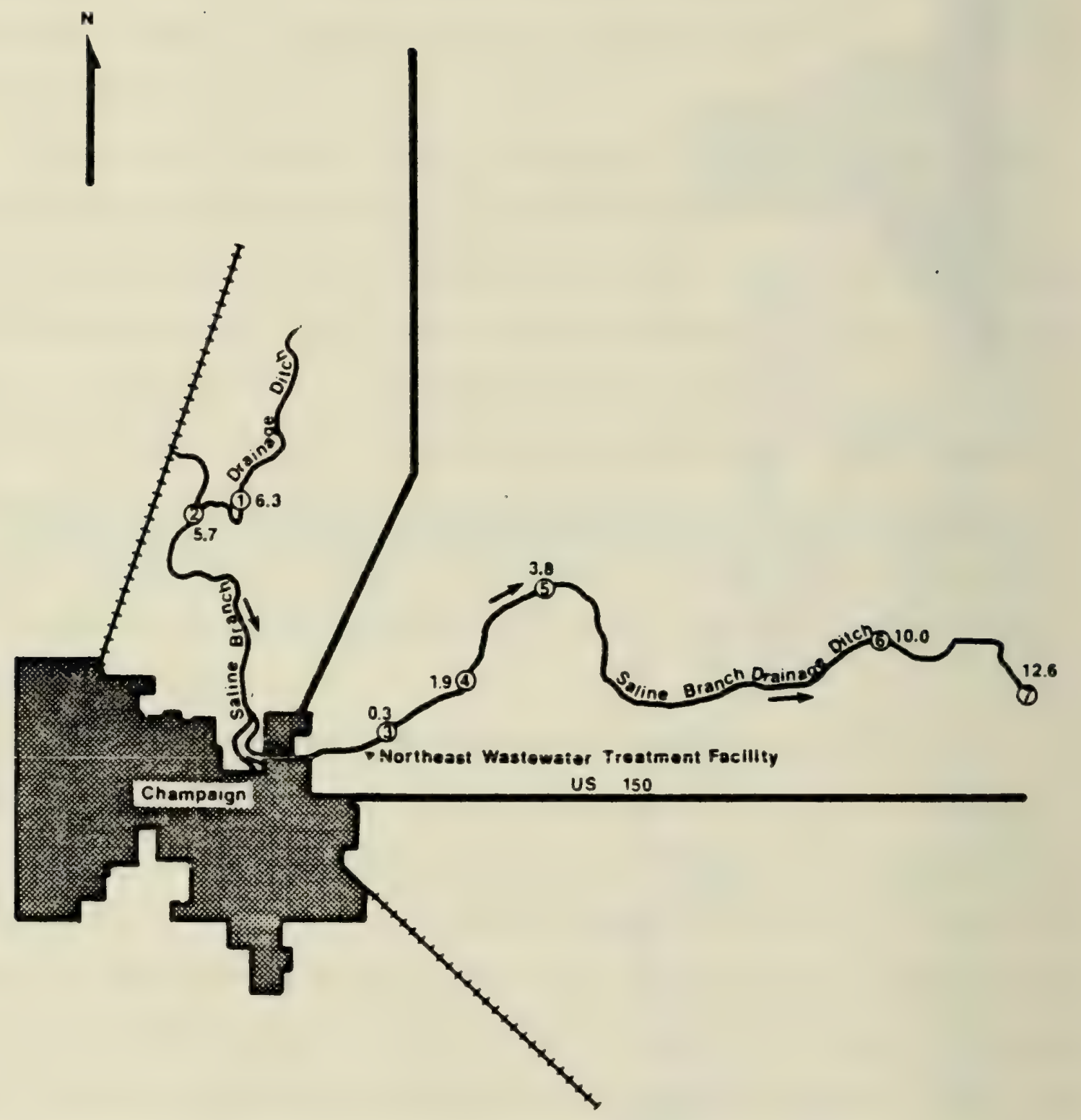

Figure 2. Location of the seven sample stations on Saline Branch in relation to the Champaign-Urbana Northeast Wastewater Treatment Facility. Distance $(\mathrm{km})$ from the outfall is measured along the stream bed. 
was generally conducted within one hour of chemical sampling, although fish and chemical sampling above the sewage outfall were occasionally separated by up to 48 hours.

Benthic macroinvertebrates were collected with Hester-Dendy artificial substrate samplers (1). Three samplers were employed at each station, each sampler exposing approximately $929 \mathrm{~cm}^{2}$ of surface for attachment of organisms. The samplers were positioned so that they transected the middle of each 150-meter sample reach. Invertebrates collected from the three samplers at each station were pooled, weighed in aggregate, identified to the most specific classification possible and enumerated $(2,3,8,9,12,13,18$, $19,26)$.

Chlorophyll-a and pheophytin-a concentrations were measured spectrophotometrically as indicators of planktonic algal biomass (1). Water for chlorophyll and pheophytin analysis, and for all other chemical analyses, was collected by immersing the sampling containers until they were filled. Vertical integration was not employed since the water was usually quite shallow, averaging approximately $45 \mathrm{~cm}$, and relatively turbulent.

\section{Abiotic Variables}

Abiotic variables were measured as follows: 1) Total residual chlorine was measured in situ amperometrically by the iodometric method II (1). 2) Total ammonia-nitrogen was measured with the ammonia-nitrogen selective ion electrode method using orion equipment (30). 3) Unionized ammonia-nitrogen was calculated according to Emerson et al.(7). 4) Dissolved oxygen was measured in situ with a YSI polarograph. 5) Turbidity was measured with a Hach nephelometer. 6) $\mathrm{pH}$ was measured with a $\mathrm{pH}$ meter. 7) Temperature was measured with a thermometer. 8) Nitrate was measured colorimetrically using Hach procedures and equipment. 9) Total phosphorous was measured by the 
Illinois EPA. 10) Flow rate and stream volume of flow were calculated from flow rates measured with a Gurley Current Meter and field measurements of the cross-sectional area of the stream. 11) Linear alkylate sulfonate (LAS) was measured colorimetrically using Hach equipment and procedures. LAS was measured only on selected dates. 12) Arsenic, barium, boron, cadmium, copper, chromium, iron, lead, manganese, mercury, nickel, selenium, silver, zinc, fluoride, cyanide, phenols, and hardness samples were collected only at the first station below the sewage outfall on Copper Slough and Saline Branch and were analyzed by the Illinois EPA.

All chemical samples not analyzed in the field or destined for the Illinois EPA were placed on ice, acidified in the case of ammonia samples, and analyzed within 3 to 10 hours. EPA samples were collected in preservative containing bottles supplied by the EPA, placed on ice, and usually delivered to the Illinois EPA within 1 to 3 days of collection.

All meters and similar equipment were calibrated before each use and recalibrated during use as was necessary to maintain accurracy.

In addition to our electrofishing samples, a rotenone sample was taken at station 2 on Saline Branch by the Illinois Department of Conservation and Illinos Environmental Protection Agency on September 28, 1982 (Phase III). A $6.5 \mathrm{~mm}$ mesh seine was stretched across the downstream end of the sample area to prevent the loss of narcotized and dead fish.

\section{RESULTS}

\section{General Habitat}

Copper Slough, the smallest of the streams, averaged approximately $7.5 \mathrm{~m}$ in width. Depth was highly variable but seldom exceeded $50 \mathrm{~cm}$. Copper Slough was channelized years ago and, therefore, lacks well defined pools and riffles. Its banks are steep and grassy with scattered trees of small to 
moderate size. Cultivated fields extend to the edge of the bank. The stream bottom is comprised largely of sand, gravel, rubble, small rocks and occasional boulders. Bottom conditions are comparable above and below the sewage outfall.

Kaskaskia Ditch is somewhat larger than Copper Slough. Its width above its confluence with Copper Slough was approximately $6 \mathrm{~m}$; its width below the confluence approximately $8 \mathrm{~m}$. Depth seldom exceeded $40 \mathrm{~cm}$. Like Copper Slough, Kaskaskia Ditch has been channelized and generally lacks well defined pools and riffles. Its banks are steep and grassy with a few small trees. Cultivated fields extend to the edge of the stream bank. The stream bottom above the confluence is largely sand with a little silt and gravel. The bottom below the confluence is harder and consists of sand, gravel and rubble.

Saline Branch is the largest of the three streams. Its width at the first sample station above the sewage outfall was approximately $8 \mathrm{~m}$; its width $19 \mathrm{~km}$ downstream at the last station below the outfall was approximately $10 \mathrm{~m}$. Depth generally ranged between 30 and $60 \mathrm{~cm}$. Saline Branch has been channelized, possesses few well-defined pool and riffle areas, and has steep, grassy banks. The bottom is variable, consisting largely of sand with some gravel at the sample stations above the outfall; sand, gravel, rubble, and rip-rap at the first station below the outfall; and sand, gravel, and rubble at the remaining stations. Saline Branch traverses cultivated, forested, semi-rural, and urban areas.

Chemical Parameters in Copper Slough

Water quality data by sampling date and station are given in Appendix A. In Copper slough, water quality underwent three important changes during this study. The first resulted from the cessation of continuous effluent 
chlorination on September 30, 1980, which marked the end of Phase I and beginning of Phase II. Residual chlorine concentrations during Phase I were quite high at all stations below the outfall (Table 1). No residual chlorine was measured during Phase II.

The second important water quality change in Copper slough was the reduction of ammonia concentrations below the outfall to very low levels beginning during the interregnum between Phases II and III. This change resulted first from improvements in effluent quality due to efficient operation of the Southwest Plant secondary treatment facilities, and later from tertiary nitrification at the Southwest Plant. Thus, total and unionized ammonia levels in Copper Slough were uniformly low during Phase III, even though tertiary nitrification did not begin until June 1982, approximately three months after the start of Phase III (Table 1). In contrast, total and to a lesser extent unionized ammonia levels were relatively high during Phases I and II. Highest levels occurred during Phase I (Table 1). The short time of passage in Copper Slough precluded significant ammonia decay within the stream and concentrations were fairly constant at all stations below the outfall. There was no appreciable difference between Phases I and II in this respect, indicating that effluent chlorination had little noticeable effect on ammonia reaction kinetics in Copper slough.

The third important water quality change in Copper slough was the periodic appearance of residual chlorine below the outfall during Phase III (Table 1). This resulted from the use of chlorine, in the form of sodium hypochlorite, to clean the sand filters installed at the Southwest Plant as part of its tertiary treatment system. When the filters were flushed after cleaning, washings containing residual chlorine were sometimes released into 


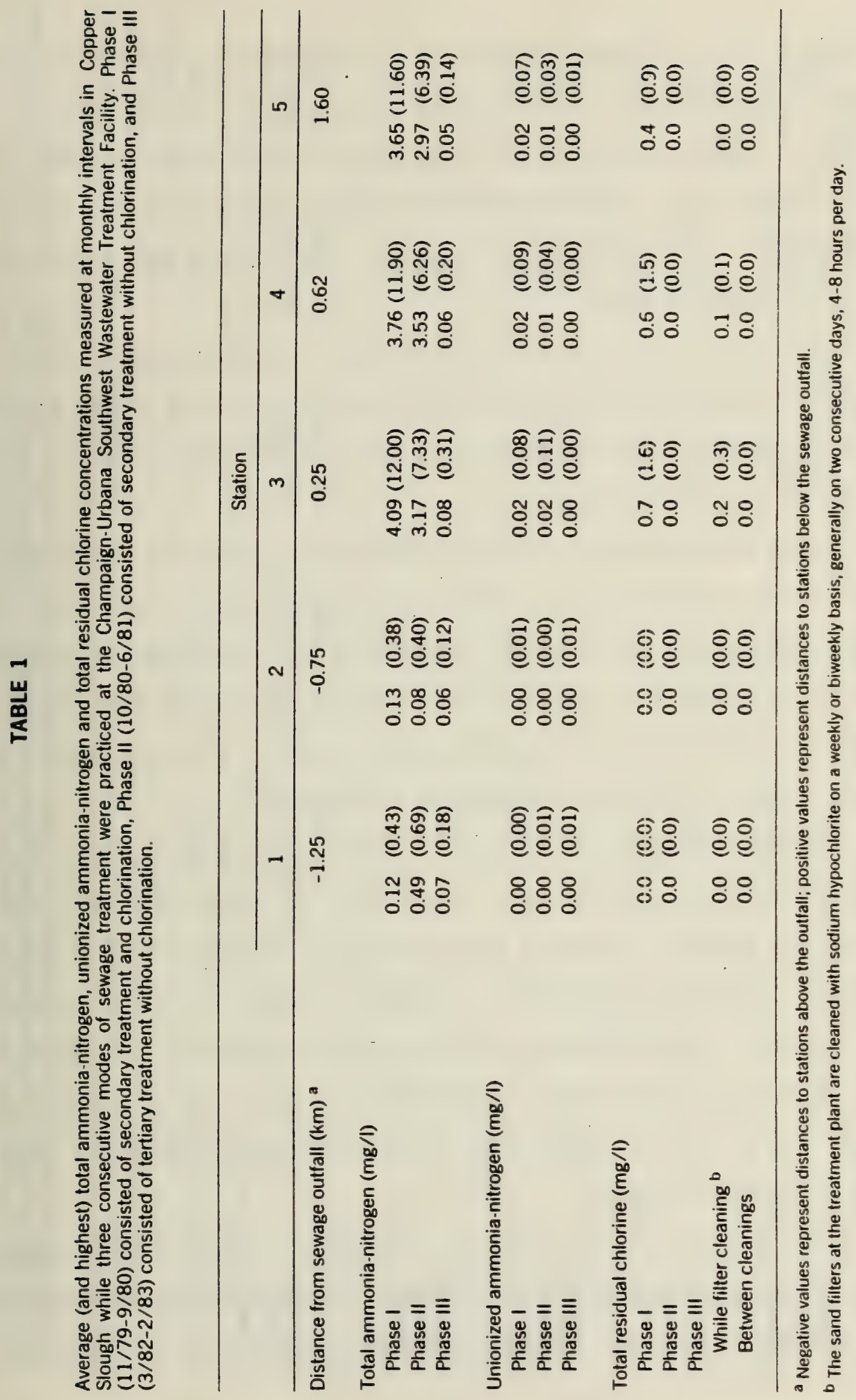


the stream. The frequency and duration of the cleaning periods varied, but usually occurred weekly or biweekly for part or all of two consecutive workdays. Samples taken on June 23 and July 23, 1982, which coincided with filter cleaning days, revealed effluent chlorine residuals of 0.3 and $0.2 \mathrm{mg} / \mathrm{l}$ respectively. In-stream residual chlorine concentrations were somewhat lower due to dilution and decay.

Other water quality parameters in Copper Slough are somewhat less important than ammonia and residual chlorine concentrations and in general indicate moderate levels of pollution. The more pertinent aspects of these parameters are discussed below.

Oxygen concentrations above the sewage outfall were high and usually exceeded saturation (Table 2). Concentrations below the outfall were only slightly lower, but levels below $7.0 \mathrm{mg} / 1$ were never measured. Slight oxygen sags were observed below the outfall during all phases, most prominently during Phase II (secondary treatment/no chlorination) and least prominently during Phase III (tertiary treatment/no chlorination).

Turbidity was somewhat lower, both above and below the outfall, during Phase III than during the earlier Phases (Table 2). The reduction below the outfall was probably related to the installation of sand filters at the Southwest Plant during Phase III. The reduction above the outfall may have been related to flow conditions prevailing during Phase III. Volume of flow, hence turbidity-causing runoff, was lower during Phase III than during earlier phases. It is also noteworthy that turbidity was similar above and below the outfall during all phases.

Total phosphorous concentrations, as expected, were far higher below the outfall than above (Table 2). In contrast, nitrate-nitrogen concentrations were fairly similar above and below the outfall suggesting that nitrogen may 


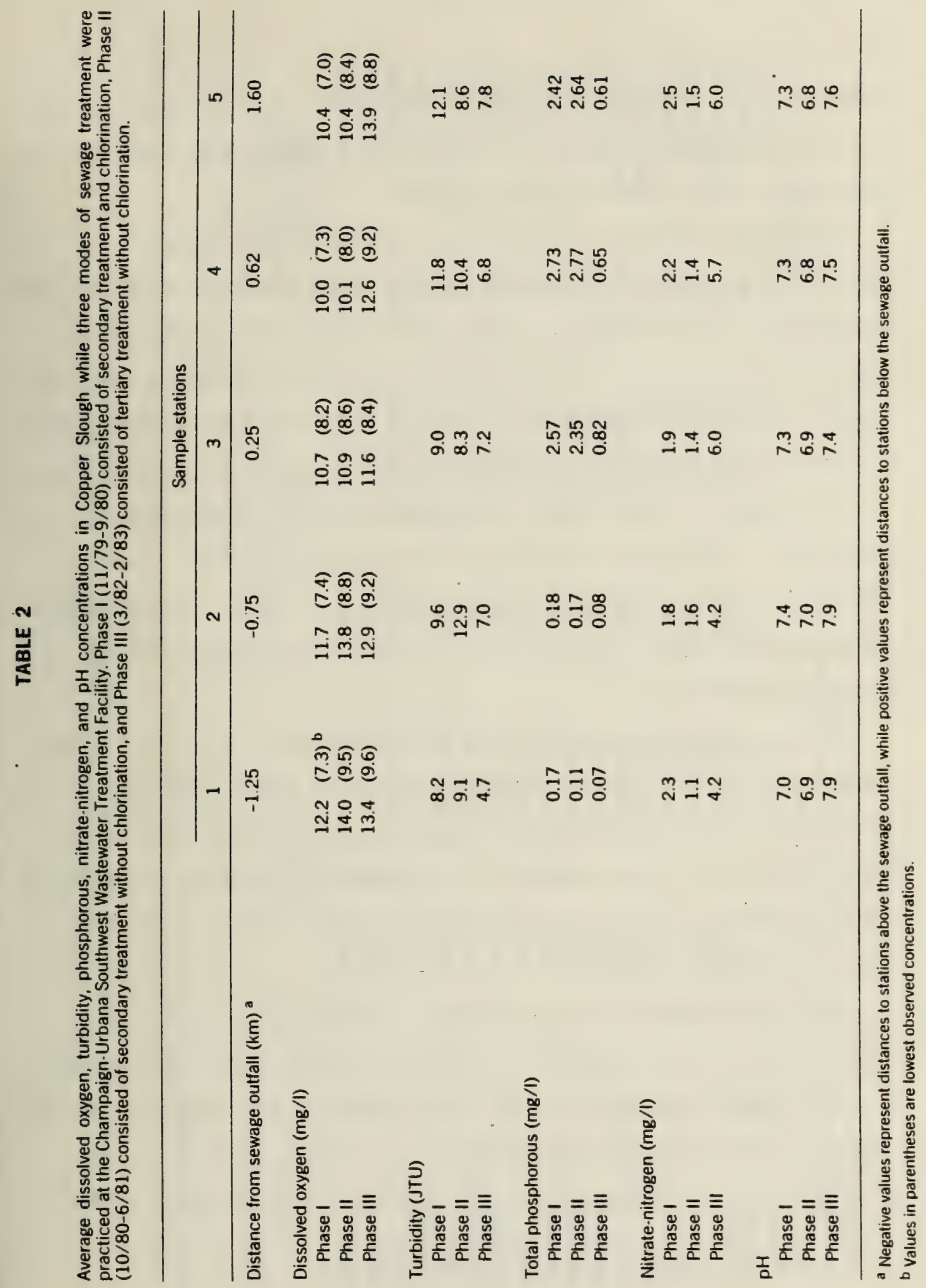


have been entering Copper Slough from sources other than the sewage effluent. One of these sources might have been runoff of nitrogen fertilizers from the agricultural fields adjoining Copper slough.

Differences between total phosphorous and nitrate-nitrogen concentrations were detected between phases. Total phosphorous was far lower during Phase III than during the other phases, while nitrate-nitrogen was just the opposite (Table 2). The Phase III phosphorous reduction below the outfall was probably related to the onset of the tertiary phosphorous removal procedures. The reduction above the outfall is less easily explained unless it is related to reduced runoff, hence reduced input of allochthonous phosphorous. The Phase III nitrate increase below the outfall was not unexpected since nitrification converts ammonia to nitrate. The increase above the outfall might have been due to fertilization practices in the adjoining watershed.

Hydrogen ion concentration varied from approximately 6.7 to 8.0 during the study. Although variation between these levels are of themselves unimportant to aquatic life, they can have a major effect on potential ammonia toxicity. In this respect it is noteworthy that $\mathrm{pH}$ was particularly low during Phase II, thus diminishing the proportion of toxic unionized ammonia during this period.

Most of the metals and other potential toxicants measured by the Illinois EPA Laboratory did not exceed the maximum safe levels for aquatic life as recommended by the U.S. EPA (29). There were some exceptions to this (Table 3 ), the most notable one being silver which reached $0.11 \mathrm{mg} / 1$ on November 25, 1980. Bioassays indicate that such levels are acutely toxic to 


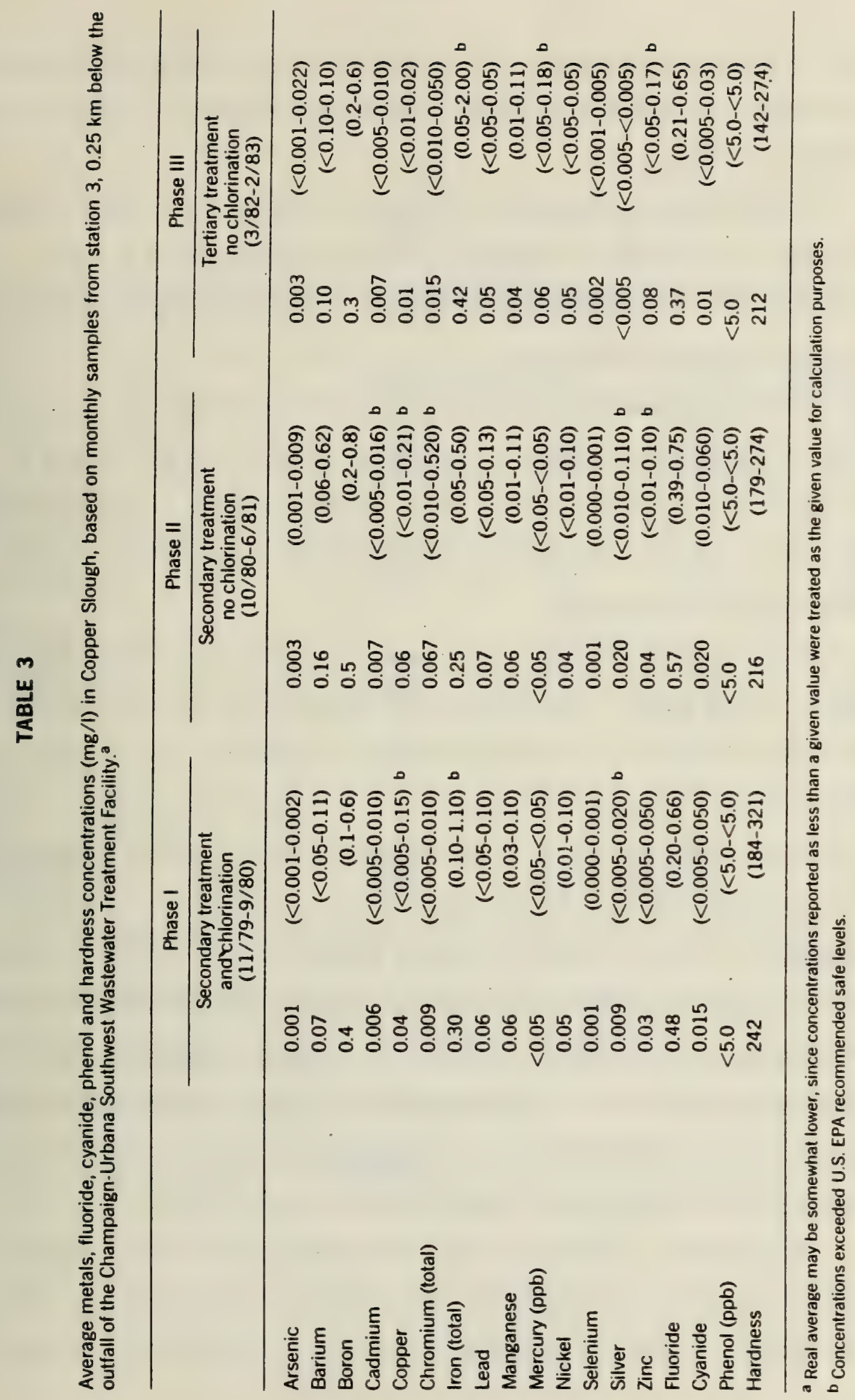


bluegill (Lepomis macrochirus) and largemouth bass (Micropterus salmoides)

(4): however, no unusual biological changes were observed in Copper Slough on November $25,1980$.

LAS concentrations, measured on March 8 and August 20, 1980, averaged $0.036 \mathrm{mg} / 1(0.012-0.060)$ at stations above the outfall and $0.043 \mathrm{mg} / \mathrm{l}$ (0.027-0.060) at stations below the outfall. Such levels are generally considered harmless to fish (10).

It is also important to note that the sewage effluent constituted most of the flow in Copper Slough, on the average about 68 percent (Table 4). This was particularly true during Phase III where natural flow was especially low. Flow rates, as well, were much higher below than above the outfall. Copper Slough Fish Community

The electrofishing samples were analyzed on the basis of species number, individuals per sample, sample weight and species composition. Species number was evaluated by pooling all samples by phase and station and separating the fish into three categories: a "sportfish" category including the sunfishes (Lepomis spp.), crappies (Pomoxis spp.), basses (Micropterus spp.), bullheads and catfish (Ictalurus spp.), and grass pickerel (Esox americanus); a "carp" category (Cyprinus carpio); and an "other" category including the native minnows (cyprinids), suckers (catostomids), freshwater drum (Aplodinotus grunniens), gizzard shad (Dorosoma cepedianum), darters (Etheostoma spp.), logperch (Percina caprodes), pirate perch (Aphredoderus sayanus), and blackstripe topminnow (Fundulus notatus) (21). Results at stations 1 and 2 were combined since they were quite similar.

On the average, each sample taken above the sewage outfall yielded 10 to 12 species (Table 5) most of which were cyprinids and catostomids, plus lesser numbers of centrarchids and other families (Appendix B). Average 


\section{TABLE 4}

Mean volumes of flow and flow rates in three sewage receiving streams, based on monthly measurements at stations above and below the sewage inflows. ${ }^{a}$

\begin{tabular}{|c|c|c|c|c|}
\hline & \multicolumn{2}{|c|}{ Above sewage inflow } & \multicolumn{2}{|c|}{ Below sewage inflow } \\
\hline & $\begin{array}{c}\text { Volume } \\
\text { of flow } \\
\left(1 / \text { day } \times 10^{8}\right)\end{array}$ & $\begin{array}{c}\text { Flow } \\
\text { rate } \\
(\mathrm{cm} / \mathrm{sec})\end{array}$ & $\begin{array}{c}\text { Volume } \\
\text { of flow } \\
\left(1 / \text { day } \times 10^{8}\right)\end{array}$ & $\begin{array}{c}\text { Flow } \\
\text { rate } \\
(\mathrm{cm} / \mathrm{sec})\end{array}$ \\
\hline \multicolumn{5}{|l|}{ Copper Slough b } \\
\hline Phase $\mid(11 / 79-9 / 80)^{c}$ & 0.85 & 19.3 & 2.56 & 39.9 \\
\hline Phase II $(10 / 80-6 / 81)$ & 0.38 & 20.5 & 1.45 & 36.4 \\
\hline Phase III $(3 / 82-2 / 83)$ & 0.19 & 23.4 & 0.42 & 34.9 \\
\hline \multicolumn{5}{|l|}{ Kaskaskia Ditch ${ }^{d}$} \\
\hline Phase I $(11 / 79-9 / 80)^{c}$ & 2.43 & 39.8 & 4.99 & 48.2 \\
\hline Phase II $(10 / 80-6 / 81)$ & 1.47 & 17.5 & 2.92 & 37.5 \\
\hline Phase III $(3 / 82-2 / 83)$ & 0.24 & 19.5 & 0.66 & 34.8 \\
\hline \multicolumn{5}{|l|}{ Saline Branch e } \\
\hline Phase I $(11 / 79-9 / 12 / 80)^{c}$ & - & 18.3 & 3.15 & 43.2 \\
\hline \multicolumn{5}{|l|}{ Phase II } \\
\hline Division $1(9 / 23 / 80-4 / 81)^{f}$ & - & 8.5 & 6.79 & 37.7 \\
\hline Division $2(5-6 / 81$ and $3-9 / 82)$ & 0.84 & 15.6 & 1.93 & 41.5 \\
\hline Phase III $(10 / 82-2 / 83)$ & 0.24 & 20.8 & 0.77 & 33.4 \\
\hline
\end{tabular}

a Volumes of flow were measured only at one station above and one station below the sewage inflow. Flow rates were neasured at all stations.

b There were 5 sample stations on Copper Slough, 2 above the Champaign-Urbana Southwest Wastewater Treatment Facility and 3 below. Respective distances of the stations from the sewage outfall were $-1.25,-0.75,0.25,0.62$ and $1.60 \mathrm{~km}$.

c Secondary treatment and chlorination were practiced during Phase I, secondary treatment without clorination during Phase II, and tertiary treatment without chlorination during Phase III.

d Kaskaskia Ditch received sewage from Copper Slough, its tributary stream. Station 1 was $0.25 \mathrm{~km}$ above the confluence; stations 2 and 3 were 1.10 and $2.70 \mathrm{~km}$ below the confluence.

e There were 7 sample stations on Saline Branch, 2 above the Champaign-Urbana Northeast Wastewater Treatment Facility and 5 below. Respective distances of the stations from the sewage outfall were $-6.3,-5.7,0.3,1.9,3.8,10.1$ and $12.5 \mathrm{~km}$.

if The Northeast Wastewater Treatment Facility was renovated during Division 1. Division 2 includes the period after renovation. 


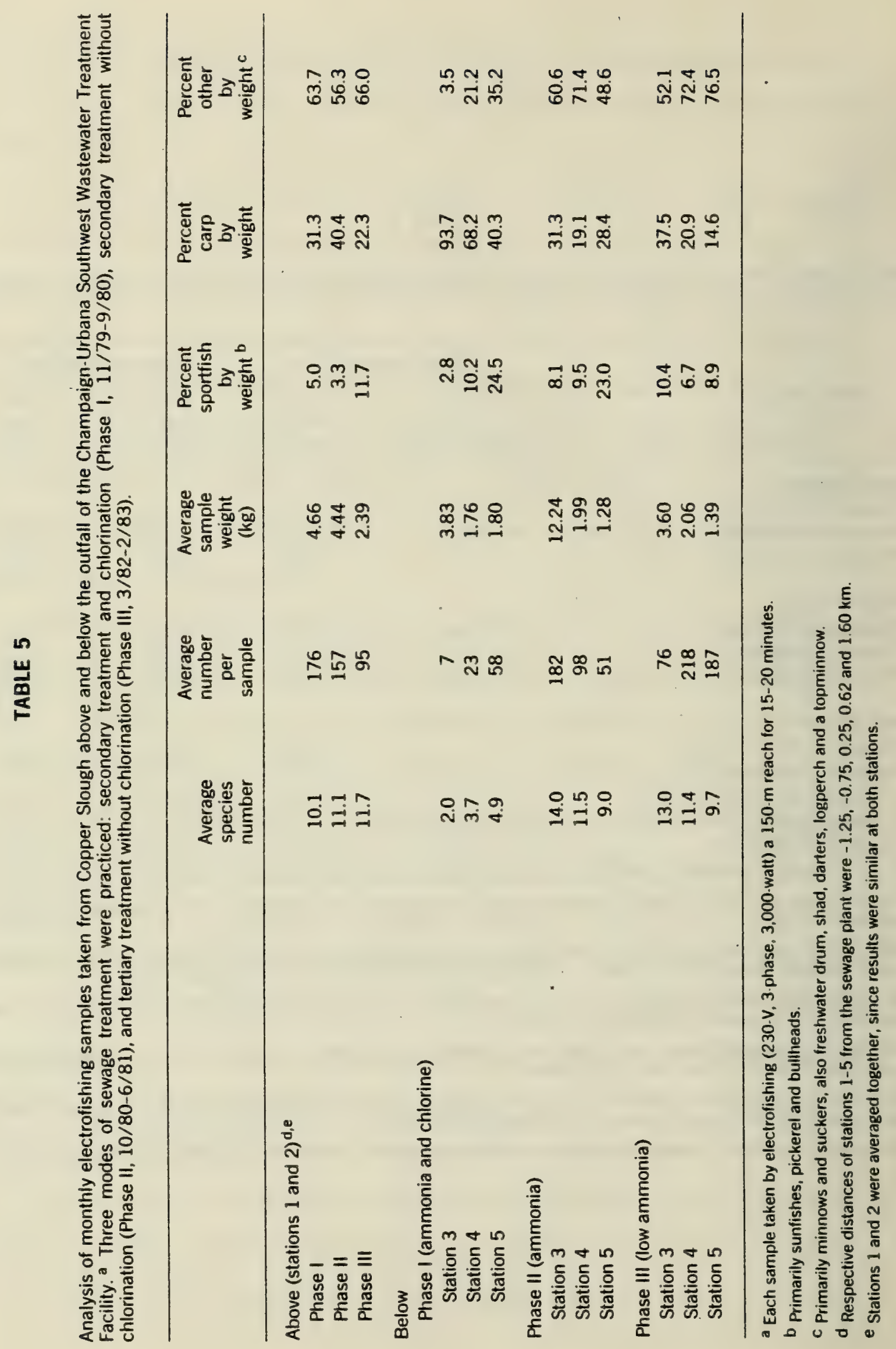


species number above the outfall was quite similar between phases; however, average number, average sample weight, and taxonomic composition all showed marked differences in Phase III as compared to Phases I and II (Table 5). The changes probably stemmed from the fact that volume of flow was 80 percent lower during Phase III than during Phases I and II, resulting in habitat loss and corresponding reductions in number of fish, particularly large fish.

Species number below the sewage outfall indicated severe degradation during the Phase I chlorination period (Table 5). Average species number at stations 3, 4 and 5 during Phase I was 3.5 or approximately one-third the average at stations above the outfall. Degradation was most severe at station 3 , the first station below the outfall, where species number averaged 2 as opposed to 10 above the outfall. Species number tended to increase somewhat with distance from the outfall, but even at station 5 was well below ambient levels.

Number of fish per sample also indicated degradation during Phase I, averaging 26 at stations 3,4 and 5 below the outfall as opposed to 154 at stations 1 and 2 above the outfall. Sample weight exhibited the same trend, averaging $2.45 \mathrm{~kg}$ at stations 3,4 and 5 , in contrast to $4.56 \mathrm{~kg}$ at stations 1 and 2. There was, however, an interesting difference between numbers and sample weight. Number per sample was lowest at station 3 and progressively increased at stations 4 and 5, while sample weight was greatest at station 3 and declined at 4 and 5 (Table 5). This trend was caused by changes in species and size composition. Large carp predominated at station 3, while smaller species were found at the other stations.

Degradation during Phase I was further demonstrated by species composition. The carp, a sewage tolerant species, was far more abundant below the outfall than above (Table 5), while the opposite was true for fish 
from the "other" category. Surprisingly, sportfish were somewhat more abundant below the outfall than above, particularly at station 5 (Table 5). However, the actual biomass in grams of sportfish at station 5 was less impressive than the percentage figure.

It is noteworthy that the percent of sportfish steadily increased with distance from the sewage outfall, while the percent of carp decreased during Phase I (Table 5). Although this was undoubtedly partly related to pollution factors, habitat may have also played a part. Station 3 was by far the deepest station $(0.8 \mathrm{~m})$, thus offering suitable habitat to large fish such as carp, while stations $4(0.3 \mathrm{~m})$ and $5(0.2 \mathrm{~m})$ were progressively shallower. The Copper Slough fish community improved dramatically after chlorination was discontinued. Species number increased to ambient levels within seven days of the cessation of chlorination (Appendix A). Average species number at the first station below the outfall increased from 2 during Phase I to 14 during Phase II, a greater number than found above the outfall (Table 5). Species number decreased somewhat further downstream but still remained near upstream levels. This decrease was probably due to habitat factors, since the water became increasingly shallow near the end of Copper Slough.

In Phase II, numbers, sample weight, and species composition of fish also showed marked improvements in the absence of chlorination (Table 5). Average number of fish per sample from stations 3, 4, and 5 was much higher than during the chlorination period, although the cumulative average for all 3 stations (110) did not reach upstream levels of 157 . Sample weight at the first station below the outfall (station 3) increased from $3.8 \mathrm{~kg}$ during chlorination to $12.2 \mathrm{~kg}$ after its discontinuation. Lastly, species composition shifted away from carp and towards the less sewage tolerant fish 
in the "other" category and to a lesser extent towards sportfish (Table 5). In fact, species composition below the outfall following the cessation of chlorination was superior to species composition above the outfall during the same period. Thus the percentage of sportfish was greater and the percentage of carp less than above the outfall (Table 5).

Some of the fishes reappearing during Phase II began reproductive behaviors. Many creek chub (Semotilus atromaculatus) nests appeared below the outfall towards the end of Phase II (May and June 1981), and numerous young-of-the-year white suckers (Catostomus commersoni) were collected in the August 23 follow-up sample between Phases II and III.

It should be remembered that the recovery just described occurred while secondary treatment was still being practiced at the Southwest Plant. Total ammonia-nitrogen concentrations at station 3 averaged $3.17 \mathrm{mg} / \mathrm{l}(0.27-7.33)$ during this period (i.e., Phase II) and unionized ammonia-nitrogen concentrations averaged $0.02 \mathrm{mg} / 1(0.00-0.11)$ (Table 6). Concentrations at stations 4 and 5 were somewhat lower.

The reduction of ammonia concentrations to very low levels during Phase III did not result in further improvements in the Copper slough fish community. Species number during Phase III was approximately the same as during Phase II and species composition was slightly worse, since carp increased somewhat at the expense of other fishes (Table 5). More notable differences between Phases I and II are seen in number per sample and sample weight. Weight and number of individuals at station 3 during Phase III were 30 to 40 percent lower than during Phase II. The opposite was true of stations 4 and 5 where numbers and weight were far higher during Phase III than during Phase II. 


\section{TABLE 6}

Unionized ammonia-nitrogen concentrations and species number taken by electrofishing at station 3 on Copper Slough while secondary treatment without chlorination was practiced at the Champaign-Urbana Southwest Wastewater Treatment Facility, a,b

\begin{tabular}{lcccc}
\hline Date & $\begin{array}{c}\text { Species } \\
\text { number }\end{array}$ & $\begin{array}{c}\text { Total } \\
\text { ammonia- } \\
\text { nitrogen } \\
(\mathrm{mg} / \mathrm{l})\end{array}$ & $\begin{array}{c}\text { Unionized } \\
\text { ammonia- } \\
\text { nitrogen } \\
(\mathrm{mg} / \mathrm{l})\end{array}$ & $\begin{array}{c}\text { Temperature } \\
(\mathrm{C})\end{array}$ \\
\hline $10 / 7 / 80$ & 15 & 3.67 & 0.01 & 17 \\
$10 / 29 / 80$ & 12 & .7 .33 & 0.11 & 10 \\
$11 / 25 / 80$ & 12 & 2.18 & 0.00 & 6 \\
$12 / 20 / 80$ & 13 & 1.66 & 0.01 & 6 \\
$1 / 15 / 81$ & 15 & 1.14 & 0.00 & 8 \\
$2 / 21 / 81$ & 12 & 0.27 & 0.00 & 8 \\
$3 / 24 / 81$ & 14 & 6.09 & 0.03 & 15 \\
$4 / 28 / 81$ & 16 & 3.91 & 0.01 & 14 \\
$5 / 23 / 81$ & 15 & 0.91 & 0.00 & 19 \\
$6 / 30 / 81$ & 16 & 4.50 & 0.00 & 6 \\
\hline
\end{tabular}

a Each sample taken by electrofishing (230-V, 3-phase, 3,000-watt) a 150-m reach for $15-20$ minutes.

b Station 3 was $0.25 \mathrm{~km}$ below the sewage outtall. 
These trends in number and weight may be due to several factors unrelated to the change in ammonia concentration between phases. Reduced number and weight at station 3 during Phase III were probably due to the release of residual chlorine during filter cleaning periods (Table 1). The increased numbers at stations 4 and 5 during Phase III is probably due to chronological factors. Phase I lasted until september 30, 1980, thus chlorination was practiced during the prime spawning months of 1980 . This set the stage for reduced numbers during the following fall and winter which comprised the bulk of Phase II. Furthermore, Phase II sampling terminated at the end of June 1981. Thus, the Phase II samples also failed to pick up the 1981 spawn. If the average number of fish are calculated in Phase III without using data from the months following June, the average numbers at stations 3,4 , and $5(74,161$, and 59 respectively) are more comparable to the Phase II numbers than if the young-of-the-year appearing after June of Phase III are included in the averages (Table 5).

Statistical analysis of the Copper Slough fish data was restricted to species number. Species number was less variable than numbers or sample weight (Table 7), since it was less affected by spawning or seasonal fish movements. The Kruskal-Wallis test, a nonparametric analog of the ANOVA, was used to analyze the data (16). An a priori design was employed, since previous research enabled us to formulate specific questions prior to the start of this study (14). The 0.05 probability level was used in all contrasts.

The statistical analysis (Table 8) indicated the following: 1) Species number above the outfall was not significantly different from species number below the outfall during Phases II and III; 2) Species number above the outfall was significantly different from species number below the outfall 


\section{TABLE 7}

Coefficients of variation (percent) of several electrofishing sample parameters. ${ }^{2}$

\begin{tabular}{|c|c|c|c|}
\hline \multirow[b]{2}{*}{$\begin{array}{l}\text { Stream and } \\
\text { sample station }\end{array}$} & \multicolumn{3}{|c|}{ Parameters } \\
\hline & $\begin{array}{l}\text { Species } \\
\text { number }\end{array}$ & $\begin{array}{c}\text { Total fish } \\
\text { weight }\end{array}$ & $\begin{array}{l}\text { Number } \\
\text { of fish }\end{array}$ \\
\hline \multicolumn{4}{|l|}{ Copper Slough } \\
\hline Station 1 & 20 & 115 & 43 \\
\hline Station 2 & 19 & 75 & 45 \\
\hline Station 3 & 25 & 113 & 45 \\
\hline Station 4 & 35 & 99 & 61 \\
\hline Station 5 & 27 & 150 & 140 \\
\hline \multicolumn{4}{|l|}{ Kaskaskia Ditch } \\
\hline Station 1 & 31 & 158 & 158 \\
\hline Station 2 & 19 & 88 & 63 \\
\hline Station 3 & 20 & 118 & 59 \\
\hline \multicolumn{4}{|l|}{ Saline Branch } \\
\hline Station 1 & 17 & 68 & 124 \\
\hline Station 2 & 19 & 66 & 70 \\
\hline Station 3 & 9 & 79 & 47 \\
\hline Station $4^{b}$ & - & - & - \\
\hline Station 5 & 13 & 38 & 24 \\
\hline Station 6 & 18 & 65 & 74 \\
\hline Station 7 & 23 & 51 & 50 \\
\hline
\end{tabular}

a Monthly samples were taken during :he period 3/82-2/83 (Copper Slough and Kaskaskia Ditch) or 10/82-2/83 (Saline Branch). All streams were rece ving unchlorinated tertiary effluent during these periods.

b Station 4 accessibility prohibited; this site is eliminated from all further sampling. 


\section{TABLE 8}

Statistical analysis (Kruskal-Wallis Test) (16) of species number taken by electrofishing at sample stations on Copper Slough. Stations 1 and 2 were above the outfall of the Cha.npaign-Urbana Southwest Wastewater Treatment Facility; stations 3, 4, and 5 were below it. Secondary "reatment with chlorination was practiced during Phase I (11/79-9/80), secondary treatment without $\mathrm{c}$ lorination during Phase II $(10 / 80-6 / 81)$, and tertiary treatment without chlorination during Phase III $(3 / 82-2 / 83)$.

\section{Sample size}

Six to 12 samples were taken at one month intervals at each station during each phase. Total sample size equals 149 separated into 15 groups by station and phase.

II. Omnibus test

$H_{0}$ : Species number is equal at all stations during all phases.

$\mathrm{H}_{1}$ : Species number is not equal at all stations and/or is not equal between phases.

Decision rule: Reject the null if $\mathrm{H}(\mathrm{df}=14,0.95)$ is greater than or equal to 23.68 .

$\mathrm{H}$ (with correction for ties) $=61.43$. The null is rejected.

III. A priori nonorthoganol comparisons

Decision rule: Reject any contrast if $H(d f=1,0.95)$ is greater than or equal to the problem-wise critical value of 6.97 .

1) $H_{0}$ : Species number at stations 1 and 2 during Phase $I$ is equal to species number at stations 3,4 , and 5 during Phase I. $H=29.58$.

2) $H_{0}$ : Species number at stations 1 and 2 during Phase $I 1$ is equal to species number at stations 3,4 , and 5 during Phase II. $H=0.17$.

3) $H_{0}$ : Species number at stations 1 and 2 during Phase III is equal to species number at stations 3,4 , and 5 during Phase III. $H=0.48$.

4) $H_{0}$ : Species number at stations 3,4 , and 5 during Phase $I$ is equal to species number at stations 3, 4, and 5 during Phase II. $\mathrm{H}=29.58$.

5) $H_{0}$ : Species number at stations 3,4 , and 5 during Phase $I$ is ec|ual to species number at stations 3,4 , and 5 during Phase III. $H=28.68$.

6) $H_{0}$ : Species number at stations 3,4 , and 5 during Phase $\|$ is equal to species number at stations 3,4 , and 5 during Phase III. $H=0.11$. 
during Phase I; 3) Species number below the outfall was not significantly different between Phases II and III; 4) Species number below the outfall during Phase I was significantly different from both species number below the outfall during Phase II and species number below the outfall during Phase III. Thus, the statistical analysis corroborated the trends described earlier in the report.

The statistical analysis did not include data from the two "follow-up" samples taken between Phases II and III. These samples were taken on August 23, 1981, and October 7-8, 1981, to investigate the effects of a temporary 48-hour resumption of chlorination beginning on October 6, 1981. Except at station 5, species number before the 48-hour resumption of chlorination was fairly similar above $(11,15)$ and below $(15,15,3)$ the outfall at stations 1 through 5 respectively. The low species number at station 5 was due to very shallow water at this station. In contrast, species number after the resumption of chlorination dropped to 6 at station 3 and 3 at station 4 , while remaining high at stations above the outfall (10 at station 1 and 13 at station 2). Residual chlorine concentrations on 8 october were $0.1 \mathrm{mg} / 1$ at stations 3 and 4 . Total and unionized ammonia-N concentrations were less than 1.00 and $0.01 \mathrm{mg} / \mathrm{l}$, respectively. These data illustrate the speed with which residual chlorine impacts fish communities. Copper Slough Macroinvertebrate Samples

The macroinvertebrate samples were analyzed by number of taxa (most identifications were to genera) per sample, number of specimens per sample, sample weight (expressed as $\mathrm{g} / \mathrm{m}^{2}$ of sampler substrate), and taxonomic composition (Appendix C) $(2,3,8,9,12,13,18,19,26)$. Taxonomic composition was evaluated by pooling data by phase and location (above outfall and below outfall) and separating all specimens into 6 categories on 
the basis of order (Table 9). Stations below the outfall (stations 3 to 5) were combined in the taxonomic composition analysis since trends across them were absent.

On the average, macroinvertebrate samples from above the sewage outfall during all three phases contained 9 to 14 taxa (Figure 3) including crustaceans, molluscs, annelids, dipterans, other insects, and to a lesser extent turbellarians (Table 9). Taxon number above the outfall was similar between Phases I and II, but increased somewhat during Phase III (Figure 3, Table 9). Number of specimens per sample and sample weight also increased during Phase III and, in fact, tended to progressively increase across all phases. These changes in taxon number, number per sample, and sample weight were accompanied by less regular changes in taxonomic composition (Table 9). The reason for such trends and fluctuations at stations above the outfall are unknown but might be related to any of the following: stochastic variation, differences in volume of flow between phases, chronological differences between phases, and unusually mild winter weather during Phase III.

Taxon number and sample weight were far lower below the outfall than above during the chlorination period (Phase I) (Figure 3, Table 9). Average number of individuals, in contrast, was only slightly lower below the outfall than above, indicating in conjunction with the weight data, a reduction in mean size. This reduction was due to the prevalence of small chironomids (a family in the order Diptera known for its pollution tolerant members) below the sewage outfall as opposed to the larger insects, molluscs, and crustaceans that predominated above the outfall (Table 9). In summary, all parameters indicated marked degradation below the sewage outfall when chlorination was practiced. 


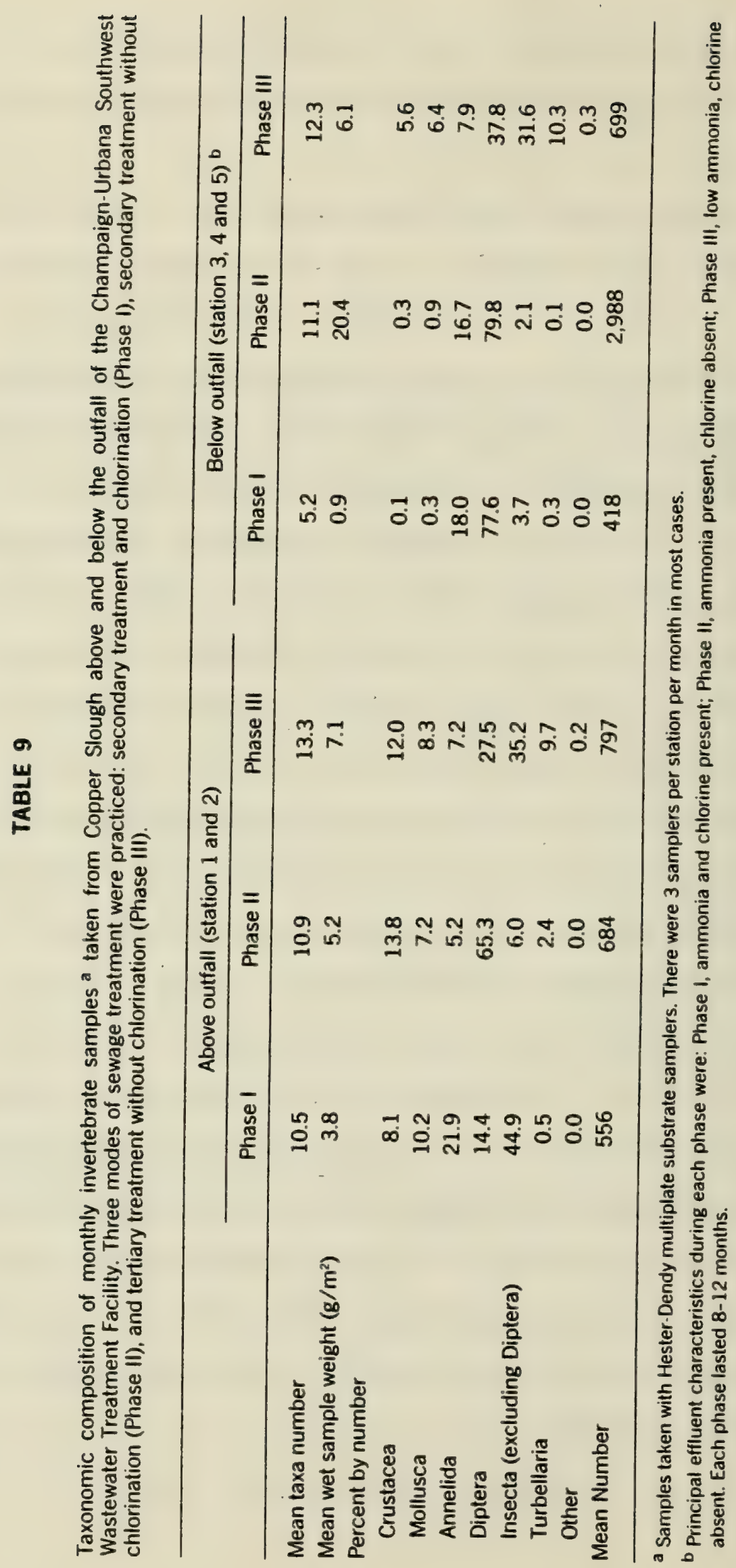




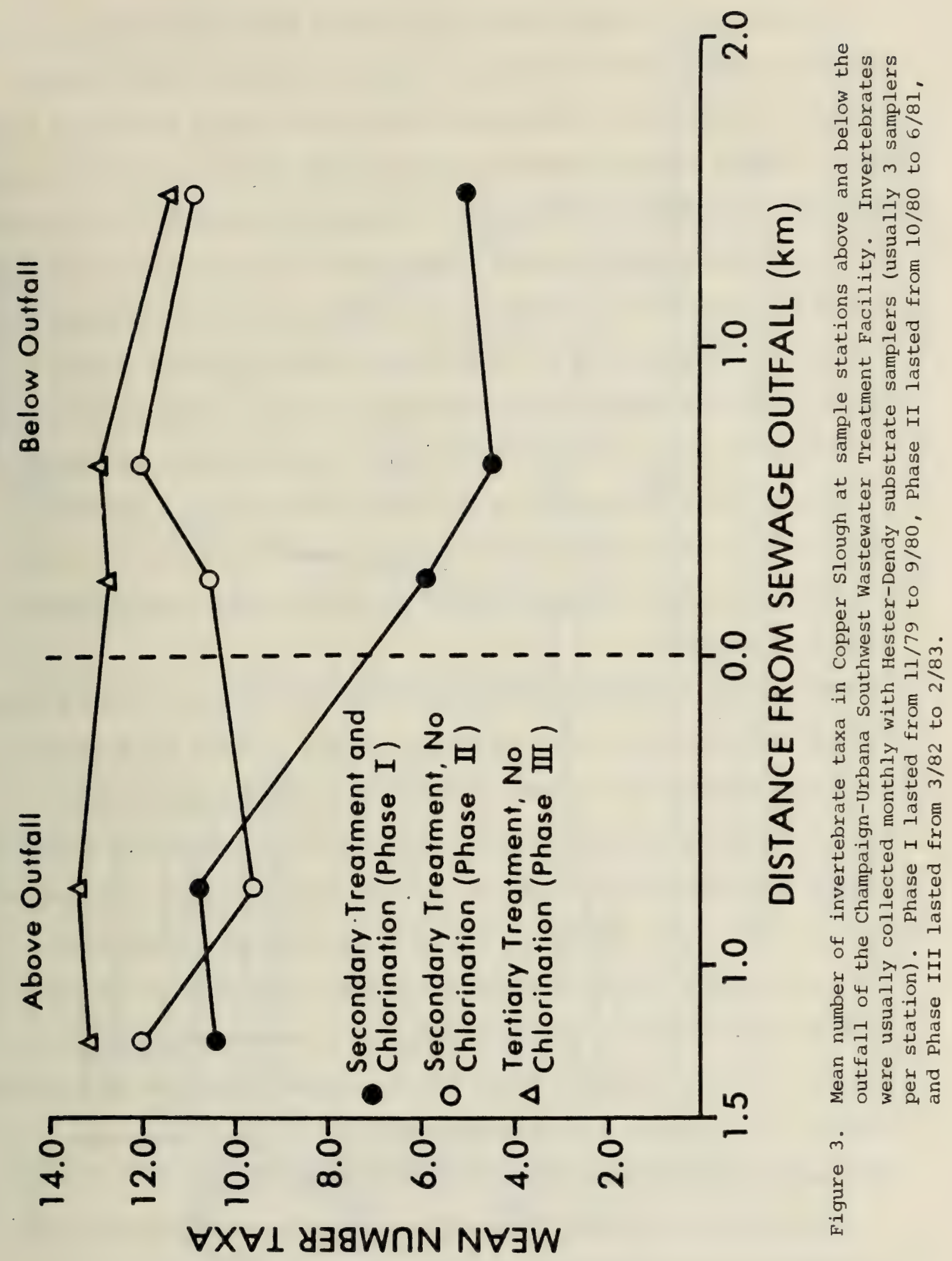


The cessation of chlorination at the end of Phase I resulted in striking increases in taxon number, number per sample, and sample weight (Table 9, Figures 3 and 4). These changes were very evident, and in the case of taxon number, largely complete within two months of the cessation of chlorination. Thus, data from the month immediately following the cessation of chlorination are not included in this analysis. Taxon number at all stations below the outfall increased from an average of 5.2 during Phase I to 11.1 during Phase II, which was comparable to the taxon number above the outfall (Figure 3 ). Average number per sample and sample weight below the outfall demonstrated even greater increases than did taxon number, reaching levels many times greater than those occurring below the outfall during Phase I and greatly exceeding levels above the outfall (Figure 4, Table 9). The bulk of this increase consisted of dipterans, especially blackfly larvae (Simulium sp.) (Table 9, Appendix C).

The tertiary treatment conditions of Phase III resulted in only a slight increase in taxon number below the outfall (Figure 3, Table 9). Furthermore, this slight increase was probably unrelated to effluent changes, since a comparable increase also occurred above the outfall. In contrast, number of specimens and sample weight below the outfall showed a precipitious drop from Phase II levels. This decline reflects a large reduction in dipterans, especially blackfly larvae, compared to the high Phase II levels (Table 9). The reduction in dipterans was associated with a commensurate increase in other types of insects, making taxonomic composition, number and weight below the outfall during Phase III quite comparable to taxonomic composition, number and weight above the outfall during the same period.

Considering all factors, the macroinvertebrate community during Phase III appeared to be slightly superior to the macroinvertebrate community 


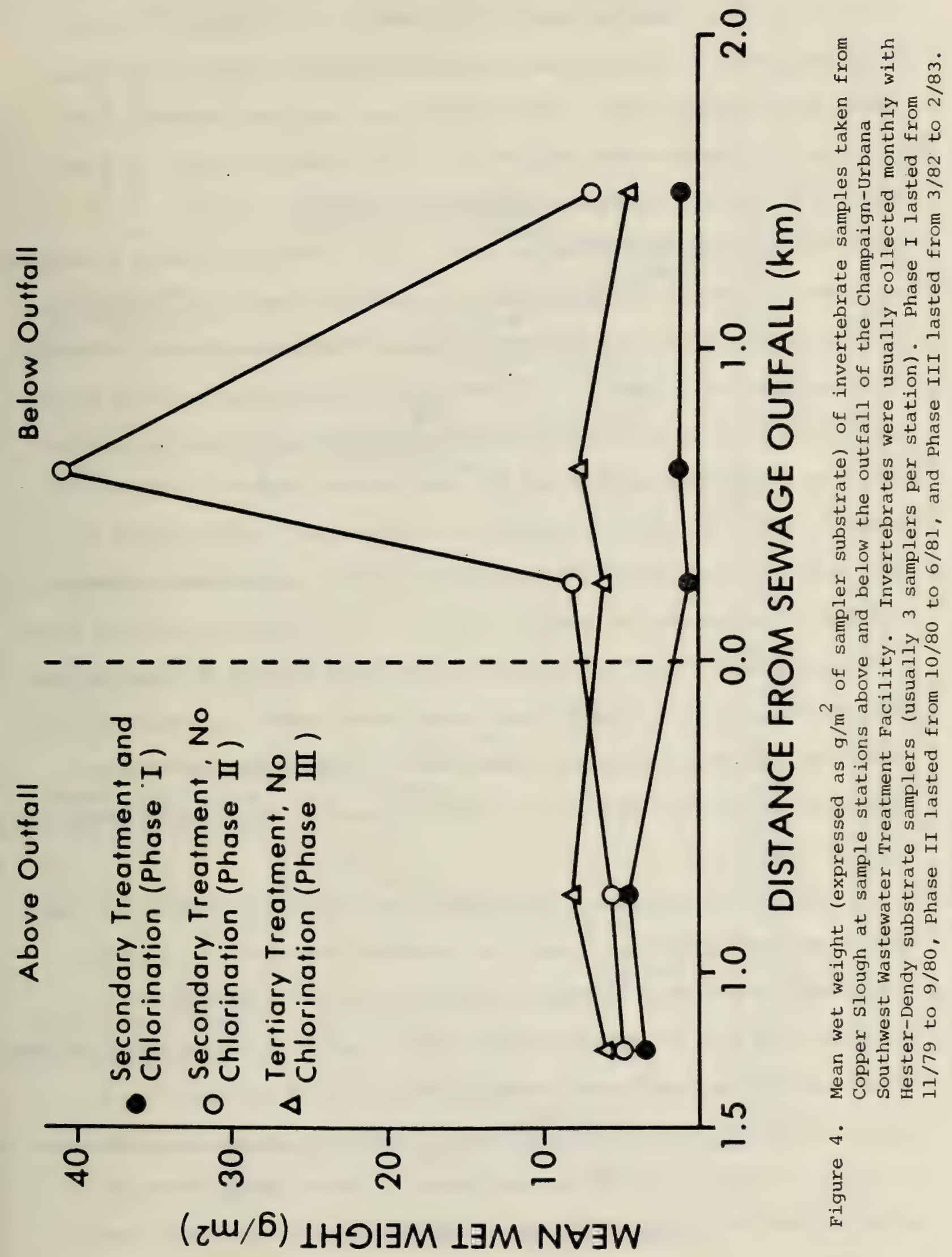


during Phase II. Taxonomic composition seemed to be normalized and the inflated numbers of dipterans and annelids typical of organically polluted waters were largely absent. There are at least four ways, besides random variation, to explain these differences. 1) Low ammonia levels and other benefits of tertiary treatment permitted full recovery of the macroinvertebrate community during Phase III. 2) The improvements associated with Phase III actually resulted from the earlier cessation of chlorination. In other words, the Copper slough macroinvertebrate community was in a state of transition during Phase II (and the subsequent eight-month hiatus between phases) and would have demonstrated the improvements associated with Phase III, even if effluent quality had not been further enhanced. However, definite trends in taxonomic composition were not noted within Phase II (Figure 5). 3) The reductions in number and weight associated with Phase III were due to the release of residual chlorine into Copper Slough during filter cleaning periods. This view assumes that inflated numbers of dipterans and annelids at stations 3,4 and 5 were normal under prevailing conditions and that their reduction constitutes degradation. 4) Predation by the fish community reduced the number and weight of insects in Phase III from what was found in Phase II.

Statistical analysis of the Copper Slough macroinvertebrate data was restricted to taxon number, since this parameter underwent less seasonal variation than the other variables. The data were analyzed with the Kruskal-Wallis test (as were the fish data). A post-hoc design employing the Scheffe method was used, since research questions were not specified a priori. The 0.05 problem-wise probability level was used in all contrasts. The only significant differences were: 1) taxon number below the outfall (stations 3,4 and 5) during Phase I versus taxon number below the 
outfall during Phase III; and 2) taxon number below the outfall during Phases II and II combined versus taxon number below the outfall during Phase I. Taxon number below the outfall during Phase II was not significantly different from taxon number below the outfall during phase I. The results of this analysis basically support the contention that taxon number below the outfall during the chlorination period was quite different from taxon number below the outfall after chlorination was discontinued.

Copper Slough Phytoplankton

Chlorophyll-a is an indicator of algal biomass since it averages $1.5 \%$ of the dry weight organic matter of algae. Pheophytin-a is a degradation product of chlorophyll-a.

Chlorophyll-a and pheophytin-a concentrations (Appendix D) were lower below the outfall than above during Phases I and II and were comparable above and below during Phase III, indicating that none of the sewage treatment modes promoted excessive phytoplankton growth within the study area (Table 10). It is also noteworthy that algal biomass was much the same before and after the discontinuation of chlorination. The most dramatic change in chlorophyli-a and pheophytin-a concentrations was their marked decrease above and below the outfall during Phase III (Table 10).

Chemical Parameters in Kaskaskia Ditch

The effluent received by Kaskaskia Ditch was weakened and diluted by passage through Copper slough. Thus most parameters indicate less pollution in Kaskaskia Ditch than in Copper Slough, and with few exceptions follow the same trends observed in Copper Slough (Tables 1, 2, 11 and 12). Important aspects of the Kaskaskia Ditch chemical data are: 1) The average total residual chlorine concentration during Phase I in Kaskaskia Ditch was onethird of that in Copper Slough. Kaskaskia Ditch was free of residual 


\section{TABLE 10}

Average chlorophyll-a and pheophytin-a concentrations in Copper Slough above and below the discharge of the Champaign-Urbana Southwest Wastewater Treatment Facility. Three modes of sewage treatment were practiced: secondary treatment and chlorination (Phase I), secondary treatment without chlorination (Phase II), and tertiary treatment without chlorination (Phase III)..$^{\mathrm{a} b \mathrm{~b}}$

\begin{tabular}{lcc}
\hline & $\begin{array}{c}\text { Mean } \\
\text { chlorophyll-a } \\
\left(\mathrm{mg} / \mathrm{m}^{3}\right)\end{array}$ & $\begin{array}{c}\text { Mean } \\
\text { pheophytin-a } \\
\left(\mathrm{mg} / \mathrm{m}^{3}\right)\end{array}$ \\
\hline $\begin{array}{l}\text { Above } \\
\text { Phase I }\end{array}$ & 4.40 & 3.35 \\
Phase II & 5.43 & 6.02 \\
Phase III & 0.19 & 1.56 \\
Below & & \\
Phase I (ammonia and chiorine) ${ }^{c}$ & & 1.56 \\
Phase II (ammonia) & 2.24 & 2.01 \\
Phase III (low ammonia) & 3.65 & 1.53 \\
\hline
\end{tabular}

a Phase I extencled from $11 / 79$ to $9 / 80$, Phase II from $10 / 80$ to $6 / 81$, and Phase III from $3 / 82$ to $2 / 83$.

b Samples were taken monthly and analyzed spectrophotometrically.

c Principal efflu ent characteristics during each phase are in parentheses. 


\section{TABLE 11}

Average (and highest) total ammonia-nitrogen, unionized ammonia-nitrogen and total residual chlorine concentrations measured at monthly intervals in Kaskaskia Ditch above and below its confluence with Copper Slough. Three modes of sewage treatment were practiced at the Champaign-Urbana Southwest Wastewater Treatment Facility which discharges into Copper Slough. Phase I (11/79-9/80) consisted of secondary treatment and chlorination, Phase II (10/80-6/81) consisted of secondary treatment without chlorination and Phase III $(3 / 82-2 / 83)$ consisted of tertiary treatment without chlorination.

\begin{tabular}{|c|c|c|c|c|c|c|}
\hline & \multicolumn{6}{|c|}{ Station } \\
\hline . & \multicolumn{2}{|c|}{1} & \multicolumn{2}{|c|}{2} & \multicolumn{2}{|c|}{3} \\
\hline Distance from confluence with Copper Slough $(\mathrm{km})^{a}$ & \multicolumn{2}{|c|}{-0.25} & \multicolumn{2}{|c|}{1.10} & \multicolumn{2}{|c|}{2.70} \\
\hline \multicolumn{7}{|l|}{ Total ammonia-nitrogen $(\mathrm{mg} / \mathrm{l})$} \\
\hline Phase I & 0.57 & $(1.40)$ & 1.89 & $(5.06)$ & 1.86 & $(4.79)$ \\
\hline Phase II & 1.15 & $(8.55)$ & 2.74 & $(8.40)$ & 2.02 & $(4.50)$ \\
\hline Phase III & 0.2 .7 & $(0.68)$ & 0.11 & $(0.26)$ & 0.19 & $(0.94)$ \\
\hline \multicolumn{7}{|l|}{ Unionized ammonia-nitrogen (mg/l) } \\
\hline Phase I & 0.01 & $(0.05)$ & 0.01 & $(0.01)$ & 0.01 & $(0.01)$ \\
\hline Phase II & 0.0 .2 & $(0.18)^{b}$ & 0.01 & $(0.03)$ & 0.01 & $(0.03)$ \\
\hline Phase III & 0.01 & $(0.06)$ & 0.00 & $(0.02)$ & 0.01 & $(0.13)$ \\
\hline Total residual chlorine $(\mathrm{mg} / \mathrm{l})$ & 0.0 & $(0.0)$ & 0.1 & $(0.3)$ & 0.1 & $(0.2)$ \\
\hline Phase I & 0.0 & $(0.0)$ & 0.1 & $(0.3)$ & 0.1 & $(0.2)$ \\
\hline Phase II & 0.0 & $(0.0)$ & 0.0 & $(0.0)$ & 0.0 & $(0.0)$ \\
\hline \multicolumn{7}{|l|}{ Phase III } \\
\hline While filter cleaning ${ }^{c}$ & 0.0 & $(0.0)$ & 0.0 & $(0.0)$ & 0.0 & $(0.0)$ \\
\hline Between cleanings & 0.0 & $(0.0)$ & 0.0 & $(0.0)$ & 0.0 & $(0.0)$ \\
\hline
\end{tabular}

\footnotetext{
a Negative value represents distance to the station above the confluerice; positive values represent distances to stations below the confluence.

b An exceptionally high unionized ammonia-nitrogen level $(0.18 \mathrm{mg} / \mathrm{l})$ was recorded at station 1 on $10 / 7 / 80$. If this value is excluded, the average value is $0.00 \mathrm{mg} / \mathrm{l}$ instead of $0.02 \mathrm{mg} / \mathrm{l}$. The pHt remained abcut the same.

$c$ The sand filters at the treatment plant are cleaned with sodium hypochlorite on a weekly or biweekly basis, generally on two consecutive days, 4-8 hours per day. However, chlorine residuals decayed within Copper Slough and failed to reach Kaskaskia Ditch.
} 


\section{TABLE 12}

Average dissolved oxygen, turbidity, phosphorous, nitrate-nitrogen, and pH concentrations in Kaskaskia Ditch at stations above and below its confluence with Copper Slough. Three modes of sewage treatment were practiced at the Champaign-Urbana Southwest Wastewater Treatment Facility, which discharges into Copper Slough: secondary treatment with chlorination (Phase 1), secondary treatment without chlorination (Phase 11), and tertiary treatment without chlorination (Phase III). . $^{\text {b }}$

\begin{tabular}{|c|c|c|c|}
\hline & \multicolumn{3}{|c|}{ Sample stations } \\
\hline & 1 & 2 & 3 \\
\hline Distance from confluence with Copper Slough $(\mathrm{km})^{c}$ & -0.25 & 1.10 & 2.70 \\
\hline \multicolumn{4}{|l|}{ Dissolved oxygen $(\mathrm{mg} / \mathrm{l})$} \\
\hline Phase I & $11.3(9.2)^{d}$ & $10.5(6.8)$ & $10.1(8.1)$ \\
\hline Phase II & $13.3(9.4)$ & $10.9(8.8)$ & $11.9(8.2)$ \\
\hline Phase III & $12.4(9.9)$ & $13.7(9.1)$ & $13.8(9.1)$ \\
\hline \multicolumn{4}{|l|}{ Turbidity (JTU) } \\
\hline Phase I & 9.7 & 10.4 & 12.1 \\
\hline Phase II & 10.3 & 11.5 & 11.7 \\
\hline Phase III & 7.0 & 7.1 & 7.1 \\
\hline \multicolumn{4}{|l|}{ Total phosphorous (mg/l) } \\
\hline Phase I & 0.07 & 1.18 & 1.19 \\
\hline Phase II & 0.06 & 1.68 & 1.50 \\
\hline .Phase III & 0.08 & 0.44 & 0.36 \\
\hline \multicolumn{4}{|l|}{ Nitrate-nitrogen $(\mathrm{mg} / \mathrm{l})$} \\
\hline Phase I & 2.5 & 2.5 & 2.5 \\
\hline Phase II & 1.8 & 1.9 & 1.9 \\
\hline Phase III & 6.9 & 6.6 & 6.7 \\
\hline \multicolumn{4}{|l|}{$\mathrm{pH}$} \\
\hline Phase I & 7.4 & 7.3 & 7.2 \\
\hline Phase II & 6.8 & 6.7 & 6.8 \\
\hline Phase III & 7.7 & 7.7 & 7.7 \\
\hline
\end{tabular}

a Phase I extended from $11 / 79$ to $9 / 80$, Phase II from $10 / 80$ to $6 / 81$, and Phase III from $3 / 82$ to $2 / 83$.

b Samples were taken monthly.

c Negative value represents distance to the station above the confluence, while positive values represent distances to stations below the confluence.

d Values in parentheses are lowest observed concentrations. 
chlorine during Phase II and Phase III. Thus, in Phase III, the residual chlorine released during filter cleaning decayed in Copper Slough before reaching Kaskaskia Ditch. 2) Ammonia concentrations in Kaskaskia Ditch were generally lower than in Copper Slough; however, high concentrations from unknown sources were occasionally observed at station 1 above the Kaskaskia Ditch-Copper Slough confluence (Appendix E, Table 11). 3) Nitrate-nitrogen concentrations at all stations in Kaskaskia Ditch consistently exceeded nitrate-nitrogen concentrations in Copper slough (Tables 2 and 12). Instream nitrification of sewage ammonia might partially account for this at stations below the confluence, but not at the station above the confluence. Once again, the input of nitrogen from nonpoint sources must be considered a possible explanation. 4) Slight oxygen sags were observed below the confluence, particularly during Phase II (Table 12).

\section{Kaskaskia Ditch Fish Community}

Because Kaskaskia Ditch received a weak effluent, its fish community never manifested the obvious degradation during Phase I that characterized the Copper Slough fish community (Appendix F). Species number in Kaskaskia Ditch below its confluence with Copper Slough was never lower than species number above, and number of individuals and sample weight showed only modest decreases below the confluence (Table 13). Nevertheless, obvious improvements followed the cessation of chlorination at the start of Phase II. Species number at stations 2 and 3 increased from 9.3 to 14.0. This was considerably more than the average of 8 species found above the confluence. In addition, the number of individuals per sample doubled, and sample weight showed a 10 percent gain (Table 13). As with Copper Slough, further improvements were not observed during the low ammonia conditions of 


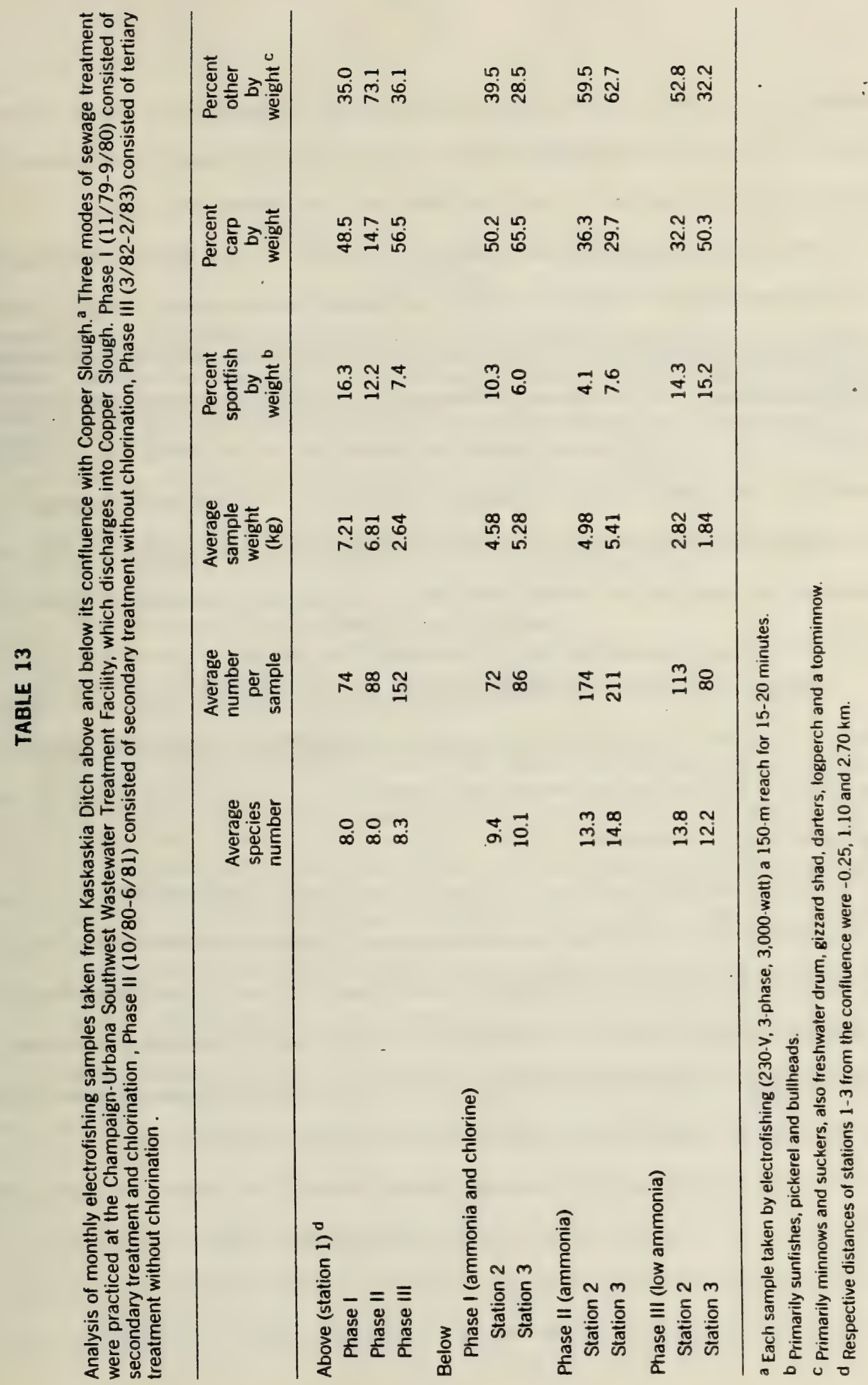


Phase III. In fact, numbers and sample weight dropped to or below Phase I levels. This drop was possibly due to low flow conditions in Kaskaskia Ditch during Phase III rather to any influence of the sewage effluent.

Taxonomic composition in Kaskaskia Ditch was quite labile, even above the confluence where conditions were presumably more stable. Thus, changes in taxonomic composition between phases at stations below the confluence are of problematical significance. However, it is noteworthy that: 1) The percentage of carp decreased after the cessation of chlorination, while the percentage of "other" fish increased (Table 13). 2) The percentage of sportfish increased after the onset of tertiary treatment, due more to a decrease in quantity of other fish than to an actual increase in quantity of sportfish.

Species number was analyzed with the Kruskal-Wallis Test. An a priori design was used, since previous research enabled us to formulate specific questions prior to the start of this study (15). The 0.05 probability level was used in all contrasts.

The statistical analysis (Table 14) indicated the following: 1) Species number below the confluence was significantly greater than species number above the confluence during Phase II and Phase III but not during Phase I. 2) Species number below the confluence during Phase II and Phase III was significantly greater than species number below the confluence during Phase I. 3) Species number below the confluence during Phase II was not significantly different from species number below the confluence during Phase III. Thus, the analysis demonstrates that species number below the confluence increased significantly after the cessation of chlorination, reaching levels significantly greater than found above the confluence; and 


\section{TABLE 14}

Statistical analysis (Kruskal-Wallis Test) (16) of species number taken by electrofishing at sample stations on Kaskaskia Ditch. Kaskaskia Ditch receives sewage effluent from Copper Slough, its tributary stream. Station 1 was above the Kaskaskia Ditch-Copper Slough confluence; stations 2 and 3 were below it. Secondary treatment with chlorination was practiced during Phase I (11/79-9/80), secondary treatment without chlorination during Phase II (10/80-6/81), and tertiary treatment without chlorination during Phase III (3/82-2/83).

\section{Sample size}

Eight to 10 samples were taken at one month intervals at each station during each phase. Total sample size equals 91 separated into nine groups by station and phase.

II. Omnibus test

$H_{0}$ : Species number is equal at all stations during all phases.

$H_{1}$ : Species number is not $\epsilon$ qual at all stations and/or is not equal between phases.

Decision rule: Reject the nu I if $\mathrm{H}(\mathrm{df}=8,0.95)$ is greater than or equal to 15.51 .

$H$ (with correction for ties) $=34.87$. The null is rejected.

III. A priori nonorthoganol comparisons

Decision rule: Reject any ciontrast if $H(d f=1,0.95)$ is greater than or equal to the problem-wise critical value of 6.97 .

1) $H_{0}$ : Species number at station 1 during Phase $I$ is equal to species number at stations 2 and 3 during Phase $\mathrm{I}$. $\mathrm{H}=0.60$.

2) $H_{0}$ : Species number of station 1 during Phase $I 1$ is equal to species number at stations 2 and 3 during Phase II. $\mathrm{H}=14.17$.

3) $\mathrm{H}_{0}$ : Species number at station 1 during Phase III is equal to species number at stations 2 and 3 during Phase III. $\mathrm{H}=10.93$.

4) Species number at stations 2 and 3 during Phase $I$ is equal to species number at stations 2 and 3 during Phase $1 \mathrm{H} . \mathrm{H}=11.18$.

5) Species number at stations 2 and 3 during Phase $I$ is equal to species number at stations 2 and 3 during Phase III. $\mathrm{H}=7.47$.

6) Species number at stations 2 and 3 during Phase II is equal to species number at stations 2 and 3 during Phase III. $\mathrm{H}=0.7$ ' . 
that species number did not improve with the onset of tertiary treatment. Kaskaskia Ditch Macroinvertebrate Samples

The major trends of the Copper Slough macroinvertebrate community of degradation during Phase I and inflated numbers and weight (expressed as $\mathrm{g} / \mathrm{m}^{2}$ of sampler substrate) during Phase II were not evident in the Kaskaskia Ditch macroinvertebrate samples. Number of taxa in Kaskaskia Ditch below the confluence were comparable during Phases I and II (Figure 6, Table 15). Number of specimens and weight were somewhat higher during Phase II, (Figure 7. Table 15), but did not show the increases observed in Copper Slough. Together these parameters indicate that the Kaskaskia Ditch macroinvertebrate community, as reflected in artificial substrate samples, was not seriously affected by the low levels of residual chlorine and ammonia entering from Copper Slough during Phase I.

Perhaps the most notable change between phases was the increase in taxon number associated with Phase III. This increase cannot be attributed to changes in effluent quality since it occurred both above and below the outfall (Figure 6, Table 15). Possible explanations are mild winter weather during Phase III or chronological differences between phases.

Another trend is the decrease in macroinvertebrate weight from station 2 to station 3 (Figure 7). Taxonomic composition fluctuated widely and showed few interpretable changes between phases (Table 15, Appendix G).

Taxon number was analyzed with the Kruskal-Wallis test. A post-hoc design employing the Scheffe method was employed, since research questions were not specified a priori. The 0.05 probability level was used in all contrasts. We were not able to identify any significant differences. These results suggest that the number of macroinvertebrate taxa was basically unrelated to qualitative changes in the relatively weak effluent entering 


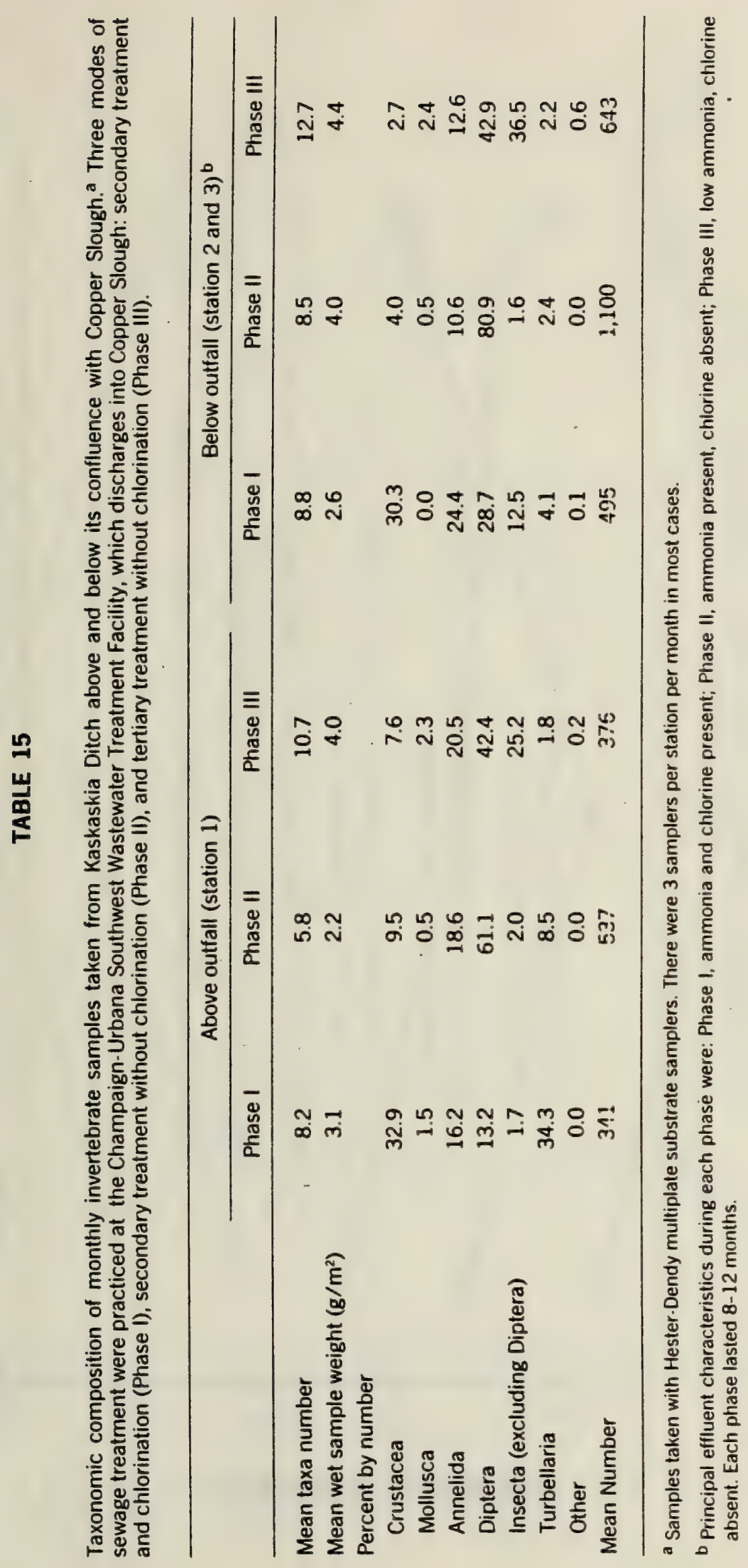




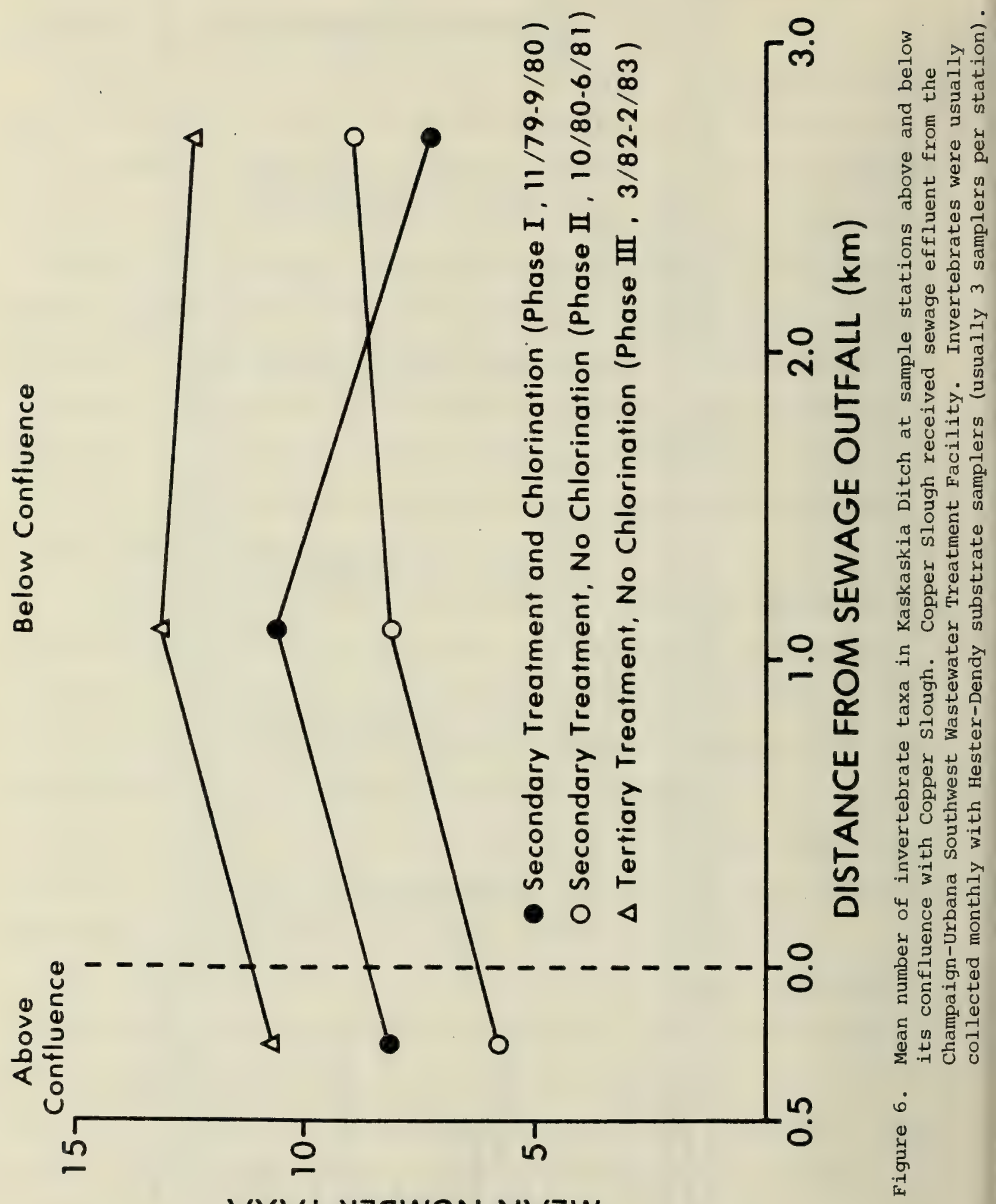

$\forall X \forall 1$ \& $\exists g W \cap N N \forall \exists W$ 


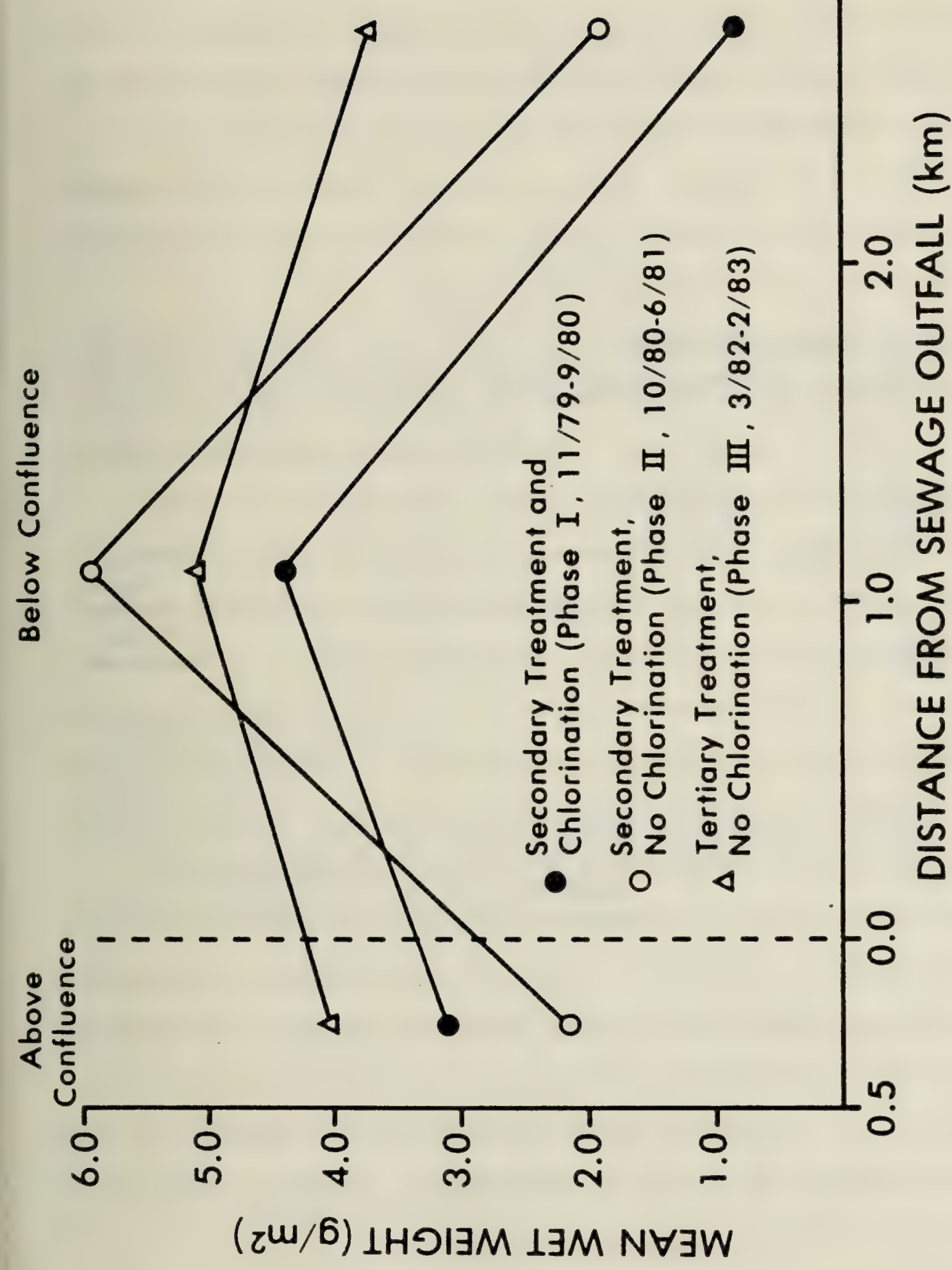

तु

व (1) 2. Q 07 일

E (4) ० 0 प्रे ट्रे + E बै

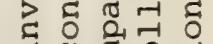
-

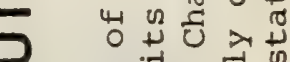
0 -

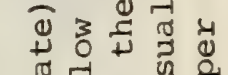
U प्र (1) की $<$ वे क्षे > $\quad 0$ व या $\Omega$ 跑出 5 का थै ते

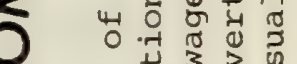
人 N 1 के का थ U क व $\cup$ व 2 वृ. $\varangle$ का क्ष -

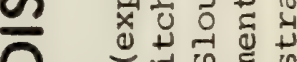
प प का . ๑ 药

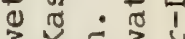
कृष ซี है ठิ ए ำ 
Kaskaskia Ditch.

Kaskaskia Ditch Phytoplankton

Chlorophyll-a and pheophytin-a concentrations (Appendix H) were similar above and below the outfall during all phases (Table 16) indicating that none of the sewage treatment procedures promoted phytoplankton blooms within the study area. Other notable features of the chlorophyll-a and pheophytin-a data are the lack of change in these parameters in response to the cessation of chlorination and the marked reduction both above and below the confluence in chlorophyll-a values associated with Phase III.

Saline Branch Chemical Parameters

The situation in Saline Branch was more complicated than in the other streams. As previously mentioned, the Northeast Plant underwent extensive renovation during the first part of Phase II. The renovation process interfered with normal plant performance and an unusually poor effluent resulted. However, renovation was completed and effluent quality restored to typical secondary treatment levels by the middle of Phase II. Thus Phase II has been split into two divisions: division 1, characterized by poor effluent quality due to renovation; and division 2, characterized by better effluent quality following the completion of renovation. Measured chemical parameters by station and sampling date are listed in Appendix I. Moderately high total and unionized ammonia levels occurred below the outfall during Phase I (Table 17). Unionized ammonia levels, in particular, were considerably higher than in either of the other streams. On September 12, 1980, high unionized ammonia levels also occurred at stations 1 and 2 above the outfall, skewing the average for these stations upwards. If this one date is deleted, the average unionized ammonia-nitrogen concentrations at stations 1 and 2 is 0.00 . 


\section{TABLE 16}

Average chlorophyll-a and pheophytin-a concentrations in Kaskaskia Ditch above and below its confluence with Copper Slough. Three modes of sewage treatment were practiced at the Champaign-Urbana Southwest Wastewater Treatment Facility, which discharges into Copper Slough: secondary treatment and chlorination (Phase I), secondary treatment without chlorination (Phase II), and tertiary treatment without chlorination (Phase III). ${ }^{a . b}$

\begin{tabular}{lcc}
\hline & $\begin{array}{c}\text { Mean } \\
\text { chlorophyll-a } \\
\left(\mathrm{mg} / \mathrm{m}^{3}\right)\end{array}$ & $\begin{array}{c}\text { Mean } \\
\text { pheophytin-a } \\
\left(\mathrm{mg} / \mathrm{m}^{3}\right)\end{array}$ \\
\hline Above & 2.59 & 0.73 \\
Phase I & 2.21 & 1.22 \\
Phase II & 0.17 & 1.27 \\
Phase III & & \\
Below & & 1.90 \\
Phase I (amimonia and chlorine) ${ }^{c}$ & 2.22 & 1.22 \\
Phase II (arnmonia) & 2.40 & 1.45 \\
Phase III (Icw ammonia) & 0.22 & \\
\hline
\end{tabular}

a Phase I lastec' from $11 / 79$ to $9 / 80$, Phase II from $10 / 80$ to $6 / 81$, and Phase III from $3 / 82$ to $2 / 83$.

b Samples were taken monthly and analyzed spectrophotometrically.

c Principal effllent characteristics during each phase are in parentheses. 


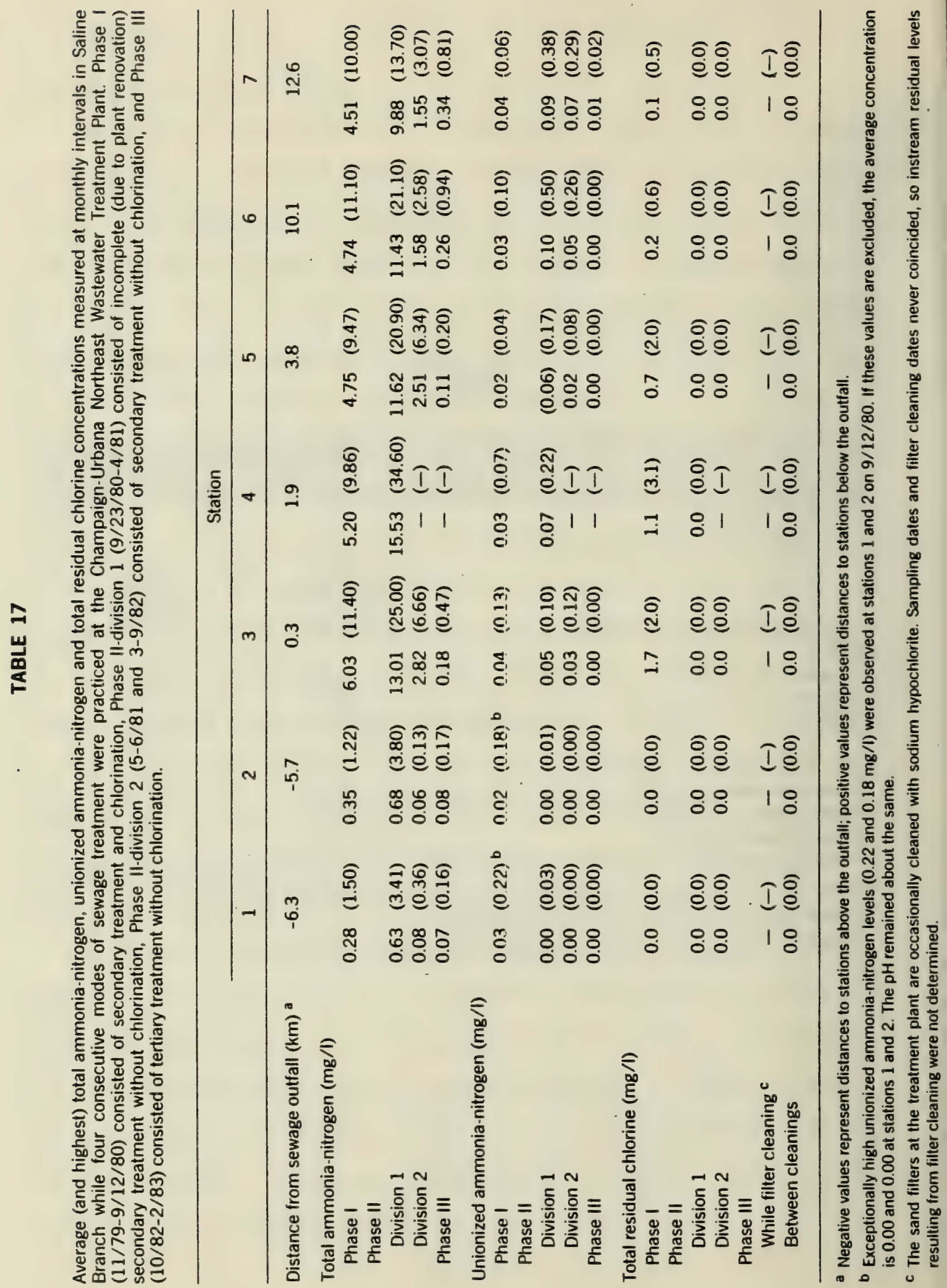


Phase I is further characterized by high residual chlorine concentrations at stations below the outfall, especially stations 3 and 4 (Table 18). Concentrations progressively decreased with distance from the outfall. The kinetics of residual chlorine decay in Saline Branch are described in an earlier report (15).

Phase II-division 1 began with the cessation of effluent chlorination on September 13, 1980. As a result, residual chlorine was absent from Saline Branch during Phase II-division 1; however, other aspects of effluent quality worsened. These problems, discussed in more depth below, actually began during the last month of Phase I with the onset of extensive construction activities at the Northeast Plant.

Total and unionized ammonia levels fluctuated widely, but averaged two to three times higher during Phase II-division 1 than during Phase I (Table 17). The highest total and unionized ammonia-nitrogen concentrations observed were 35.0 and $0.5 \mathrm{mg} / \mathrm{l}$ respectively. The latter value is in the toxic range for some warmwater fish as indicated by bioassay (22). The exceptionally high ammonia-nitrogen levels of Phase II-division 1 were matched by exceptionally low nitrate-nitrogen levels (Table 17). This indicates that nitrification was virtually nonexistent at the Northeast Plant during Phase II-division 1.

Dissolved oxygen problems were particularly severe during the last month of Phase I and first several months of Phase II-division 1. The oxygen sag below the outfall was very pronounced during this period and nearly anoxic conditions occurred on several occasions (Table 18). Dissolved oxygen conditions improved considerably during the latter part of Phase II-division 2. The period of oxygen depletion during Phase II-division 1 was associated with an increase in turbidity below the outfall (Table 18). The turbidity- 


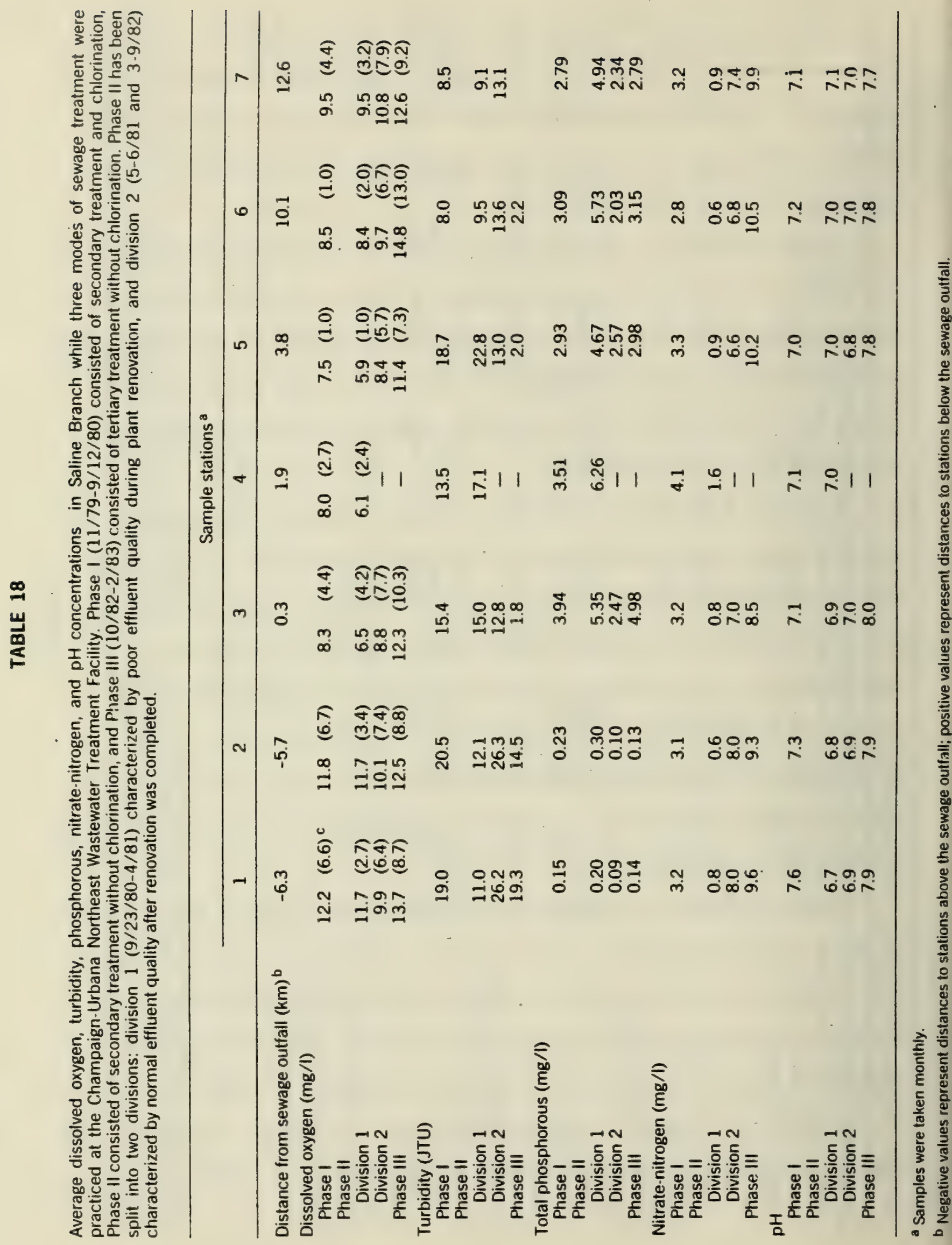


causing material was particulate sewage sludge which settled onto the stream bottom and resulted in the formation of an extensive fungus carpet and sludge bank, particularly at stations 3,4 and 5 . The sludge banks remained until Spring 1981 when they were washed out by high water flow.

The remaining Phase II-division 1 effluent quality problem of high silver levels was observed on only two dates: November 24, 1980 and December 19, 1980. Silver concentrations on these dates were respectively 0.12 and $0.14 \mathrm{mg} / 1$. These levels are considerably higher than the $0.07 \mathrm{mg} / 1$ shown to be lethal to largemouth bass in bioassay studies (4). Other Illinois EPA measured parameters either remained below or only slightly and temporarily exceeded EPA recommended safe levels (Table 19).

All the aforementioned problems were alleviated with the end of construction activities and the arrival of the 1981 spring spates. Division 2 of Phase II began in May 1981. Most of the Phase II-division 2 chemical parameters indicated moderate pollution typical of that associated with secondary treatment (Tables 17 and 18). However, it is important to note that unionized ammonia levels remained fairly high in total ammonia levels (Table 17). This was due to the high $\mathrm{pH}$ concentrations that prevailed during division 2. It is also noteworthy that the ammonia concentration change with distance was fairly similar between Phase I and Phase II-division 2 , suggesting that ammonia kinetics were not affected by chlorination.

The relatively high unionized ammonia levels associated with Phase II-division 2 diminished with the onset of tertiary nitrification at the start of Phase III. Total ammonia concentrations likewise diminished to ambient levels (Table 17). Other important water quality changes from Phase II to Phase III were an increase in dissolved oxygen, a very conspicuous decrease in turbidity and an increase in nitrate-nitrogen (Table 18). These 


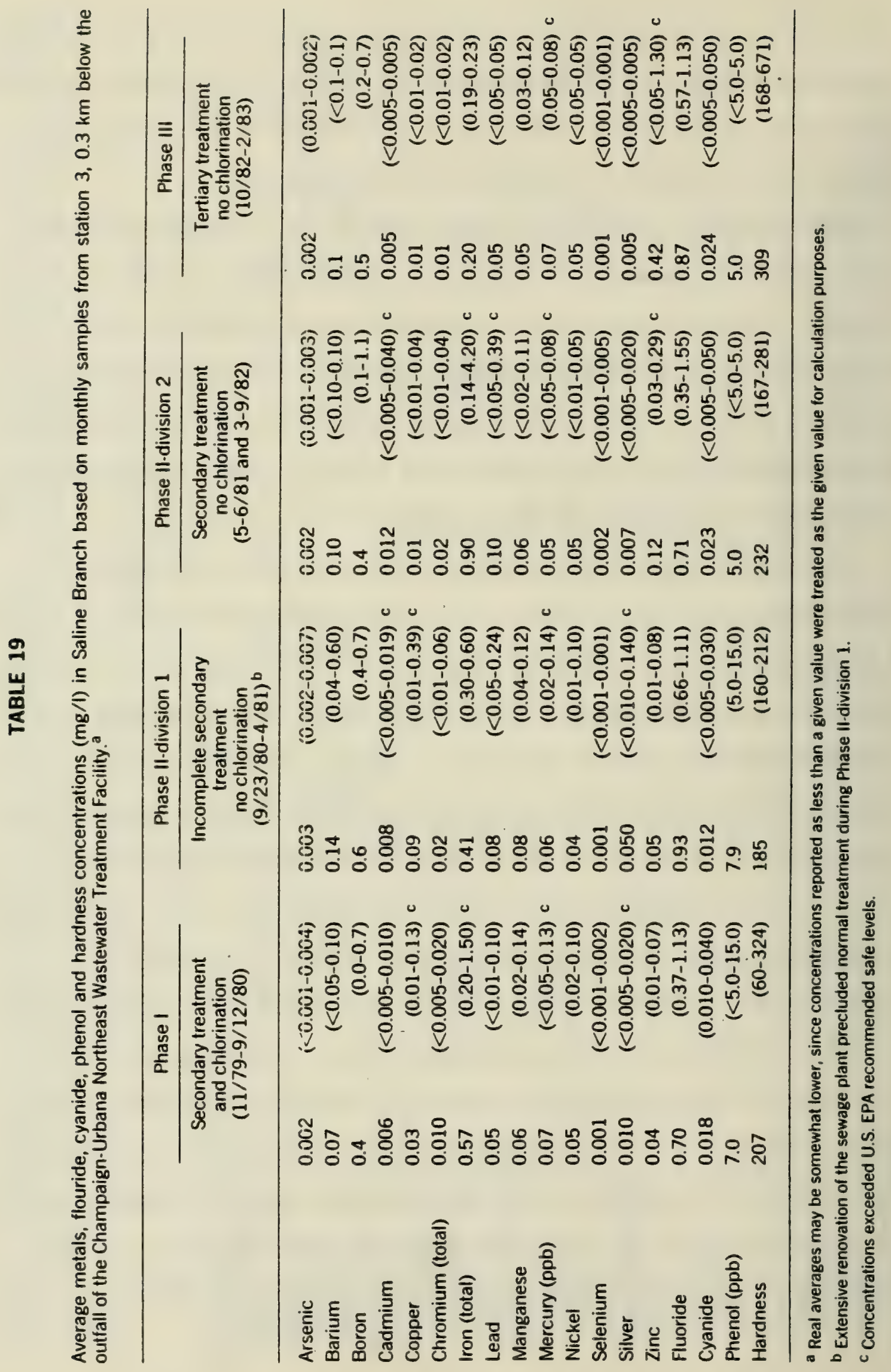


changes were undoubtedly related to tertiary treatment. The turbidity decrease was due to sand filtration, and the nitrate and dissolved oxygen increases were due to nitrification. It is significant, however, that phosphorous concentrations were as high during Phase III as during earlier phases (Table 18). Phosphorous removal was not part of the tertiary treatment at the Northeast Plant.

Tertiary treatment was responsible for the intermittent release of residual chlorine during sand filter cleaning periods. The sand filters actually began operating during the last two months of Phase II-division 2 and continued through Phase III. We were not able to determine residual chlorine levels in Saline Branch resulting from filter cleaning since filter cleaning dates and sampling dates never coincided.

Another aspect of the Saline Branch chemical and physical data that requires consideration is the volume of flow and flow rate. Volumes of flow and flow rates were much higher below the outfall than above (Table 4). Most of this increase was due to the contribution of the sewage effluent. Thus, sewage effluent constituted most of the flow below the sewage outfall, particularly during the summer and fall when natural stream flow was negligible.

Saline Branch Fish Samples

The fish community was severely degraded below the outfall during Phase I. Average species number dropped from 8.9 at stations above the outfall to 0.6 at station 3, immediately below the outfall. Average number per sample and sample weight showed commensurate reduction (Table 20). All parameters improved with distance from the outfall and, with the exception of number of individuals per sample, were approaching ambient levels by station 7 . This 

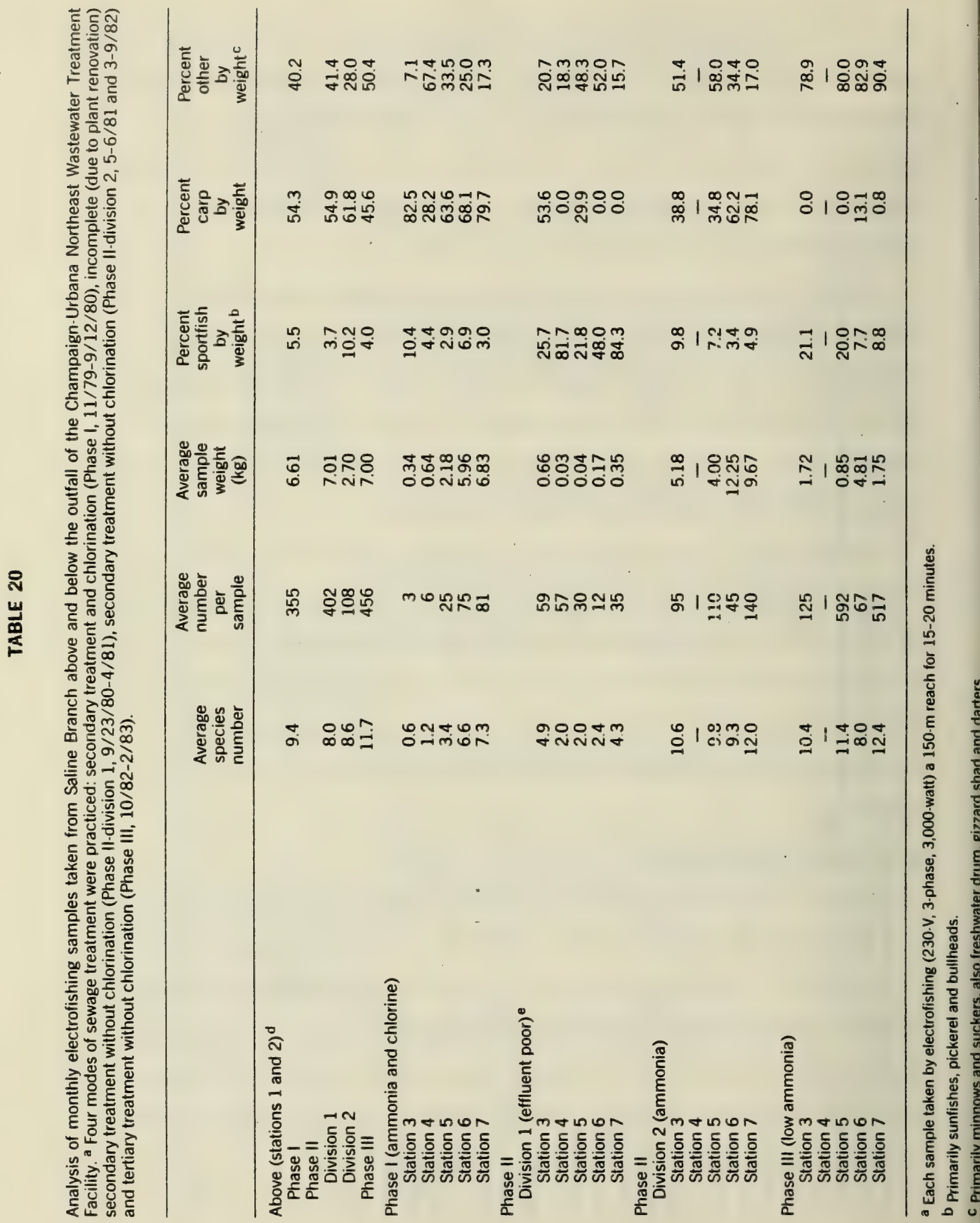
recovery trend was associated with a steady reduction in residual chlorine concentration with distance from the outfall (Table 17).

The Saline Branch fish community, unlike those in Copper Slough and Kaskaskia Ditch, failed to recover after effluent chlorination was halted. All parameters demonstrated slight improvement at station 3 , but continued to indicate severe degradation at the remaining stations (Table 20). Average sample weight, in particular, was low during Phase II-division 1. However, about half (by weight) of the small numbers of fish captured below the outfall during this period were sportfish, principally green sunfish (Lepomis cyanellus) (Appendix J).

The continued degradation of the Saline Branch fish community after the cessation of chlorination is attributed to poor effluent quality. Possible causative agents include the formation of sludge banks, low oxygen levels, high silver levels, and high unionized ammonia levels. Pearson productmoment correlations and multiple regression analysis were used in an effort to assess the contribution of each of these factors to reductions in species number. These analyses, presented in detail in Lewis et al. (15) pointed to turbidity and dissolved oxygen concentration as possible causes, while unionized ammonia concentrations and unionized ammonia-temperature interactions seemed unrelated to species number. Silver concentration was not included in the analysis. However, this should not be interpreted to mean that the high ammonia levels of Phase II-division 1 were innocuous. It is more probable that any relationship between ammonia concentration and species number was obscured by extreme short-term fluctuations in effluent ammonia concentration.

Phase II-division 2 began with the return of effluent quality parameters to typical secondary treatment levels and the removal of the sludge banks by 
the 1981 spring spates. These changes were followed by strong improvements in the Saline Branch fish community. Species number returned to ambient levels by the second month of Phase II-division 2 and stayed at high levels during the following sampling hiatus, as indicated by the follow-up sample on November 13-14, 1981, and the remaining months of Phase II-division 2 (Table 20, Figure 8). In fact, average species number at stations 3 to 7 during Phase II-division 2 ranged between 9.8 and 12.0 , which was somewhat higher than the average species number above the outfall during the same period. Number per sample and sample weight demonstrated commensurate improvements and, in the case of sample weight, greatly exceeded levels above the outfall. If should be noted that these improvements occurred in the presence of occasionally high unionized ammonia concentrations, particularly at stations 3 and 5 (Table 21).

The fish community showed mixed response to the virtual elimination of ammonia from Saline Branch during Phase III (Table 20). Species number remained the same, sample weight declined markedly, and number per sample increased markedly. It would be precipitate, however, to attribute these changes in number and weight to changes in effluent quality. Division 2 of Phase II took place during the spring and summer, while Phase III occurred during the fall and winter. The changes in number per sample and average size between periods are expected as young fish hatched during spring and summer are recruited into the catchable population during fall and winter. In this connection, it is important to note that increasing numbers actually began during the end (August and September 1982) of Phase II-division 2, when unionized ammonia levels were still quite high (Figure 9, Table 17).

Seasonal factors might also be responsible for the differences in species composition between Phase II-division 2 and Phase III. The basic 


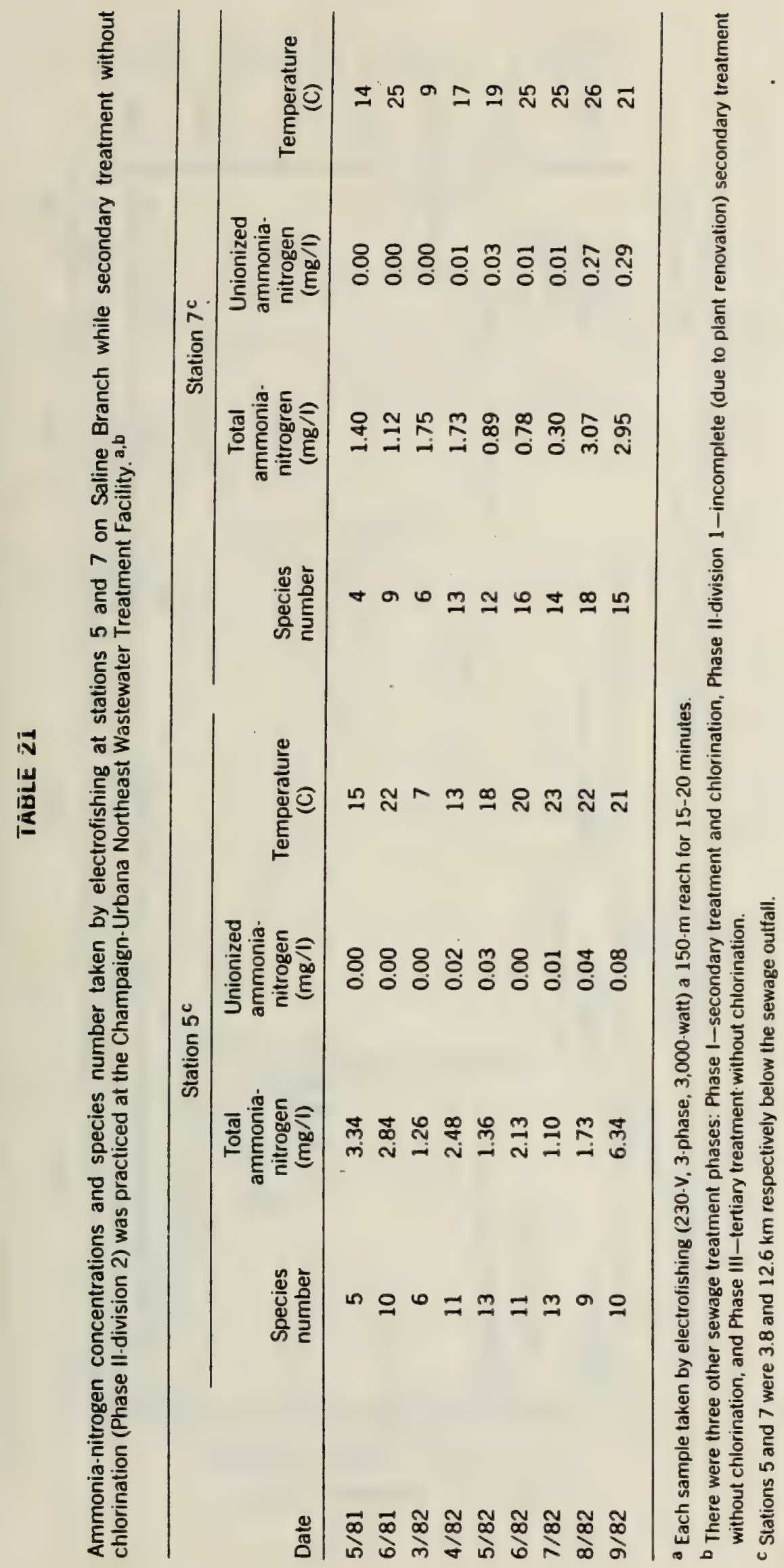




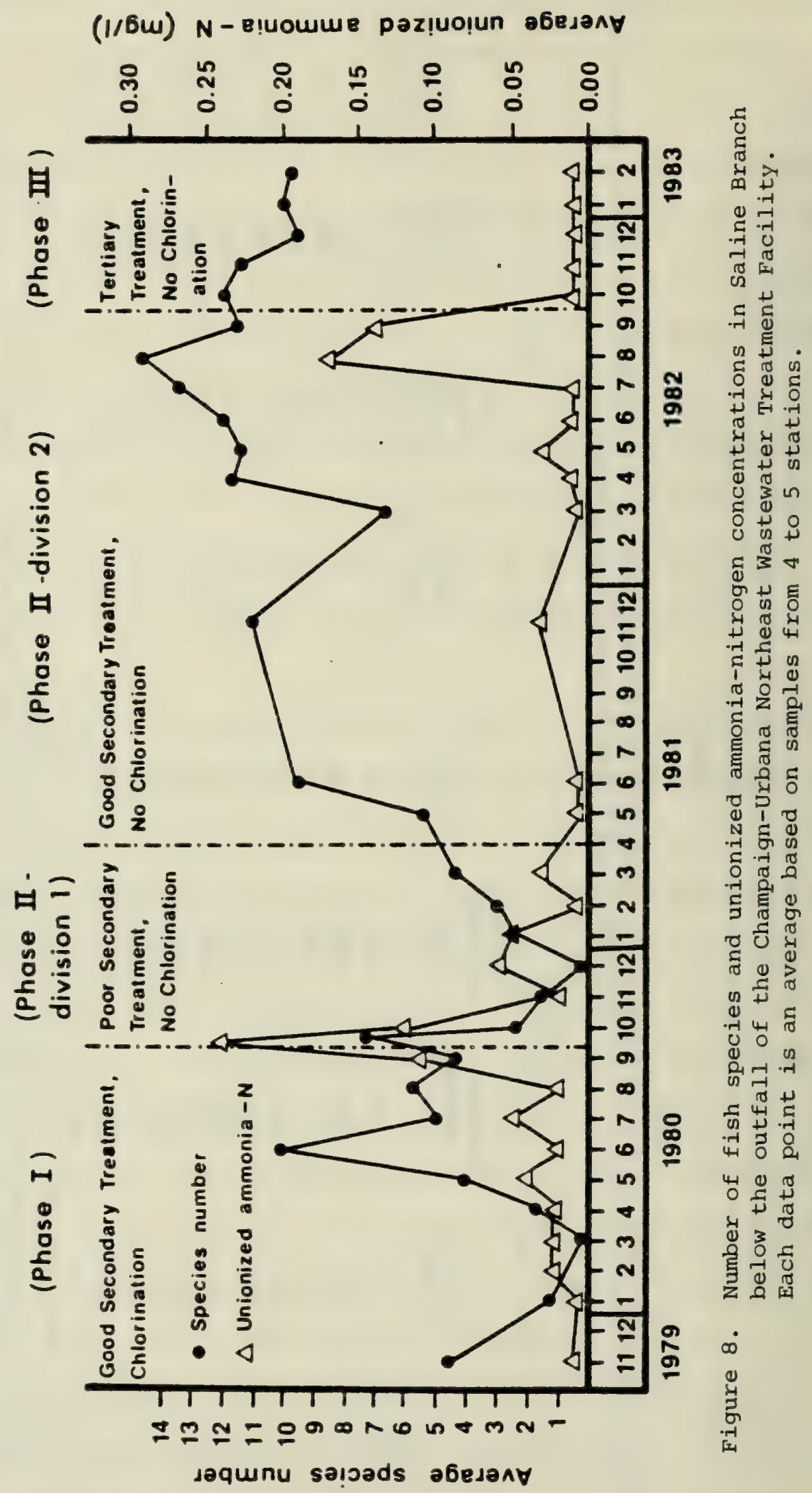




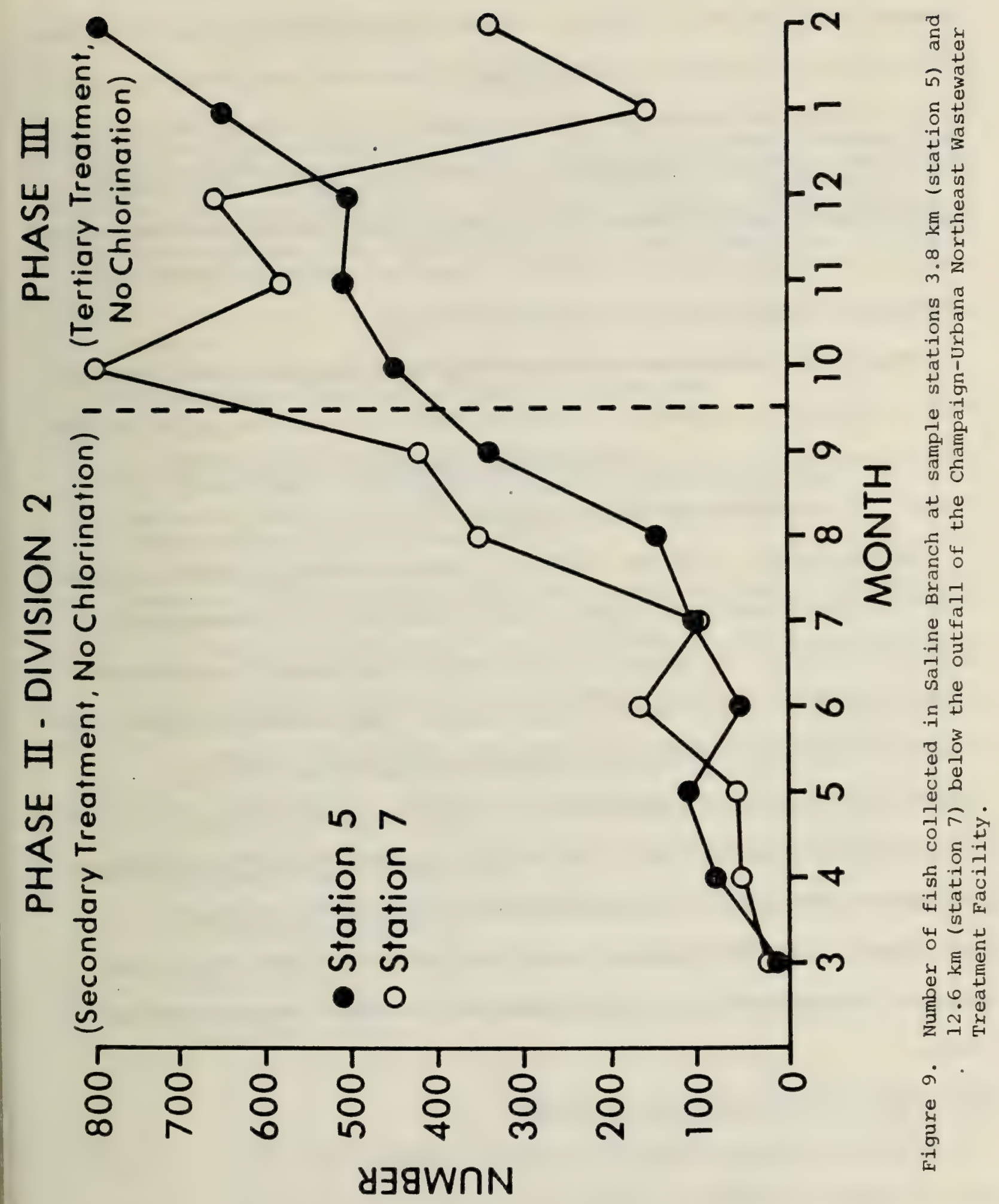


difference between these periods is that carp were largely absent below the outfall during Phase III, but comprised approximately 50 percent of the community during Phase II-division 2. While this difference might be related to water quality changes, it is important to note that carp showed strong seasonal changes in abundance. They appeared in large numbers during the spring and early summer (Appendix J). Phase II-division 2 included the spring and summer, while Phase III did not. Furthermore, water levels were unusually low during Phase III (Table 4) creating habitat changes particularly unfavorable to large fish like carp.

The Kruskal-Wallis test was used to analyze changes in species number between stations and phases. An a priori design was employed, since we were able to specify research questions before examining the data. The 0.05 probability level was used in all contrasts.

The statistical analyses (Table 22) indicated that: 1) Species number above the outfall was significantly higher than species number below the outfall during Phase I, but not during Phase II or Phase III. 2) Species number below the outfall was not significantly different between Phase I and Phase II-division 1. 3) Species number below the outfall was not significantly different between Phase II-division 2 and Phase III. 4) Species number below the outfall was significantly different between Phase I and Phase II-division 2. 5) Species number below the outfall was significantly different between Phases I and III. Thus, the statistical analysis largely corroborates the previously described trends in species number.

Saline Branch Macroinvertebrate Samples

The Saline Branch artificial substrate samples indicated a far better macroinvertebrate community during Phase II-division 2 and Phase III than 


\section{TABLE 22}

Statistical analysis (Kruskal-Wallis Test) (16) of species $n$ umber taken by electrofishing at sample stations on Saline Branch. Stations 1 and 2 were located above the outfall of the Champaign-Urbana Northeast Wastewater Treatment Facility; stations 3, 4, 5, 6 and 7 were below it. Secondary treatment with chlorination was practiced during Phase I (11/79-9/12/80), poor secondary treatment (due to plant renovation) without chlorination during Phase II-division $I(9 / 23 / 80-4 / 81)$, secondary treatment without chlorination during Phase II-division 2 (5-6/81 and 3-9./82), and tertiary treatment without chlorination during Phase III (10/82-2/83).

I. Sample size

Five to 10 samples were taken at one month intervals at each station during each phase. Total sample size equals 191 separated into 26 groups by station and phase.

II. Omnibus test

$\mathrm{H}_{0}$ : Species number is equal at all stations during all phases.

$\mathrm{H}_{1}$ : Species number is not equal at all stations and/or is not equal between phases.

Decision rule: Reject the null if $\mathrm{H}(\mathrm{df}=25,0.95)$ is greater than or equal to 36.42 .

$H$ (with tie correction $)=113.25$. The null is rejectecl.

III. A priori nonorthoganol comparisons

Decision rule: Reject any contrast if $H(d f=1,0.95)$ is greater than or equal to the problem-wise critical value of 7.51 .

1) $H_{0}$ : Species number at stations 1 and 2 during Phase $I$ is equal to species number at stations 3-7 during Phase $\mathrm{I}$. $\mathrm{H}=17.66$.

2) $H_{0}$ : Species number at stations 1 and 2 during Phase II-division 1 is equal to species number at stations 3-7 during Phase II-division 1. $H=6.58$.

3) $H_{0}$ : Species number at stations 1 and 2 during Phase 11 -division 2 is equal to species number at stations 3-7 during Phase II-division 2. $\mathrm{H}=2.14$.

4) $H_{0}$ : Species number at stations 1 and 2 during Phase III is equal to species number at stations $3-7$ during Phase III. $\mathrm{H}=0.55$.

5) $H_{0}$ : Species number at stations 3-7 during $P$ ase $I$ is equal to species number at stations 3-7 during Phase II-division 1. $\mathrm{H}=0.47$.

6) $H_{0}$ : Species number at stations 3-7 during $P$ nase $I$ is equal to species number at stations 3-7 during Phase Il-division 2. $\mathrm{H}=24.32$.

7) Species number at stations 3-7 during Phase $I$ is equal to species number at stations 3-7 during Phase III. $\mathrm{H}=19.35$.

8) Species number at stations 3-7 during Phase II-division 2 is equal to species number at stations 3-7 during Phase III. $\mathrm{H}=0.05$. 
during Phase I and Phase II-division 1 (Appendix K). The difference involves nearly all parameters and cannot be attributed to effluent modifications since it is equally evident both above and below the outfall (Table 23, Figure 10).

The macroinvertebrate samples from Phase I indicated degradation below the outfall. Average numbers of taxa at station 3, and to a lesser extent station 4 , were lower than at stations above the outfall (Figure 10). Average sample weight (expressed as $\mathrm{g} / \mathrm{m}^{2}$ of sampler substrate) was also low immediately below the outfall, then progressively increased to very high levels with distance from the outfall, primarily due to the presence of large numbers of dipterans and annelids (Table 23).

Due to the low water quality, the macroinvertebrate samples did not improve with the cessation of chlorination at the start of Phase II-division 1 (Table 23). Numbers and weight of the few taxa adapted to polluted condition remained high during Phase II-division 1, whereas other taxa were absent (Table 23, Figure 11).

The Phase II-division 2 macroinvertebrate samples demonstrated marked improvements over the Phase II-division 1 samples in terms of all measured parameters (Table 23). These improvements cannot be completely attributed to effluent quality changes, since they occurred both above and below the outfall (as described earlier). However, the many similarities between macroinvertebrate samples from above and below the outfall during Phase II-division 2 reflect positively on effluent quality during this period. The only major differences between samples from above and below the outfall during Phase II-division 2 were qualitative. Annelids and dipterans dominated below the outfall, while insects other than dipterans dominated above the outfall (Table 23). 


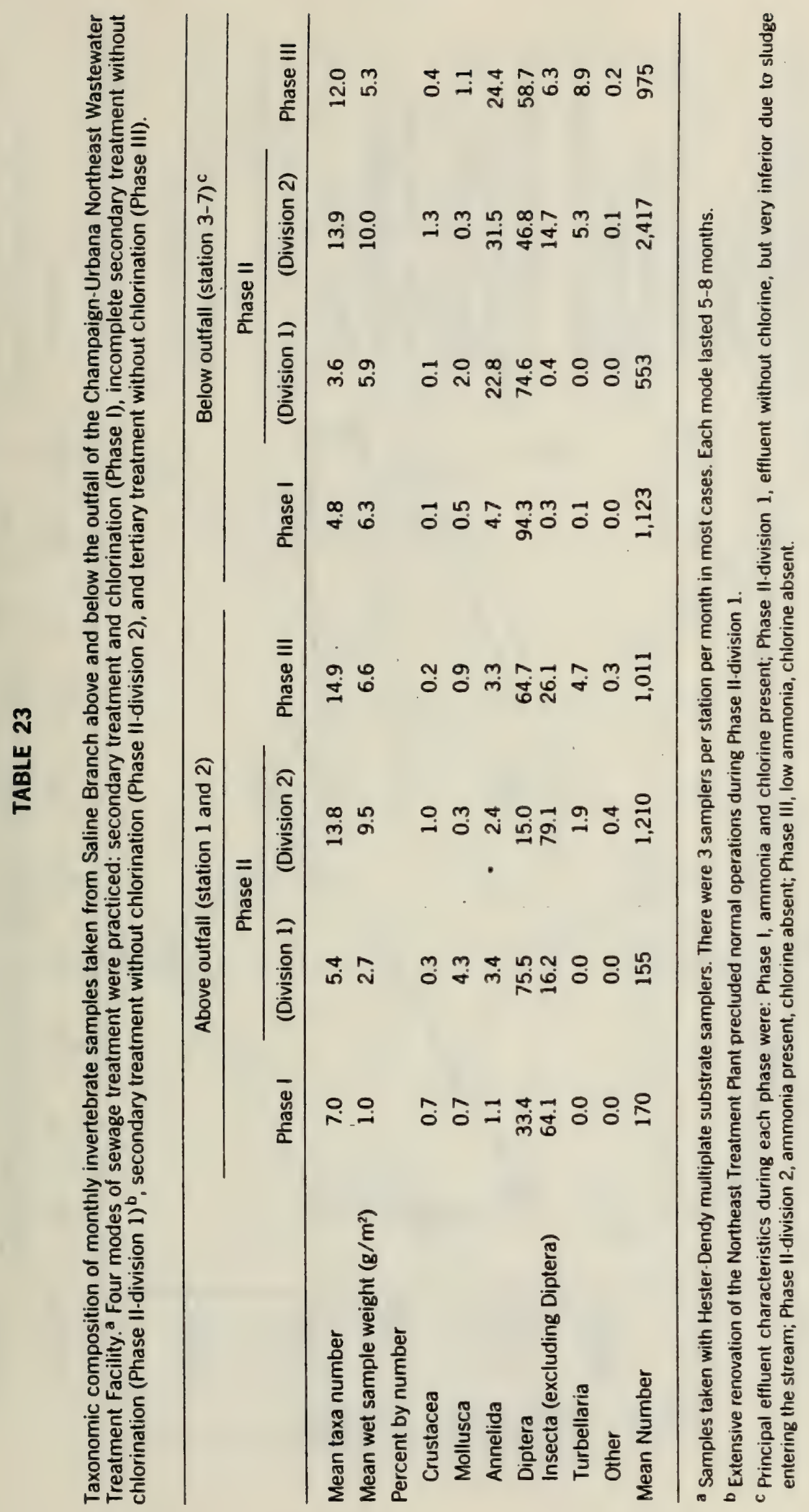




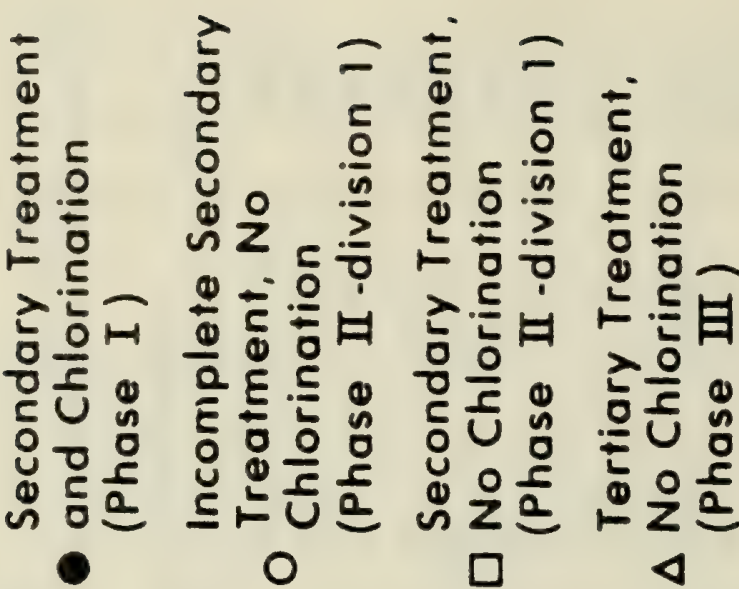

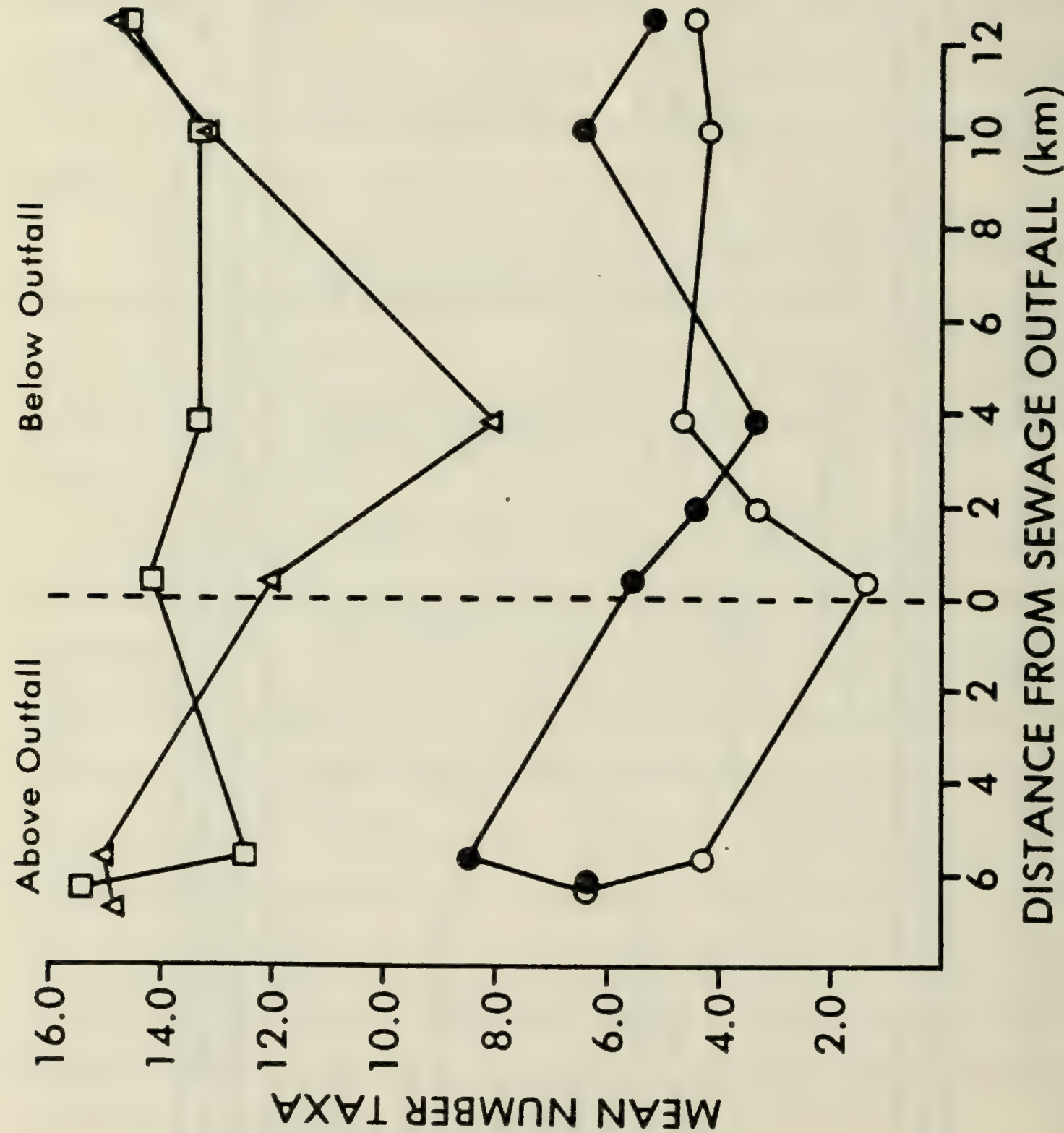

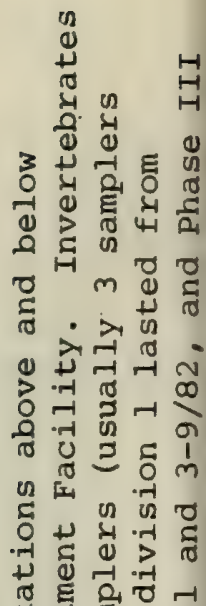

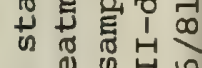

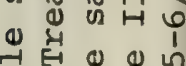
世 ช $+32$. 㶽

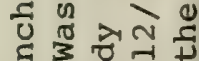
त प 1) 0100 工 牙昰 is 0 \% -

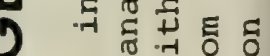
तु है 3 म्र न्न

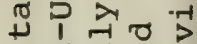
(1) है ए ग न * ${ }^{-1}$ ह थ 1 \% की है प्रेण

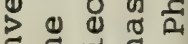
. प1 410 4 궁

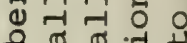
है उ 5

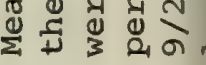

iे 乌్ 


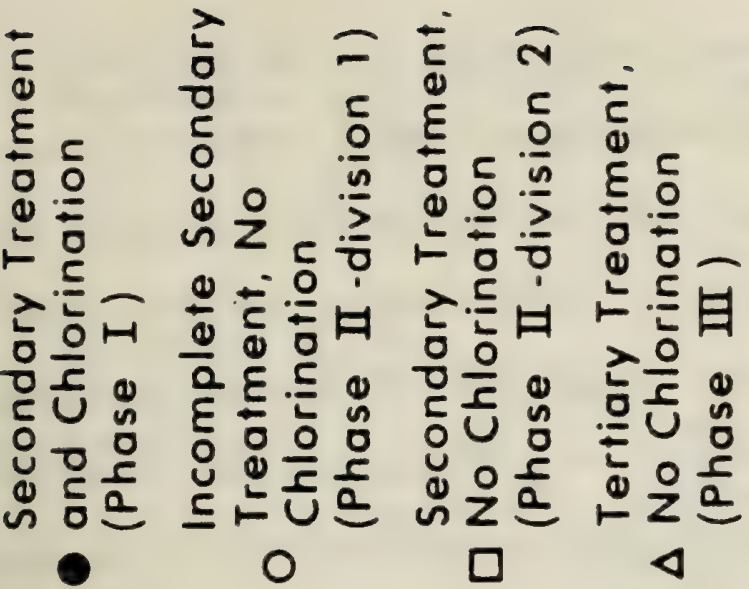

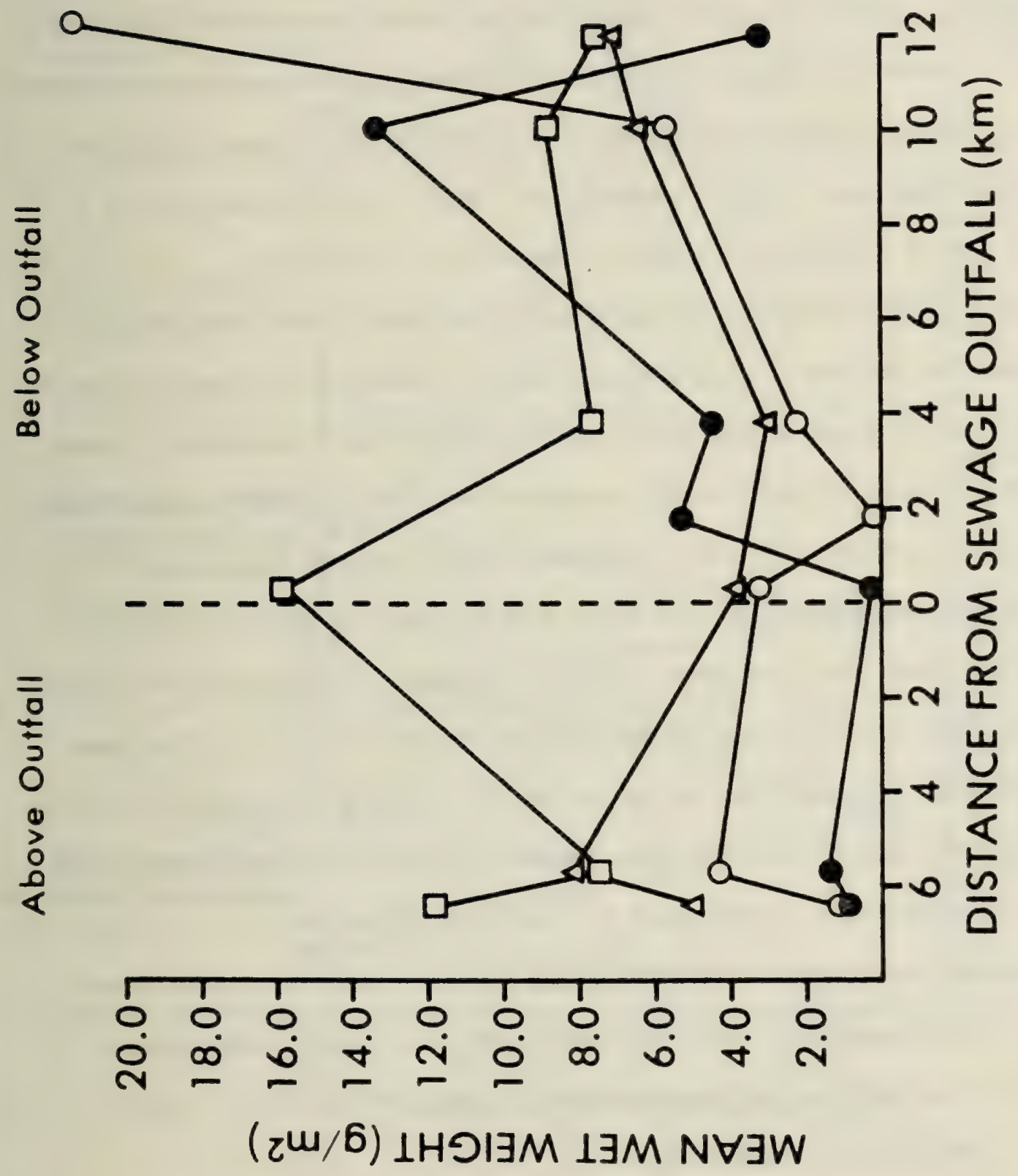

द 0 응

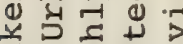

(1)

कू ता

(1) न

窟哭

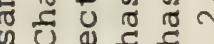

(1)

嵌号

造㟧

प्र

ब न 30

¿4

य ठ ङ य्र ले

०

(1) मु थै के था

उ 3 엄

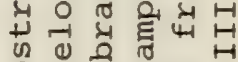

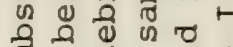

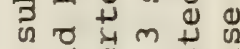

प वै $>$ त

乔 व

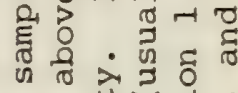

山 थ

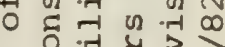

NE

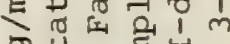

की

ข อ ฮี

(1) ह

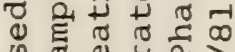

ज त 0 प्र

( )

แั้

क्ष की

य ำ

म है दू वे

क्षिए

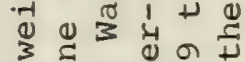

3]$.

t) $\rightarrow$ o 12

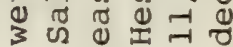

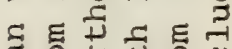

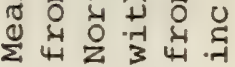

-1
-1
0
है
है
ज्ञ 
The onset of tertiary treatment during Phase III did not result in further improvements in the macroinvertebrate samples (Table 23, Figures 10 and 12). In fact, taxa number and sample weight actually declined somewhat at stations 3 and 5 possibly because of the release of residual chlorine during sand filter cleaning periods. Lastly, it is important to remember that Phase III lasted only five months. More time might have been needed before other changes associated with tertiary treatment became evident.

Statistical analysis of the Saline Branch macroinvertebrate data was restricted to number of taxa. Differences between stations and phases were evaluated with the Kruskal-Wallis test. A post-hoc design employing the Scheffe method was used, since research questions were not specified a priori. The 0.05 probability level was used in all contrasts.

The only significant and interpretable findings of the statistical analysis were as follows: 1) The mean number of taxa at all stations below the outfall during Phase I and Phase II-division 1 was significantly lower than the mean number of taxa at all stations below the outfall during Phase II-division 2 and Phase III. 2) The mean number of taxa at all stations above and below the outfall during Phase I and Phase II-division 2 was significantly lower than the mean number of taxa at all stations above and below the outfall during Phase II-division 2 and Phase III. 3) The mean number of taxa at all stations below the outfall during Phase II-division 1 was significantly lower than the mean number of taxa at all stations below the outfall during Phase II-division 2. Other differences, such as those between stations above and below the sewage outfall, were not significant. In summary, the statistical analysis emphasizes the largely unexplained increases in taxa number that occurred both above and below the outfall during the latter half of the study. 


\section{Saline Branch Phytoplankton}

This most prominent feature of the Saline Branch chlorophyll-a and pheophytin-a data is that these materials were present in much lower concentrations during Phase II-division 2 and Phase III than during the earlier phases (Table 24, Appendix L). This reduction cannot be attributed to effluent quality since it occurred both above and below the outfall, nor was it associated with any other water quality parameter measured in this study or chronological differences between phases. The only factor that coincided with reduced chlorophyll-a and pheophytin-a concentrations during Phase II-division 2 and Phase III is reduced flow rate and volume of flow (Table 4).

It is also noteworthy that chlorophyll-a and pheophytin-a concentrations were much lower below the outfall than above during Phase I and Phase II-division 1 (Table 24). Effluent quality was very poor during both periods. In contrast, chlorophyll-a and pheophytin-a concentrations were, with one exception, slightly higher below the outfall than above during Phase II-division 2 and Phase III, which were characterized by much better effluent quality than the earlier phases (Tables 17 and 18). These data suggest that the phytoplankton community was degraded below the outfall, when chlorination was practiced and during the subsequent period of very poor effluent quality during Phase II-division 2, but then recovered to ambient levels after effluent quality improved due to the resumption of normal secondary treatment at the Northeast Plant.

\section{Electrofishing and Rotenone Comparison}

On September 28, 1982, (Phase III) a rotenone sample was taken at station 2 on Saline Branch by the Illinois Department of Conservation and Illinois Environmental Protection Agency. We compared these data with data 


\section{TABLE 24}

Average chlorophyll-a and pheophytin-a concentrations in Saline Branch above and below the discharge of the Champaign-Urbana Northeast Wastewater Treatment Facility. Four modes of sewage treatment were practiced: secondary treatment and chlorination (Phase 1), incomplete secondary treatment without chlorination (Phase II-division 1), secondary treatment without chlorination (Phase II-division 2), and tertiary treatment without chlorination (Phase III). ${ }^{a}, \mathrm{~b}, \mathrm{c}$

\begin{tabular}{lcc}
\hline & $\begin{array}{c}\text { Mean } \\
\text { chlorophyll-a } \\
\left(\mathrm{mg} / \mathrm{m}^{3}\right)\end{array}$ & $\begin{array}{c}\text { Mean } \\
\text { pheophytin-a } \\
\left(\mathrm{mg} / \mathrm{m}^{3}\right)\end{array}$ \\
\hline $\begin{array}{l}\text { Above } \\
\quad \text { Phase I }\end{array}$ & 12.15 & 5.28 \\
$\quad$ Phase II & 13.38 & 3.91 \\
$\quad$ Division 1 & 0.25 & 1.31 \\
$\quad$ Division 2 & 0.30 & 0.60 \\
Phase III & & \\
Below & & 1.98 \\
$\quad$ Phase I (ammonia and chlorine) & & \\
Phase II (ammonia) & 3.31 & 2.21 \\
$\quad$ Division 1 (renovation period) & & 1.67 \\
$\quad$ Division 2 (after renovation) & 5.66 & 0.87 \\
Phase III (low ammonia) & 0.52 & \\
\hline
\end{tabular}

a Phase I lasted from 11/79 to $9 / 12 / 80$, Phase II-division 1 from $9 / 23 / 80$ to $4 / 81$, Phase II-division 2 from 5 to $6 / 81$ and from 3 to $9 / 82$, and Phase III from $10 / 82$ to $2 / 83$.

b Extensive renovation of the Northeast Treatment Plant precluded normal operations during Phase II-division 1.

c Samples taken monthly and analyzed spectrophotometrically.

d Principal effluent characteristics durirg each phase. 
from an electrofishing sample taken 11 days prior to the rotenone sample. The rotenone sample collected 17 species, while the electrofishing sample collected 13 (Table 25). All but one of the species captured by electrofishing were also captured by rotenone fishing. The five species not captured by electrofishing appeared in relatively small numbers in the rotenone sample (Table 25 ).

Bluntnose minnows (Pimephales notatus), gizzard shad, green sunfish, longear sunfish (Lepomis megalotis), and white suckers comprised the bulk of the rotenone sample by number. The same species, with the exception of gizzard shad, also predominated in the electrofishing sample (Table 25). Differences in species distribution (by number) between the samples were compared with Chi-square of 27.6 at 17 degrees of freedom. The data were first subjected to an arcsine transformation, since some of the cell frequencies were too low to insure approximate normality of distribution (16). The resulting Chi-square of 160.2 indicates significant differences in species distribution by numbers between samples.

The differences in species distribution by weight were somewhat greater than the differences in distribution by number (Table 25). The predominant species by weight in the rotenone sample were carp, gizzard shad, longear sunfish, quillback (Carpiodes cyprinus), and white sucker. The electrofishing sample differed in that carp were absent and green sunfish were quite abundant. The arcsine transformed data were compared with Chi-square at 17 degrees of freedom. The resulting value of 201.3 indicated significant differences in species distribution by weight between the two sampling methods.

The rotenone sample taken at station 2 was probably representative of the local fish communities, since rotenone sampling is the most accurate 


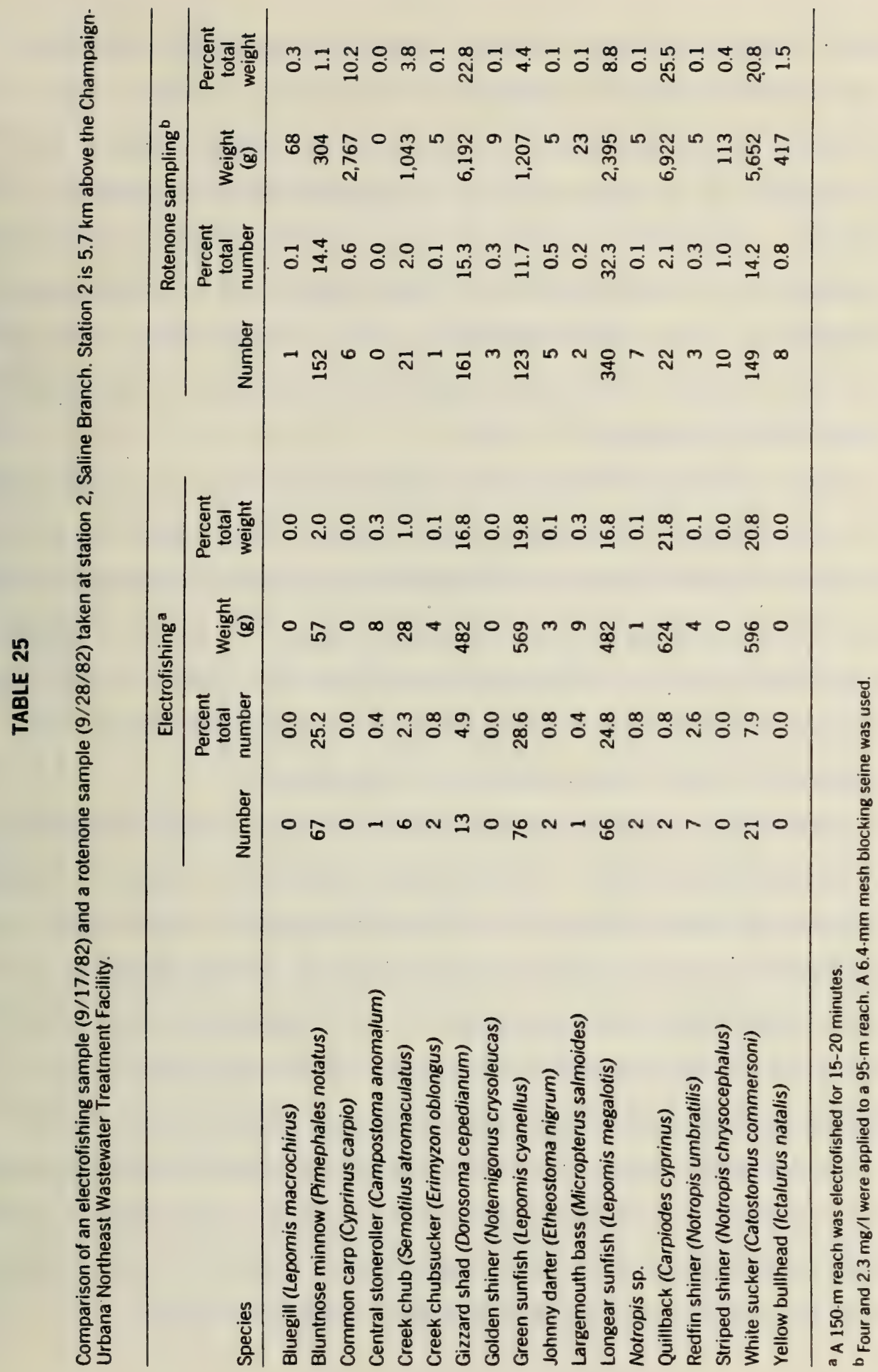


method of fish sampling in streams. Thus the discrepancies between the electrofishing and rotenone samples can probably be ascribed, at least partially, to the selectivity of electrofishing. However, despite some differences, the two samples were fairly similar from a comprehensive viewpoint. Most of the species captured by rotenone fishing were also captured by electrofishing, and the common species were well represented in both samples. It is also possible that some of the discrepancies between the rotenone sample and electrofishing sample were due to the 11-day lapse between the two samples.

When evaluating electrofishing effectiveness, it is also worth noting that electrofishing was somewhat more difficult on Saline Branch than on the shallower, narrower, and less obstructed Copper Slough and Kaskaskia Ditch. Based on field observations, electrofishing appeared to be fairly effective in all streams except on the few occasions when water levels and flow rates were exceptionally high. Variations in depth below extreme levels and variations in water clarity seemed to be unimportant.

Statistical support for the lack of relationship between water clarity and electrofishing success was generated by determining correlations between turbidity and species number. Data from all stations on Copper Slough and Kaskaskia Ditch during Phases II and III and from all stations on Saline Branch during Phase II-division 2 and Phase III (Appendix I) were used in this analysis. Data from other periods were omitted because of toxic effluent effects which confound the relationship between electrofishing success and water clarity. The resulting Pearson product-moment correlations were 0.13 (Kaskaskia Ditch, Phase III), 0.04 (Saline Branch, Phase III), 0.16 (Copper Slough, Phase III), 0.19 (Copper Slough, Phase II), 0.40 (Kaskaskia Ditch, Phase II), and -0.06 (Saline Branch, Phase II-division 2). If 
electrofishing success had indeed been reduced by low water clarity, a strong negative correlation would exist between species number and turbidity. Instead, as is apparent, most of the correlations are quite weak and, if anything, tend towards the positive.

Diel Changes in Water Quality

Photosynthesis by phytoplankton and bottom vegetation can result in large diel fluctuations in oxygen concentration and $\mathrm{pH}$, which in turn affect ammonia toxicity. The usual trend is for oxygen concentrations to reach their maximum in late afternoon due to photosynthetic oxygen production and their nadir in the early morning due to oxygen consumption by respiration. Hydrogen ion concentration behaves similarly due to photosynthetic carbon dioxide consumption during the daylight hours and respiratory carbon dioxide evolution at night. Thus the grab samples taken in this study provide a comprehensive view of water quality, but not a profile of diel changes.

Diel sample series were taken by the Illinois EPA at two locations on Saline Branch. One sample was taken at station 1 above the outfall and one at a point approximately halfway between stations 5 and 6 . Both samples were taken on September 8, 1981. The station 1 sample (Figure 13) indicated large diel fluctuations in oxygen concentration, from a low of approximately 3.5 $\mathrm{mg} / \mathrm{l}$ in the early morning to a high of about $22.0 \mathrm{mg} / \mathrm{l}$ in late afternoon. Hydrogen ion concentration behaved similarly, reaching a low of approximately 7.1 in the morning, then rising to 8.8 in the early evening. At $20 \mathrm{C}$, an increase in $\mathrm{pH}$ of this magnitude would increase the amount of total ammonia in the unionized form from 0.4 to 20 percent. The sample below station 5 showed the same trends, but to a lesser degree (Figure 14). Oxygen concentrations varied from a low of slightly less than $3.0 \mathrm{mg} / \mathrm{l}$ to a high of nearly 12.0 , and $\mathrm{pH}$ varied from approximately 6.7 to 7.3 . At $20 \mathrm{C}$, this 


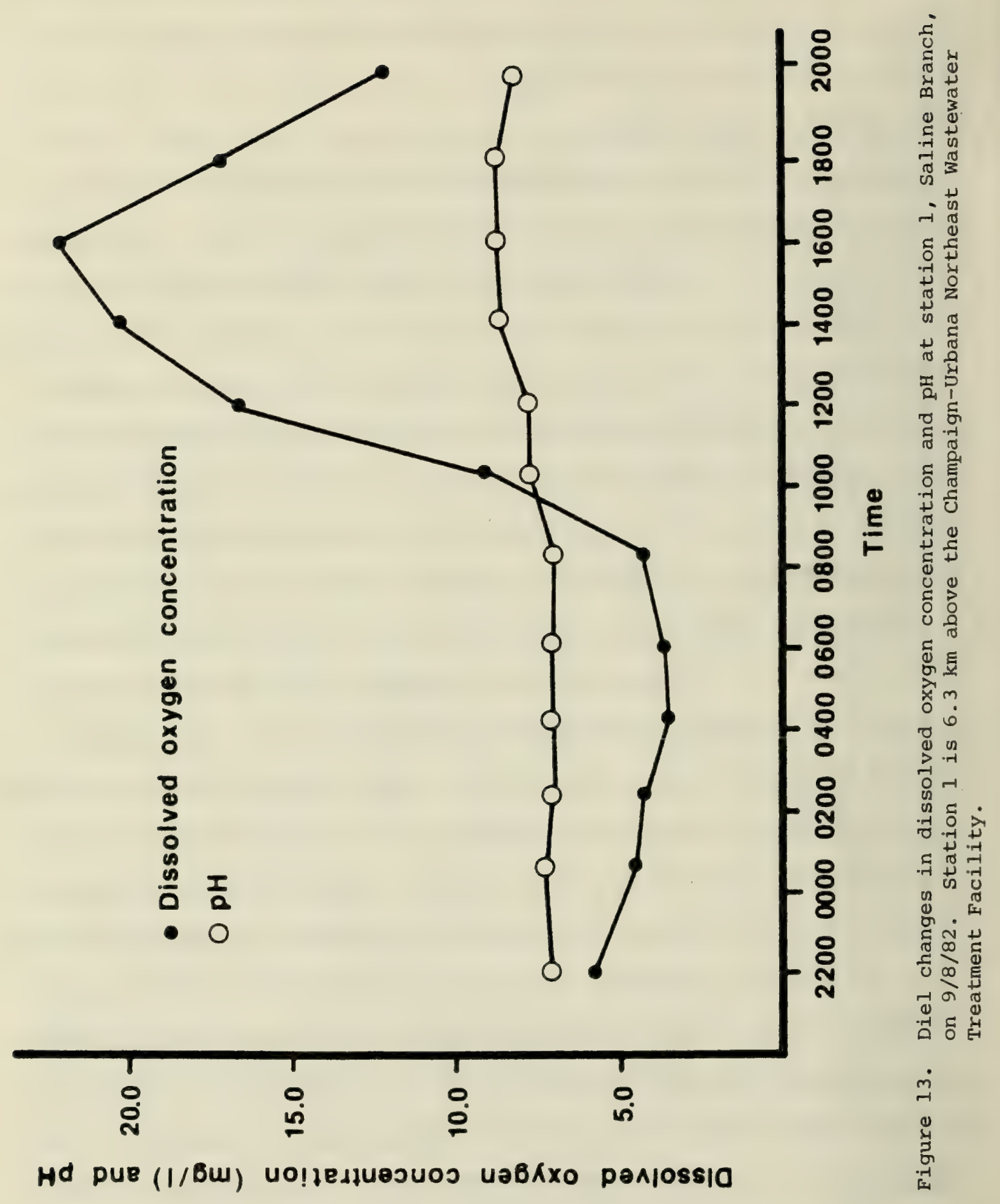




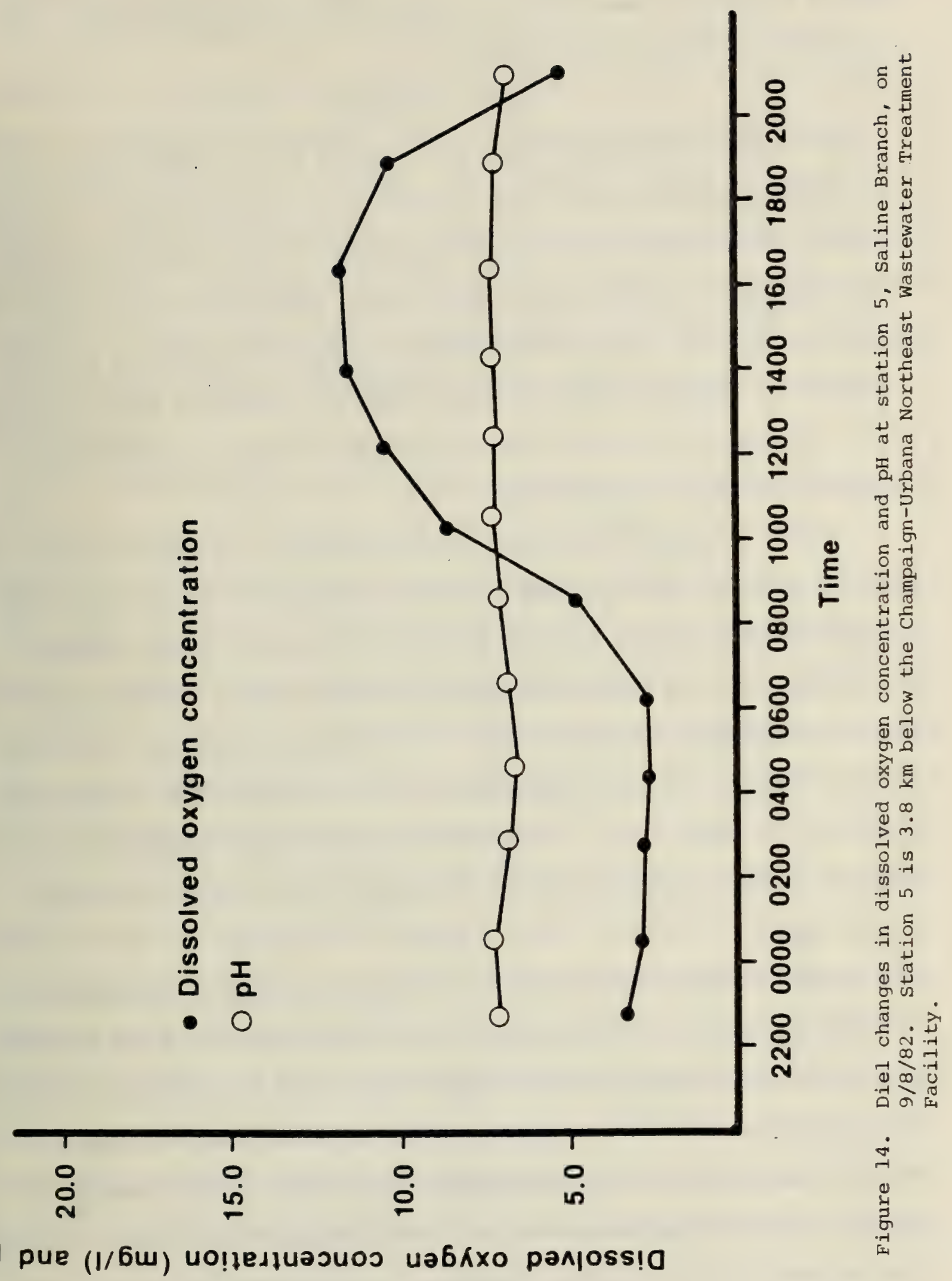


increase in $\mathrm{pH}$ would mean that 1.0 percent of the total ammonia was in the unionized form instead of 0.3 percent.

\section{DISCUSSION}

The methods of biological sampling employed in this study were chosen because their consistency was less affected by variations in field conditions than most other methods, and because they could be used repeatedly without causing cumulative damage to the sample sites. These methods were not expected to provide a complete and detailed analysis of community structure, but they were expected to portray major aspects of community structure with enough consistency to reliably detect biological changes associated with large-scale changes in water quality.

From the biological standpoint, the elimination of residual chlorine was the most important water quality improvement observed in Copper Slough and Kaskaskia Ditch. The cessation of effluent chlorination at the Southwest Plant transformed the Copper slough fish community from a highly degraded state to an essentially ambient state. The Kaskaskia Ditch fish community behaved similarly, if less impressively, since the effluent it received was rather weak to begin with. In neither stream was the fish community further enhanced by the virtual elimination of ammonia from the water by tertiary nitrification.

In Saline Branch there were two important water quality improvements. The first resulted from the cessation of chlorination at the Northeast Plant. This created the potential for biological recovery in Saline Branch; however; recovery did not begin until approximately nine months later because of extensive reconstruction of the Northeast Plant during the intervening period. The reconstruction activities precluded normal operations, resulting in an effluent more primary than secondary, and characterized by extremely 
high ammonia levels, low oxygen levels, and high levels of suspended sludge. Thus, the second important water quality improvement in Saline Branch resulted from the resumption of normal secondary treatment at the Northeast Plant, and from the occurrence of the 1981 spring spates, which flushed accumulated sludge from the stream. These events permitted the rapid recovery of the Saline Branch fish community despite the continued inflow of nonchlorinated secondary sewage. As with Copper Slough and Kaskaskia Iitch, there is no clear evidence that the Saline Branch fish community was further enhanced by the virtual elimination of ammonia from the water by tertiery nitrification.

It is important to note that the improvements in the fish communities of all tiree streams following the cessation of chlorination were very comprehensive. The distribution and occurrence of adult and juvenile fishes demonstrated no evident effluent related impacts in any stream during the period of normal secondary treatment without chlorination. Furthermore, at least some species began reproducing during this period, especially in Saline Brancri, where numerous young-of-the-year minnows appeared in areas larçely devoid of fish when chlorination was practiced.

The cessation of chlorination also had other beneficial effects. The Copper Slough macroinvertebrate community improved markedly after the cessation of chlorination. The number of macroinvertebrate taxa below the Southwest Plant increased to ambient levels, while the numbers of individual macroinvertebrates and macroinvertebrate biomass per area increased from well below to well above ambient levels. In essence, the change was to a community approaching a more normal state during the period of secondary treatment without chlorination, but still responding to the effects of 
organic pollution as evidenced by the numerical dominance of annelids, chironomids, and simulids.

The Saline Branch macroinvertebrate community demonstrated the same response to the cessation of chlorination as did the Copper Slough macroinvertebrate community if the period of abnormally poor effluent quality (Phase II-division 1) immediately following the cessation of chlorination is excluded from the Saline Branch data. The Kaskaskia Ditch macroinvertebrate community, in contrast, differed little between sewage treatment phases, because the effluent entering Kaskaskia Ditch was weakened considerably by prior passage through Copper Slough.

It is also noteworthy that the cessation of chlorination did not result in excessive eutrophication or the proliferation of algae. Such changes might have been anticipated, since chlorination is known to retard biological oxygen demand and prevent biological growth (31). However, planktonic algal biomass and quantity of attached vegetation were fairly similar before and after the cessation of chlorination. Increased eutrophication was suggested to a slight degree by the dissolved oxygen decreases observed in Copper Slough and Kaskaskia Ditch after the cessation of chlorination. The oxygen decreases observed in these streams were biologically insignificant, but streams of lesser flow with reduced re-aeration might suffer greater effects, particularly if the effluent is stronger.

The major findings of this study are: the recovery of the fish communities in each stream following the cessation of chlorination and the subsequent ability of each stream to support ambient quality fish communities despite the inflow of good quality secondary effluent; and the lack of further unambiguous improvement in the fish communities with the onset of tertiary nitrification. These findings, to the extent transferable to other 
streams, indicate that the cessation of effluent chlorination is the single most important way to improve the quality of typical secondary effluents, resulting in far greater environmental benefits than ammonia removal. The findings also infer that effluent chlorination has the potential to negate the environmental benefits expected from the upgrading of secondary treatment facilities and/or installation of tertiary treatment facilities. This was indicated in Copper Slough, where the occasional use of chlorine to clean the sand filters involved in tertiary treatment caused a slight but perceptible negative impact on the fish community.

When attempting to extrapolate the preceding findings statewide, it is important to remember that the streams we studied are basically average Illinois streams. Their watersheds are variously urban and rural; they have undergone physical modifications. Their ambient fish communities are not as diverse as those found in more remote, relatively pristine streams, but are far better than those found in many other Illinois streams. Thus the findings of this study should be applicable to many other streams, with the following exceptions. Some streams support poor quality fish communities because they are physically degraded or because they receive toxic point or nonpoint pollution. Such streams may benefit little from the cessation of chlorination, since they are unable to support desirable fish communities regardless of effluent quality. Secondly, high quality streams containing numerous pollution sensitive species may be damaged by secondary effluents even in the absence of chlorination. Lastly, effluents from overloaded plants, plants with operational problems, or plants releasing toxic industrial waste may have considerable impact whether or not chlorination is practiced. Evidence of the latter was observed in Saline Branch. 
Our analysis has emphasized changes in fish communities as the principal criterion for evaluating effluent quality changes, because fish are probably the most important resource in small Illinois streams. They provide recreational angling and figure largely in the public perception of stream quality. In fact, the distribution and occurrence of various species of fish constitutes the only meaningful criterion of stream quality to much of the public. On this basis, tertiary effluents have little advantage over good quality unchlorinated secondary effluents, since in most cases both are capable of supporting comparable fish communities. However, as discussed below, tertiary treatment does support certain benefits, some of which are subjective.

Tertiary treatment at the Southwest plant included ammonia removal by nitrification, turbidity and suspended solid removal by sand filtration, and phosphorous removal. Tertiary treatment at the Northeast Plant included only nitrification and sand filtration. Of these three aspects of tertiary treatment, sand filtration had the most obvious and aesthetically beneficial effect. Water clarity in each of the streams noticeably improved after the onset of sand filtration, resulting in a significant improvement in the physical appearance of the streams. Decreased odor was another aesthetic benefit of tertiary treatment. A characteristic sewage odor sometimes associated with the streams during the secondary treatment period was never detected when tertiary treatment was practiced.

It is also possible that the Copper Slough macroinvertebrate community benefited from tertiary treatment as indicated by a decrease in the relative abundance of pollution tolerant organisms after the onset of tertiary treatment. Although such changes might have been due to factors unrelated to tertiary treatment, it is possible that the reduction of phosphorous and 
organic matter observed in Copper slough during the tertiary treatment period might have altered the food base for invertebrates, thus causing a taxonomic shift. Similar taxonomic improvements were not observed in Saline Branch after the onset of tertiary treatment, possibly because the tertiary treatment phase in Saline Branch was too short (five months) for such changes to materialize.

There is no question that some ecological changes accompanied the transition from secondary to tertiary treatment. The magnitude and importance of these changes will depend on the sewage load of the secondary effluent and the ecological characteristics of the receiving stream. Perhaps the most salient question is whether certain types of change are important enough to warrant the expense of tertiary treatment.

This study was not designed to determine the actual toxic levels of different effluent components. Toxicity determinations are difficult in the field and require frequent or continuous monitoring in order to compensate for short-term fluctuations in effluent quality and diel changes in water quality due to photosynthesis and respiration. Although these factors impose limitations on the interpretation of toxicity data generated in this study, certain observations concerning sewage sludge, silver, and ammonia impacts are important enough to warrant further discussion.

This study has impugned residual chlorine as the most detrimental material in good quality unchlorinated secondary effluent. However, unusually poor quality secondary effluent, such as that released by the Northeast Treatment Plant during the renovation period, may contain other equally detrimental materials. Statistical analysis of the Saline Branch data from the renovation period indicated that effluent associated turbidity and low dissolved oxygen significantly reduced the number of species of fish 
taken below the outfall. At least one other study also indicates that sewage turbidity, unlike algal or silt turbidity, has deleterious impacts on fish communities (23).

The impact of sewage turbidity is probably due to the formation of sludge banks as the turbidity producing sludge particles settle out on the stream bottom. The resulting habitat alterations are undoubtedly inimical to the normal stream community. Additionally, it is possible that sewage turbidity itself is not the causative agent but some other unmeasured factor associated with sewage turbidity. Sewage sludge may, for example, contain toxic materials such as heavy metals.

Silver toxicity may have contributed to the pollution problems in Saline Branch during the period of sewage plant renovation. Silver concentrations of 0.12 and $0.14 \mathrm{mg} / \mathrm{l}$ were observed below the outfall on two occasions during the renovation period; number of fish species was severely depressed on both dates. It is tempting to hypothesize a causal relationship between reduced species number and silver concentration in Saline Branch, since silver levels of 0.12 and $0.14 \mathrm{mg} / 1$ are considerably higher than the $0.07 \mathrm{mg} / 1$ found to be lethally toxic to largemouth bass in bioassay studies. However, this conclusion is weakened by the fact that a silver concentration of $0.11 \mathrm{mg} / \mathrm{l}$ was observed in Copper Slough on November 25, 1980, without a corresponding decrease in number of fish species.

Statistical analysis of the Saline Branch data during the period of renovation at the Northeast Plant (Phase II-division 1) demonstrated a lack of correlation between species number and unionized ammonia-nitrogen concentration. In fact, unionized ammonia-nitrogen concentrations as high as $0.5 \mathrm{mg} / 1$ were found in association with a fairly high number of fish species. Such levels exceed those shown to be acutely toxic to the bluegill in 
bioassay studies (22). Thus it is probable that any relationship between ammonia concentrations and species number in Saline Branch during Phase II-division 1 was obscured by extreme short-term fluctuations in effluent ammonia concentration.

However, there were also other occasions during which ambient quality fish communities were found in association with unionized ammonia-nitrogen levels considerably in excess of the $0.02 \mathrm{mg} / \mathrm{l}$ maximum safe level recommended by the U.S. EPA. In Copper Slough, apparently ambient level fish communities were found in the presence of unionized ammonia-nitrogen concentrations averaging $0.02 \mathrm{mg} / \mathrm{l}$ and ranging as high as $0.11 \mathrm{mg} / 1$. Observations in Saline Branch during the last two months of the normal secondary treatment/no chlorination period (Phase II-division 2) revealed ambient quality communities of adult and juvenile fishes in the presence of 0.27 and 0.29 $\mathrm{mg} / \mathrm{l}$ of unionized ammonia-nitrogen. These data are weakened by the fact that the unionized ammonia concentrations are based on grab samples which do not integrate fluctuations in effluent total ammonia levels or diel fluctuations in pH. Furthermore, toxic effects might have been noted at lower temperatures, or in the egg, larval, or early juvenile stages of species that were seemingly unaffected as late juveniles and adults. However, these data still suggest the possibility that average Illinois fish communities are unaffected by relatively high unionized ammonia-nitrogen concentrations and point out the need for further investigations in this area.

\section{CONCLUSIONS}

1. During Phase $I$ of this study the toxicity of residual chlorine overshadowed the effects of ammonia.

2. The elimination of residual chlorine from good quality secondary sewage effluents derived primarily from domestic wastes will result in 
quantitative and qualitative improvement of the fish communities in most Illinois streams.

3. The elimination of residual chlorine from poor quality secondary sewage effluents or secondary sewage effluents containing toxic wastes will not necessarily result in recovery of the fish communities in streams receiving such effluents.

4. Invertebrate communities in streams receiving good quality secondary sewage effluent derived primarily from domestic waste respond favorably to the cessation of chlorination from a quantitative standpoint, but may contine to be dominated by taxonomic groups characteristic of organically polluted waters.

5. Any sewage effluent containing residual chlorine is potentially detrimental to aquatic life. Attempts to mitigate effluent impacts by upgrading sewage treatment facilities will at least partially fail if chlorination is continued.

6. The virtual removal of ammonia, turbidity and phosphorous from sewage effluents by tertiary treatment does not result in apparent improvements in the fish communities of streams already receiving good quality unchlorinated secondary effluent. This applies to average Illinois fish communities. High quality fish communities might benefit from tertiary treatment.

7. The virtual removal of ammonia, turbidity and phosphorous from sewage effluents by tertiary treatment may result in qualitative improvements in the macroinvertebrate communities of streams already receiving unchlorinated secondary effluent.

8. Turbidity removal by sand filtration improves the appearance of sewage receiving streams. 
9. Data from this study suggest the possibility that average Illinois stream fish communities are unaffected by unionized ammonia concentrations occasionally exceeding $0.2 \mathrm{mg} / 1$.

\section{REFERENCES}

1. APHA (American Public Health Association), American Water Works Association, and Water Pollution Control Federation. 1975. Standard methods for the examination of water and wastewater, fourteenth edition. American Public Health Association, Washington, DC.

2. Brinkhurst, R. O. and B. G. M. Jamieson. 1971. Aquatic oligochaeta of the world. University of Toronto Press. Canada.

3. Brown, H. P. 1972. Biota of freshwater ecosystems identification manual no. 6. Aquatic dryopoid beetles (Coleoptera) of the United States. U.S. Government Printing office, Washington, D.C.

4. Coleman, R. L., and J. E. Clearly. 1974. Silver toxicity and accumlation in largemouth bass and bluegill. Bull. Environ. Contamination and Toxicology $12(1): 53-61$.

5. Colt, J., and G. Tchobanoglous. 1976. Evaluation of the short-term toxicity of nitrogenous compounds to channel catfish, Ictalurus punctatus. Aquaculture 8:209-224.

6. Ellis, M. M. 1973. Detection and measurement of stream pollution. Bull. Bur. Fish. 48:365-437.

7. Emerson, K., R. C. Russo, R. E. Lund, and R. V. Thurston. 1975. Aqueous ammonia equilibrium calculations: effects of $\mathrm{pH}$ and temperature. $\mathrm{J}$. Fish. Res. Bd. Can. 32(12):2378-2383.

8. Ferris, V. R., J. M. Ferris, J. P. Tjepkema. 1973. Biota of freshwater ecosystems identification manual no. 10. Genera of freshwater nematodes 
(Nematoda) of eastern North America. U.S. Government Printing office, Washington, D.C.

9. Holsinger, J. R. 1972. Biota of freshwater ecosystems identification manual no. 5. The freshwater amphipod crustaceans (Gammaridae) of North America. U.S. Government Printing office, Washington, D.C.

10. Holman, W. F., and K. J. Macek. 1980. An aquatic safety assessment of linear alkylbenzene sulfonate (LAS): chromic effects on fathead minnows. Trans. Amer. Fish. Soc. $109(1): 122-131$.

11. Jones, J. R. E. 1964. Fish and river pollution. Butterworth and Co., Ltd. , London.

12. Kenk, R. 1972. Biota of freshwater ecosystems identification manual no. 1. Freshwater planarians (Turbellaria) of North America. U.S. Government Printing Office, Washington, D.C.

13. Klemm, D. J. 1972. Biota of freshwater ecosystems identification manual no. 8. Freshwater leeches (Annelida: Hirudinea) of North America. U.S. Government Printing office, Washington, D.C.

14. Lewis, W. M., R. C. Heidinger, M. H. Paller, and L. J. Wawronowicz. 1981. Effects of municipal sewage on fish communities in selected Illinois streams. Pages 224-240 in L. Krumholz, editor, The Warmwater Streams Symposium. Southern division, Amer. Fish. Soc.

15. Lewis, W. M., R. C. Heidinger, M. H. Paller, and L. J. Wawronowicz. 1981. Relative effects on stream biota of chlorine and ammonia occurring in secondary sewage. Il1: Dep. Energy Natur. Resour. Doc. 81/35.

16. Marascuilo, L. A., and M. McSweeney. 1977. Nonparametric and distribution-free methods for the social sciences. Brooks/Cole Publishing Company, Monterey, California. 
17. Muchmore, C. B., W. M. Lewis, R. C. Heidinger, M. H. Paller, and L. J. Wawronowicz. 1981. Economic impact of existing ammonia-nitrogen water quality standard, IPCB Chapter 3 Rule 203(f). Ill. Dep. Energy Natur. Resour. Doc. $81 / 23$.

18. Pennak, R. W. 1953. Freshwater invertebrates of the United States. The Ronald Press Co. N.Y.

19. 1978. Freshwater invertebrates of the United States. Second Edition. John Wiley and Sons. N.Y.

20. Reinbold, K. A., A. M. Pescitelli, and R. E. Sparks. 1982. Sublethal and cold temperature toxic effects of ammonia to early life stages of selected fish species. 20th Annu. Meeting Ill. Chap. Amer. Fish. Soc., Carbondale, IL (Abstract).

21. Robins, C. R. [Chaiman]. 1980. A list of common and scientific names of fishes from the United States and Canada. 4th edition. Amer. Fish. Soc. Sp. Publ. no. 12 .

22. Roseboom, D. P., and D. L. Richey. 1977. Acute toxicity of residual chlorine and ammonia to some native Illinois fishes. Rept. Invest. 85, Ill. State Water Surv., Urbana, IL.

23. Tsai, C. F. 1973. Water quality and fish life below sewage outfalls. Trans. Amer. Fish. Soc. $102(2): 281-292$.

24. Ward, R. W., R. O. Griffin, G. M. de Graeve, and R. A. Stone. 1976. Disinfection efficiency and residual toxicity of several wastewater disinfectants. U. S. Environmental Protection Agency, EPA 600/2-76-156, Washington, DC.

25. White, G. C. 1972. Handbook of chlorination. Van Nostrand Reinhold Co., New York, NY. 
26. Williams, W. D. 1972. Biota of freshwater ecosystems identification manual no. 7. Freshwater isopods (Asellidae) of North America. U.S. Government Printing Office, Washington, D.C.

27. Willingham, W. T. (Coordinator), J. E. Colt, J. A. Fava, B. H. Hillaby, C. L. Ho, M. Katz, R. C. Russo, D. L. Swanson, and R. V. Thurston. 1979. Ammonia. Pages 6-18 in A Review of the EPA Red Book: Quality criteria for water. R. V. Thurston, R. C. Russo, E. M. Fetterolf, Jr., T. A. Edsall, and Y. M. Barber, Jr. (editors). Water Quality Section, Amer. Fish. Soc. Bethesda, MD.

28. Woker, H. 1949. Die Temperaturabhangigheit der Giftierkumg von Ammonia auf Fische (The temperature dependence of the toxic effect of ammonia on fish.) Int. Assoc. Theoc. Appl. Limnol. 10:575-579 (in English translation).

29. U. S. Environmental Protection Agency. 1976. Quality criteria for water. U. S. Environmental Protection Agency, Washington, DC.

30. U. S. Environmental Protection Agency. 1974. Manual of methods for chemical analysis of water and wastes. Methods Development and Quality Assurance Research Laboratory, Natur. Resour. Cent., Cincinnati, OH. 31. Young, J. C., and C. O. MCCallion. 1979. Investigation of the long-term effects of chlorine in the oxygen demand of wastewater. Rep. PB-292 161 , Nat. Tech. Infor. Serv., Springfield, VA.

\section{A NOTE CONCERNING THE APPENDICES} TO THIS REPORT

The appendices referred to in this report are not included in this volume. They have been printed separately, and a limited number of copies are available upon request from the Department of Energy and Natural Resources, Clearinghouse, 325 W. Adams, Springfield, Illinois 62706 (217) 785-2800. 


\section{DOCUMENTATION PAGE \\ trubitio \\ tive Effects of Chlorine and Ammonia From Wastewater Treatment cilities on Stream Biota}

i) Roy C. Heidinger, William M. Lewis, Michael H. Paller, V H. Wadde 11, Larry J. Wawronowicz

inne Organiration Nome and addroces

eries Research Laboratory

ern Illinois University

ondale, IL 62901
(2.

2 Anciplente necoselen Ma.

2. Ropor Dote

2. Portoming Orzanization Ropt. Ma.

14. ProloctrTwak/Work Unit Me. $83 / 2002$

11. ContrectiC or Gremt(G) No.

(ब)

(a)

12. Typo of Roport 2 Porled Conned

10is Department of Energy and Natural Resources

J. Adams

igfield, IL 62706

14.

\section{a (Umil: 200 mords)}

biological, chemical and physical variables were monitored in three streams receiving :ipal wastewater from the Champaign-Urbana (IIlinois) treatment facilities from November to February 1983. In Phase I, the streams received chlorinated secondary effluents; in II, non-chlorinated secondary effluents; and in Phase III, non-chlorinated tertiary ed effluents.

The most important conclusions of this study are: 1) The elimination of residual -ine from good quality secondary sewage effluents will result in quantitative and quali'e restoration of the fish communities in average Illinois streams receiving such efflu2) The reduction of ammonia concentrations from typical secondary treatment levels to mely low levels by tertiary treatment will not necessarily effect obvious improvements e fish communities of average Illinois streams. 3) The cessation of chlorination will $t$ in marked quantitative improvements in the macroinvertebrate communities of streams ving good quality secondary effluent, but tertiary treatment may be needed for both itative and qualitative recovery. 4) The elimination of residual chlorine from poor ty secondary sewage effluents or secondary sewage effluents derived largely from toxic trial wastes will not necessarily effect biological improvements in streams receiving effluents. 




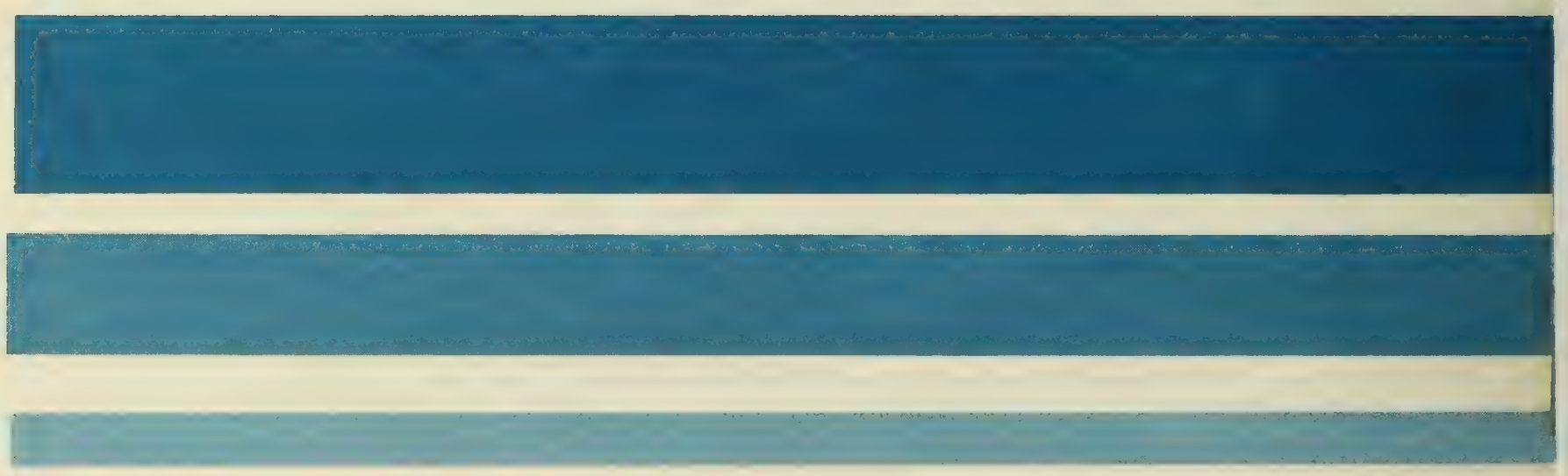







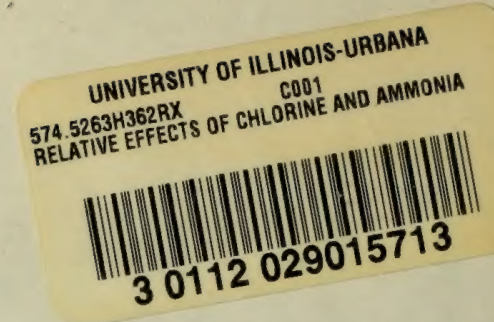

